International Scientific-Technical and Production Journal

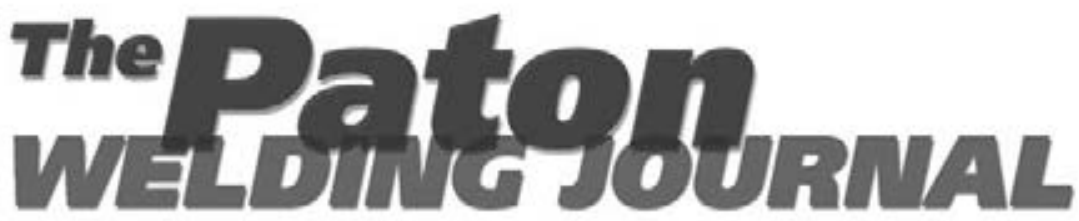

April 2014 No.4

Published since 2000

English translation of the monthly «Avtomaticheskaya Svarka» (Automatic Welding) journal published in Russian since 1948

\section{Editor-in-Chief B.E.Paton EDITORIAL BOARD}

Yu.S. Borisov,

B.V. Khitrovskaya (exec. secretary)

V.F. Khorunov, V.V. Knysh, I.V. Krivtsun,

S.I. Kuchuk-Yatsenko (vice-chief editor)

Yu.N. Lankin, V.N. Lipodaev (vice-chief editor), L.M. Lobanov, A.A. Mazur,

O.K. Nazarenko, I.K. Pokhodnya,

V.D. Poznyakov, I.A. Ryabtsev, K.A. Yushchenko,

A.T. Zelnichenko (exec. director)

(Editorial Board Includes PWI Scientists)

\section{INTERNATIONAL EDITORIAL COUNCIL \\ N.P. Alyoshin}

N.E. Bauman MSTU, Moscow, Russia

V.G. Fartushny

Welding Society of Ukraine, Kiev, Ukraine Guan Qiao

Beijing Aeronautical Institute, China v.I. Lysak

Volgograd State Technical University, Russia B.E. Paton

PWI, Kiev, Ukraine

Ya. Pilarczyk

Weiding Institute, Gliwice, Poland U. Reisgen

Welding and Joining Institute, Aachen, Germany O.I. Steklov

Welding Society, Moscow, Russia

G.A. Turichin

St.-Petersburg State Polytechn. Univ., Russia M. Zinigrad

College of Judea \& Samaria, Ariel, Israel A.S. Zubchenko

OKB «Gidropress», Podolsk, Russia

Founders

E.O. Paton Electric Welding Institute f the NAS of Ukraine,

International Association «Welding" Publisher

International Association «Welding»

Translators Fomin, O.S. Kurochko,

I.N. Kutianova

Editor

N.A. Dmitrieva

Electron galley

D.I. Sereda, T.Yu. Snegiryova

\section{Address}

E.O. Paton Electric Welding Institute, International Association «Welding"

11, Bozhenko Str., 03680, Kyiv, Ukraine

Tel: (38044) 2006016,2008277

Tel.: (38044) 2006016,2008277

ax: (38044) 20082 77, 20081

www.patonpublishinghouse.com

State Registration Certificate

KV 4790 of 09.01.2001

ISSN 0957-798X

Subscriptions

$\$ 348,12$ issues per year,

air postage and packaging included.

Back issues available. All rights reserved.

This publication and each of the articles contained herein are protected by copyright.

Permission to reproduce material contained in this

journal must be obtained in writing from the Obtained in
Publisher.

\section{CONTENTS}

Pilot Plant of Welding Equipment of the E.O. Paton

Electric Welding Institute at the nowadays stage

\section{SCIENTIFIC AND TECHNICAL}

Grigorenko G.M., Adeeva L.I., Tunik A.Yu., Stepanyuk S.N., Poleshchuk M.A. and Zelenin E.V. Structural features of FSW joints of metals with different element solubility in the solid phase

Semyonov A.P., Shuba I.V., Krivtsun I.V. and

Demchenko V.F. Modeling of weld pool behaviour in

spot welding by pulsed laser radiation

Khorunov V.F., Stefaniv B.V. and Maksymova S.V.

Effect of nickel and manganese on structure of

$\mathrm{Ag}-\mathrm{Cu}-\mathrm{Zn}-\mathrm{Sn}$ system alloys and strength of brazed

joints

Goncharov I.A., Galinich V.I., Mishchenko D.D. and

Sudavtsova V.S. Prediction of thermodynamical

properties of melts of $\mathrm{CaO}-\mathrm{Al}_{2} \mathrm{O}_{3}$ system

\section{INDUSTRIAL}

Keite/ S. and Neubert J. Hybrid laser-GMA girth welding technologies for transmission pipelines 30

Kaleko D.M. Percussion capacitor-discharge welding of wire of composite superconducting alloy

Schmidt M. and Kuryntsev S.V. Producing of bimetal joints by laser welding with full penetration

Zhiznyakov S.N. Dry ice - useful material in welding performance 


\section{PILOT PLANT OF WELDING EQUIPMENT OF THE E.O. PATON ELECTRIC WELDING INSTITUTE AT THE NOWADAYS STAGE}

Pilot Plant of Welding Equipment (PPWE) of the E.O. Paton Electric Welding Institute was founded in 1959 on the facility of experimental shop for implementation of technologies and equipment, developed by the PWI departments and Experimental Design and Technological Bureau (EDTB). At present the PPWE is manufacturing equipment for implementation of new high-effective and economic technologies for automatic submerged arc welding, mechanized and automatic pulsed-arc welding, position welding of main pipelines, and also unique equipment for automatic narrow-gap submerged arc welding of circumferential welds.

On demands of PWI the PPWE manufactures equipment for surfacing, installations for electroslag technologies, automatic systems for welding process control, etc. for machine-building enterprises of various industry branches.

Applying advanced technologies and design developments, the PPWE manufactures high-quality welding equipment with optimum technical characteristics, thus satisfying the requirements both of large industrial enterprises and also private persons in such branches as:

- machine building;

- power engineering, oil and gas industry;

- construction and transport;

- agriculture and housing and communal services.

The Plant has own industrial shops and equipment in its disposal for realizing the whole complex of works for manufacture and testing the welding machines.

PPWE has a serial manufacture of transformers and rectifiers for manual and automatic arc welding and surfacing, welding semi-automatic machines, machines for argon-arc welding, inverter-type units (MIG/MAG, TIG, MMA welding including synergic control and pulsed-mode operation), installations and power sources for electroslag technologies, welding tractors for automatic submerged arc welding of different grades of steels, etc.

One of the main types of welding equipment is power sources for different types of arc welding, application of which depends on the service conditions (site and repair works or industrial production). For site and repair works the equipment of small sizes, low weight and with limitations for work duration is used. For these purposes, the Plant manufactures both the transformers and also inverter-type rectifiers. STSh-252 transformer belongs to transformers of PATON type, providing welding at currents of up to 250 A. For industrial enterprises, for highly-intensive conditions of work, the Plant manufactures transformers of PATON type, namely STSh-315 SGD and STSh-400 SGD. The both types of transformers have built-in stabilizers of arc burning, which improve significantly not only the process of welding with rod electrodes in arc manual process, but also allow performing the argon-arc welding of aluminium alloys.

For DC manual arc welding the Plant manufactures the rectifier VD-310N together with devices for anti-sticking of electrodes and improvement of arc exciting.

For gas-electric welding the Plant manufactures 4 types of semi-automatic machines for 150, 180, 250 and 315 A currents. First two machines are designed for site and repair works, the second ones - for industrial enterprises.

For especially highly-intensive conditions of work at high currents the rectifier of BS-650SR type with a unit BP-608 for welding wire feeding is manufactured. The rectifier is versatile as it allows $\mathrm{CO}_{2}$ welding to be performed not only at one station, but also multi-station manual arc welding with rod electrodes in four stations. 
Rectifier VMG-5000 is also manufactured as a multi-station one, enabling welding to be performed in 30 stations in gas electric or manual arc welding.

For powerful installations for electroslag welding, furnaces of electroslag remelting the Plant manufactures special single- and three-phase transformers of TShS and TShP types for currents of 1000, 3000 and 10,000 A. Moreover, under special orders the Plant manufactures different specialized equipment for welding and surfacing.

Over the recent years, the household sector of applying the machines for manual and gas electric welding was widened. Small-sized rectifiers of inverter-type VDI for currents from 120 up to $250 \mathrm{~A}$ and argon-arc inverters of series ADI for currents of 160 and $200 \mathrm{~A}$ are manufactured for the household conditions.

For the same purposes a small-sized semiautomatic machine PS-152 with built-in feeding unit is used, which can perform weld-

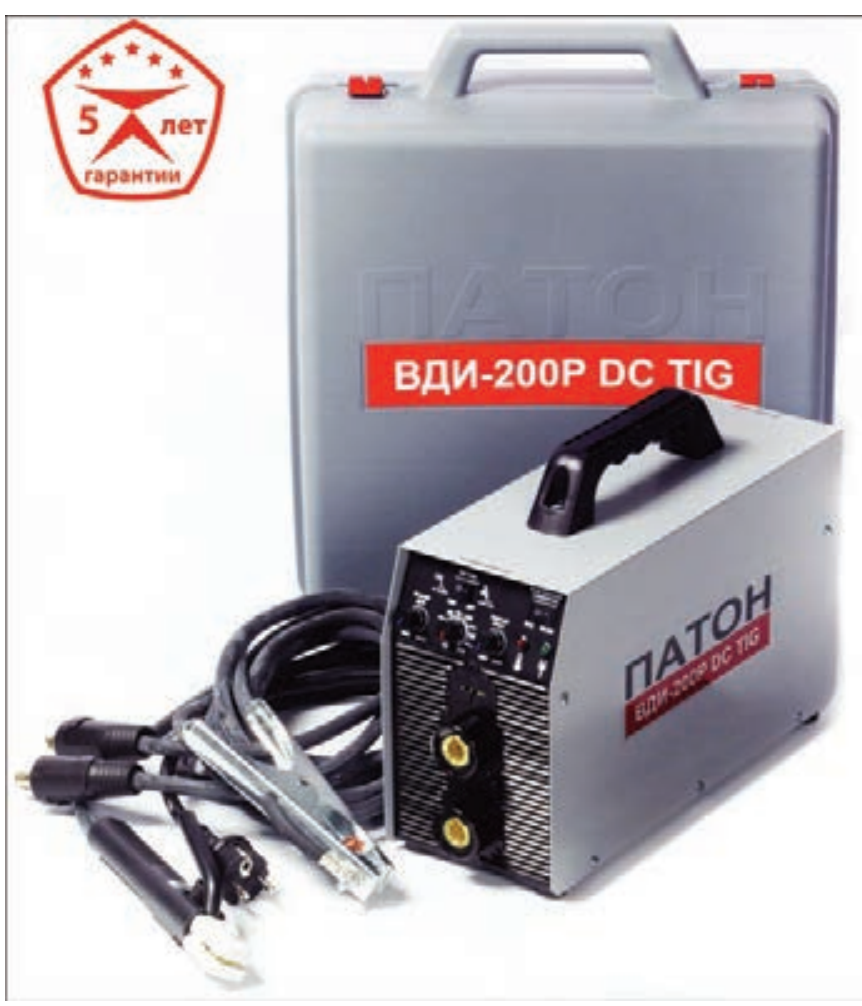

Invertor-type unit for manual and argon-arc welding ing of thin-sheet steel up to $0.5 \mathrm{~mm}$ thickness.

Various-type welding equipment, manufactured by PPWE over more than 50 years, is of a great demand not only in Ukraine and CIS countries, but also abroad due to high quality of manufacture and reliability in operation.

Starting since 2011, PPWE together with PWI and EDTB is beneficially cooperated with enterprises included into the structure of the State Oil Company of Azerbaijan Republic (SOCAR). The training was carried out at the PWI research centers on specialties of a blaster and manager of explosive works, the works were performed for separation two pontoons from a block by the method of a directed explosion in construction of offshore stationary platform on site of Guneshli oilfield in the Caspian Sea. Contract was signed with PA «Azneft» for fulfillment of underwater repair-welding works for removal of cracks in Guneshli oilfield.

At the end of November, 2013 the PPWE put into service the complex of equipment for automatic submerged arc welding (circumferential welds into narrow gap) of powerful turbine rotors. On demands of OJSC «Turboatom» (main research organization of the Ministry of Industrial Politics of Ukraine on Power Machine Building) the PWI and EDTB specialists have developed the new welding technology and equipment for manufacture of welded combined rotors using automatic narrow-gap submerged arc welding. This method of manufacture increases greatly the vibro-stability reliability of rotor in service at high- and low-temperatures conditions. Coming from the conclusion of the acceptance commission this equipment can be used in narrow-gap submerged arc welding not only for steam turbine rotors but also for products of other configuration.

Also, in 2013 the PPWE recommenced the design of special powerful power sources and equipment for electroslag remelting and widened the assortment of household welding machines due to putting into serial production of invertors PATON VDI-250S of Standard series for manual arc welding and argon-arc welding. At the present moment the tests of plasma cutter PRI-40 of inverter type for plasma cutting, supplied by $220 \mathrm{~V}$ voltage, are carried out; the semi-automatic welding machine of inverter type for $250 \mathrm{~A}$ is at the stage of designing.

Since 2014 the Plant is carrying out the development of alternative energy sources and organizing a serial manufacture of high-effective modular inverter-type power sources for welding, used as converter of a solar energy. 


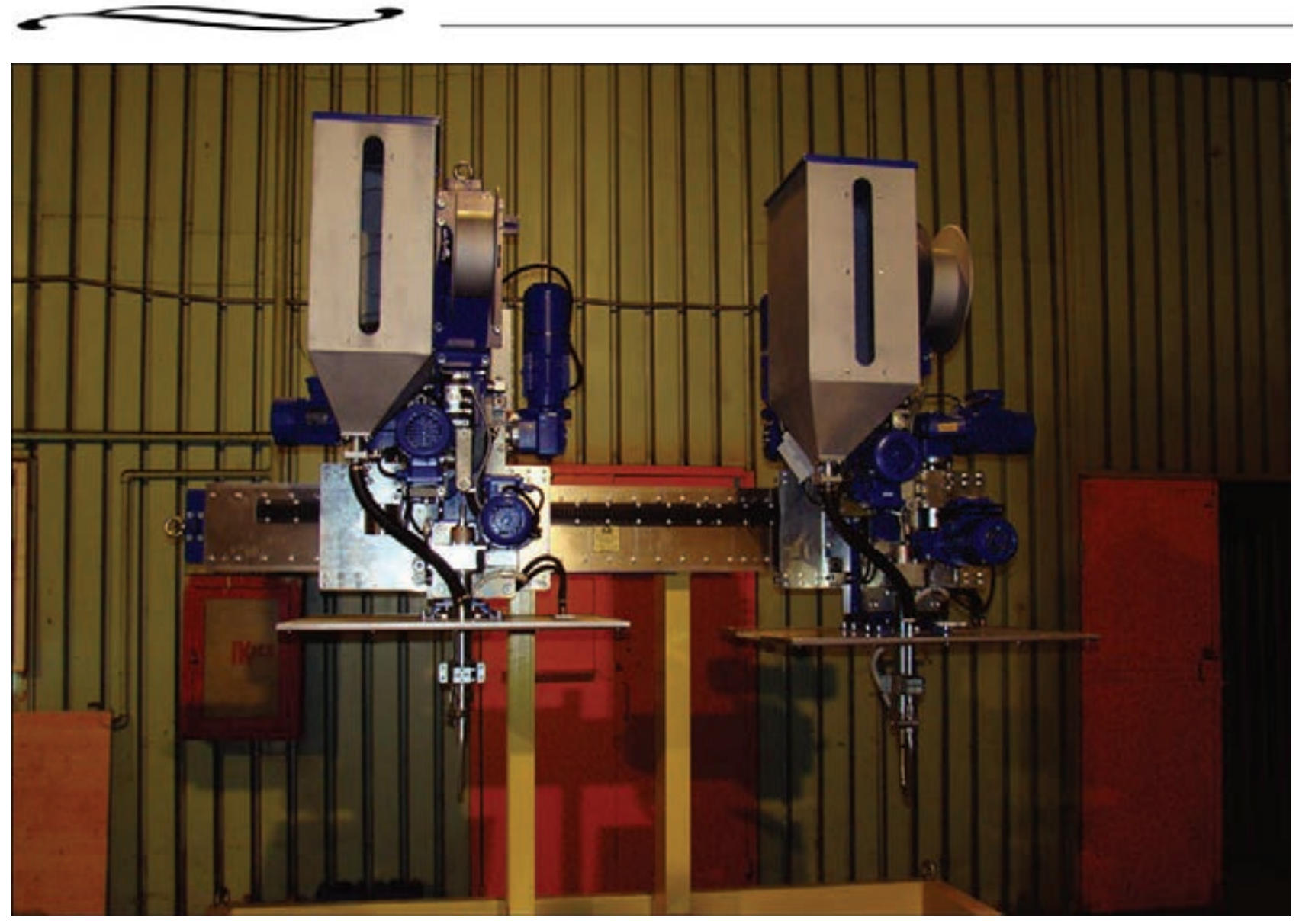

Unit for narrow-gap welding

Since January, 2014 the inverters PATON VDI-200R DC MMA/TIG are manufactured in a casing proving IR 33 class of protection in accordance with the system of classification of degrees of protection of electric equipment casing from entry of solids and water (International standard IEC 60529, GOST 14254-96). Earlier, the machines were manufactured in a casing providing the IP 21 class of protection, the same as the most welding machines of the Ukrainian production.

Since March, 2014 the PPWE established the 5-year guarantee for welding inverters of ADI and VDI series. The guarantee repair and service of the PPWE products is realized by the efforts of the own Service Center. Welding inverters of PATON type were certified in accordance with the European Standards (Certificate CE).

At the beginning of 2014 the new production lines were put into service for manufacture of electrodes for welding of carbon and low-alloy steels, namely ANO-4, ANO-21, ANO-36 and UONI-13/55 of 3-5 $\mathrm{mm}$ diameter and improved technological characteristics.

The dealer network of the PPWE covers all the regions of Ukraine, having more than hundred trade sites. The plant delivers all the assortment of welding equipment into trade networks and hypermarkets of Ukraine: Epitsentr, Novaya Liniya, OLDI, and since 2014 - to the Russian trade network STD «Petrovich».

In 2013 the inverter and transformer welding equipment of PATON types was successfully delivered to the Russian market, having already proved itself in household and industrial sector. Several large enterprises of Russia has already signed the contracts for delivery and putting into service the specialized equipment for automatic welding, and also power sources for electroslag technologies and welding equipment for construction industry. The dealer network for selling the equipment of PATON type at the territory of Russia is represented in the following cities:

- North-West region: St.-Petersburg and Leningrad region, Veliky Novgorod, Pskov;

- Central region: Moscow and region, Tula and region, Voronezh, Belgorod;

- Privolzhsky region: Orenburg, Naberezhnye Chelny, Izhevsk, Kazan, Perm, Cheboksary, Penza, Samara, Engels; 
- Urals region: Ekaterinburg;

- Siberian region: Krasnoyarsk, Novosibirsk, Omsk, Barnaul;

- South region: Krasnodar, Rostov-on-Don, Volzhsky.

The Plant delivers also equipment to the CIS countries and abroad: Russian Federation, Republic of Belarus, Republic of Kazakhstan, Azerbaijan Republic, Poland, Czech Republic, Equatorial Guinea.

Participation of the PPWE in three international exhibitions «Welding. Cutting. Surfacing» (Russia, Moscow, June, 2013), MESSE ESSEN «SCHWEISSEN\&SCHNEIDEN» (Germany, Essen, September, 2013) and Weldex (Russia, Moscow, October, 2013) allowed finding out the new challenges for development of welding machines of PATON type, well proved themselves at the market of Ukraine.

In 2014 the PPWE will participate in the specialized exhibition «WELDING 2014» (Russia, St.-Petersburg, June) and the 14th International Exhibition of Welding Materials, Equipment and Technologies «Weldex 2014» (Russia, Moscow, October).

The Plant representations were established in Russia (St.-Petersburg) and Republic of Belarus (Minsk), the negotiations are carried out about opening of representation in Poland for a full entry of PATON type equipment to the EU market.

The constant clients of the PPWE are the following companies: Azneft, Azovtranskomplekt, BelAZ, Belaruskaly, Vostok-Ruda, SOCAR, Dneprodzerzhinsk Hydroelectric Station, Zaporozhstal, K.A.N. Stroy, Kievwodokanal, Kievenergo, Korzhevsky specialized mining-crushing open pit, Krivorozhsky plant of mining equipment, First private brewery, Poznyakizhilstroy, Rostenergo, Turboatom and other.

In January this year the PPWE of the E.O. Paton Electric Welding Institute was 55 and its future plans include the further development and improvement of technologies and equipment for arc welding, shielded-gas and automatic arc welding, flash-butt welding, electroslag welding and remelting, electron beam welding and deposition, plasma-arc remelting, as well as updating of basic models of household welding machines.

Unchangeable is the Plant motto: RELIABILITY, QUALITY, TRADITIONS.

Anatoly V. Stepakhno, Chairman of Plant Board

Dr. V.A. Koritsky, Scientific consultant

Anton V. Stepakhno, Vice-Chairman of Plant Board

\section{Contacts:}

66 Novopirogovskaya Str., 03045, Kiev, Ukraine

Tel./Fax: +38(044) 259-40-00; www.paton.ua 


\title{
STRUCTURAL FEATURES OF FSW JOINTS OF METALS WITH DIFFERENT ELEMENT SOLUBILITY IN THE SOLID PHASE
}

\author{
G.M. GRIGORENKO, L.I. ADEEVA, A.Yu. TUNIK, S.N. STEPANYUK, \\ M.A. POLESHCHUK and E.V. ZELENIN \\ E.O. Paton Electric Welding Institute, NASU \\ 11 Bozhenko Str., 03680, Kiev, Ukraine. E-mail: office@paton.kiev.ua
}

\begin{abstract}
Results of investigation of the structure and properties of dissimilar metal joints made by friction stir welding (FSW) are given. Systems with unlimited $(\mathrm{Ni}-\mathrm{Cu})$ and limited $(\mathrm{Cu}-\mathrm{Fe})$ solubility, as well as absence of component solubility $(\mathrm{Al}-\mathrm{Fe})$ in the solid state were studied. FSW of copper and nickel produced a sound welded joint with metal interpenetration to $3 \mathrm{~mm}$ depth. Mechanical mixing of metals plays the leading role in this process, whereas diffusion processes are negligible. Structure refinement occurs in mechanical mixing bands as a result of recrystallization processes. Copper diffusion into nickel along grain boundaries proceeds down to $20 \mu \mathrm{m}$ depth with formation of interlayers of these metals solid solution. When studying the copper to steel welded joint, it was established that metal mixing has a leading role also in this process, and the role of diffusion processes is small. During welding a considerable grain refinement takes place both in the recrystallization zone, and in thermomechanically affected and heat affected zones. FSW of aluminium to iron resulted in formation of the joint zone of a considerable volume with aluminium penetration into iron down to $2.5 \mathrm{~mm}$ depth. Metal interaction proceeds here, namely mass transfer, primarily, of aluminum, and subsequent formation of $\mathrm{Fe}_{2} \mathrm{Al}_{7}, \mathrm{FeAl}_{2}$ compounds. The hardest regions of welded joint zone contain intermetallics in the aluminium matrix. Such a structure has the hardness of $2870 \pm 410 \mathrm{MPa}$ that is more than 3 times lower than that of iron aluminides Results of the conducted investigations allow recommending this welding process to produce bimetal joints of dissimilar metals with different solubility of elements in the solid state. 20 Ref., 5 Tables, 15 Figures.
\end{abstract}

$\boldsymbol{K} \boldsymbol{e} \boldsymbol{y} \boldsymbol{w} \boldsymbol{o r d} \boldsymbol{s}:$ friction stir welding, welded joint, bi metal mechanical mixing of metals, diffusion, solid phase solubility, microstructure, $X$-ray microprobe analysis, elemental composition, microhardness

Development of modern machine, car, aircraft, ship building and instrument making, as well as other industries, where mechanisms operate under extreme conditions, is impossible without application of new structural materials and dissimilar metal joints. These mostly are difficult-toweld metallic materials, differing considerably from each other by their physico-mechanical properties. As a rule, when joining such metals, welding with an intermediate liquid phase leads to formation of structural complexes and phase components, which greatly lower joint performance. This problem can be solved using one of the solid phase welding processes, such as diffusion welding, magnetic-pulse, resistance without flashing, friction and explosion welding. All these processes allow solving many problems of resources and energy saving. They are applied in specific technologies, for instance, in manufacture of electric contacts, engine valves, transition pieces and other structures. This allows saving expensive materials, reducing structure weight, lowering power losses and, most importantly, joining difficult-to-weld materials.

One of the promising methods to join dissimilar metals and produce sound bimetal joints is friction stir welding (FSW) patented in 1991 by The Welding Institute [1]. Most of the studies point to numerous advantages of FSW, compared to other processes of producing permanent joints [2-7]: preservation of base metal properties in the welding zone to a considerable extent, compared to fusion welding processes; absence of harmful emissions or ultraviolet radiation during welding; possibility to produce defect-free welds in alloys, which in fusion welding are prone to formation of hot cracks and porosity in weld metal; no need for application of filler material or shielding gas; removal of surface oxides from the edges before welding; no losses of alloying elements in weld metal.

At present, possibility of FSW application for dissimilar metal welded joints is of great interest. Researchers $[8,9]$ demonstrated success in welding such dissimilar metals as aluminium and steel. FSW process to produce joints of aluminium to 
magnesium was applied with success in works [10, 11]. Information on weldability and mechanical properties of dissimilar $\mathrm{Al}-\mathrm{Cu}, \mathrm{Ni}-\mathrm{Cu}$ joints is given in [12-14]. As noted by the authors of these publications, the decisive role in weldability of dissimilar metals is played by metallurgical compatibility, determined by mutual solubility of metals being joined both in the liquid and in the solid state, as well as formation of brittle chemical compounds - the intermetallics.

The objective of this work is studying structural features and properties of bimetal joints with different solubility of components in the solid state, produced by FSW, in particular, $\mathrm{Ni}-$ $\mathrm{Cu}$ system, the components of which have unlimited solubility; systems with limited solubility $(\mathrm{Cu}$-steel) and systems, in which solubility of metals being joined is absent in the solid state (Al-Fe).

Overlap welded joints were produced by FSW, the schematic of which is given in Figure 1.

Plasticizing and mixing of metals of the two plates occurs in a closed volume with application of a special rotating pin tool [14, 15], moving at a certain speed. Samples of initial alloys (copper, nickel, steel 3, aluminium and Armco-iron) were selected to conduct the FSW process. FSW modes and characteristics of materials being welded are given in Table 1.

A complex procedure was applied during investigations, including metallography (Neophot32 optical microscope) and durometric analysis (LECO hardness meter $\mathrm{M}-400$ at 0.249 and $0.496 \mathrm{~N} \mathrm{load}$ ). Electron studies of the structure and determination of its elemental composition by X-ray microprobe method (XRMM) were conducted in an analysis system consisting of JEOL scanning electron microscope JSM-35 CF (Japan) and X-ray spectrometer with dispersion by X-ray quantum energy (Oxford Instruments INCA Energy-350 model, Great Britain). A characteristic feature of this analysis is its locality minimum excitation area is equal to $1 \mu \mathrm{m}$. One of the advantages of energy-dispersive spectrometer is the possibility of simultaneous analysis of about 50 elements (from boron to uranium) with

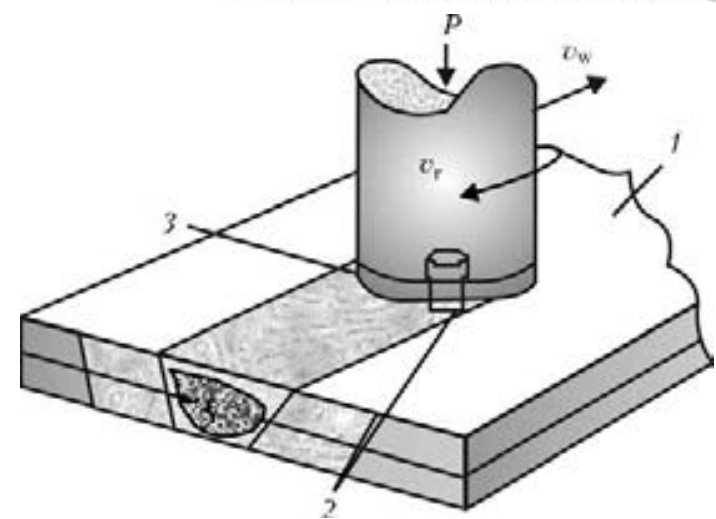

Figure 1. Schematic of FSW process: 1 - item; 2 - pin tool with special profile; $3-$ shoulder; $v_{\mathrm{w}}-$ welding speed; $v_{\mathrm{r}}-$ rotation speed; $P-$ applied load

reflection of the entire found spectrum. Structure image was obtained in secondary electron mode at $U=20 \mathrm{kV}$. To reveal the studied joint structure chemical reagents [16] and etching (Table 2) were used. To study the possibility of producing dissimilar joints, constitutional diagrams of $\mathrm{Cu}^{-}$ $\mathrm{Ni}, \mathrm{Cu}-\mathrm{Fe}$ and $\mathrm{Fe}-\mathrm{Al}$ binary systems were analyzed [17-19]. Microstructure of transverse and longitudinal sections of welded joints produced by FSW was studied. Phenomena of metal mixing in the plastic state, element diffusion, and conditions of intermetallic phase formation were studied, their composition and microhardness were determined.

Copper and nickel are two metals forming a continuous line of solid solutions (Figure 2) and having one-type crystalline lattices with close parameters (FCC). They belong to adjacent groups of periodic system (atomic radii differ by less than 10-15\%), and do not form any brittle intermetallics. In welding of these metals, joints with the most uniform properties are formed.

$\mathrm{Cu}-\mathrm{Ni}$ constitutional diagram consists of three regions. In the upper part material consists of liquid solution of copper and nickel, in the middle region it contains both liquid and solid phases, the composition of which can be calculated using the lever rule. In the lower region $\mathrm{Cu}-\mathrm{Ni}$ is substitutional solid solution, where copper and nickel atoms are irreplaceable in the crystalline lattice. Substitutional solid solution forms in $\mathrm{Cu}^{-}$

Table 1. FSW modes and welded material characteristics*

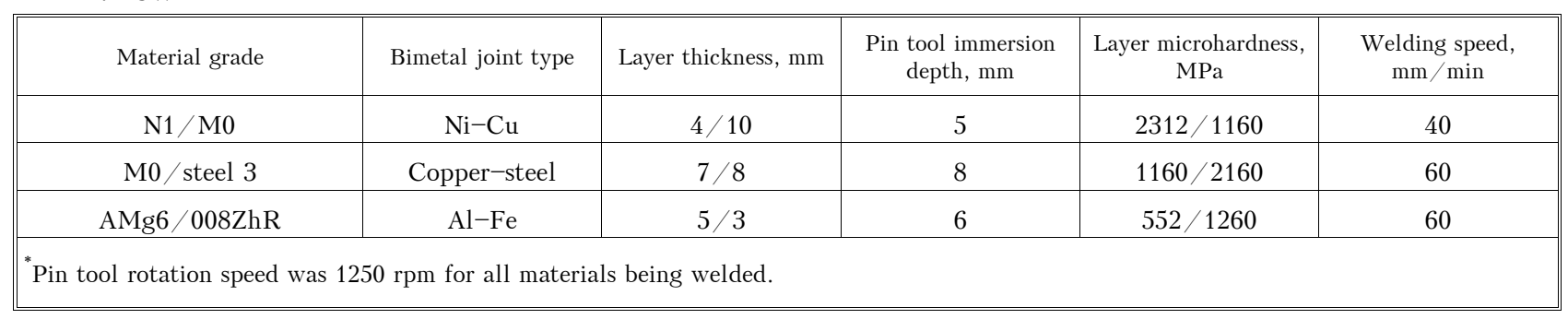


SCIENTIFIC AND TECHNICAL

Table 2. Reagents and conditions of metallographic etching

\begin{tabular}{|c|c|c|c|}
\hline Material & Reagent composition & Application method & Remark \\
\hline $\mathrm{Cu}(\mathrm{M} 0)$ & Nitric acid $(50 \mathrm{ml})+$ water $(50 \mathrm{ml})$ & $\begin{array}{l}\text { Chemical etching at intensive } \\
\text { stirring of reagent at } \tau=5-30 \mathrm{~s}, \\
T=20{ }^{\circ} \mathrm{C}\end{array}$ & $\begin{array}{l}\text { Hydrochloric acid }(80 \mathrm{ml}) \text { and water } \\
(20 \mathrm{ml}) \text { are used to remove oxide } \\
\text { film at } \tau=1-3 \mathrm{~s}, T=20^{\circ} \mathrm{C}\end{array}$ \\
\hline Ni (N1) & $\begin{array}{l}\text { Ammonium sulphate }(20 \mathrm{~g})+\text { water } \\
(100 \mathrm{ml})\end{array}$ & $\begin{array}{l}\text { Electrolytic etching at } U=6-15 \mathrm{~V}, \\
\tau=3-10 \mathrm{~s}\end{array}$ & Same \\
\hline Steel 3 & $\begin{array}{l}\text { Nitric acid }(4 \mathrm{ml})+\text { ethyl alcohol } \\
(100 \mathrm{ml})\end{array}$ & $\begin{array}{l}\text { Chemical etching at } \tau=5-30 \mathrm{~s} \text {, } \\
T=20{ }^{\circ} \mathrm{C}\end{array}$ & Sample washing in ethyl alcohol \\
\hline $\mathrm{Al}(\mathrm{AMg} 6)$ & Caustic soda $(10 \mathrm{~g})+$ water $(100 \mathrm{ml})$ & Same & $\begin{array}{l}\text { To remove oxide film hydrofluoric } \\
\text { acid }(50 \mathrm{ml}) \text { and water }(50 \mathrm{ml}) \text { are } \\
\text { used at } \tau=1-3 \mathrm{~s}, T=20^{\circ} \mathrm{C}\end{array}$ \\
\hline Fe $(008 \mathrm{ZhR})$ & $\begin{array}{l}\text { Nitric acid }(4 \mathrm{ml})+\text { ethyl alcohol } \\
(100 \mathrm{ml})\end{array}$ & » & Sample washing in ethyl alcohol \\
\hline
\end{tabular}

$\mathrm{Ni}$ system, as copper and nickel solidify with FCC lattice formation, have similar atomic radii and electronegative valency $[17,18]$. However, copper and nickel have different physico-mechanical characteristics. Copper is a soft, ductile material with high electrical conductivity, and melts at 1085 ${ }^{\circ} \mathrm{C}$, while nickel is a relatively hard corrosion-resistant metal, which melts at $1455{ }^{\circ} \mathrm{C}$.

$\mathrm{Ni}-\mathrm{Cu}$ welded joint was produced at application of concentrated thermomechanical impact of the pin tool during FSW in the modes given in Table 1. Welding was performed through $4 \mathrm{~mm}$ nickel plate of N1 grade. Thickness of copper plate (M0 grade) was $10 \mathrm{~mm}$.

Metallographic sections of this joint in the longitudinal and transverse direction were studied (Figures 3 and 4). Welded joint has no defects in the form of lacks-of-penetration, cracks or pores. An oval nugget of $4 \times 6 \mathrm{~mm}$ size is observed in the transverse section of the joint zone ( $\mathrm{Fi}-$ gure $3, a, b)$, located in copper. It consists of concentrated deformation rings with nickel particle inclusions, their content being about $10 \mathrm{vol} \%$. In the nugget upper part a region of plastic displacement of nickel into copper formed

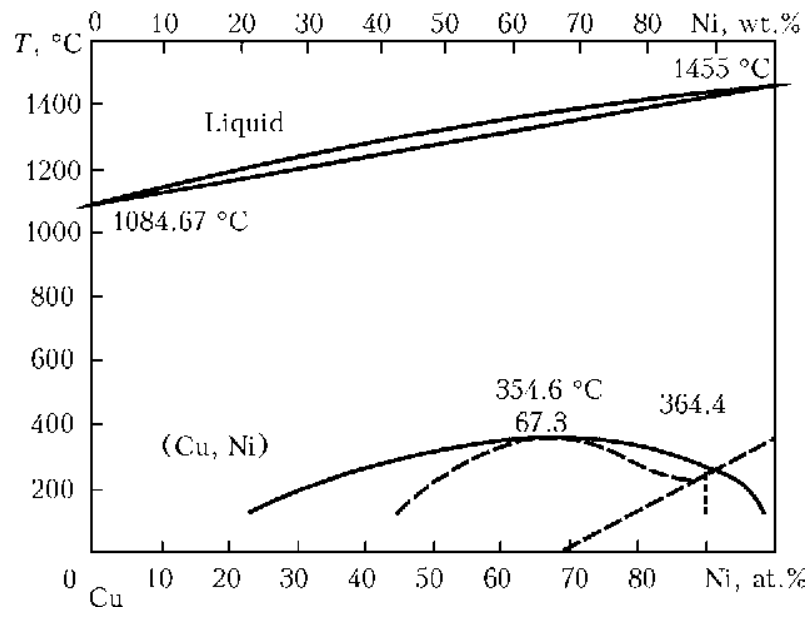

Figure 2. Constitutional diagram of $\mathrm{Cu}-\mathrm{Ni}$ system [17] as a result of pin tool impact through nickel. In this region of $2.5 \times 3.0 \mathrm{~mm}$ size copper entrapment is found, its content reaching about 15 vol.\%.

When studying the longitudinal section, interpenetration of nickel and copper to the depth of down to $3 \mathrm{~mm}$ occurs in these metals joint zone. Metal mixing is observed in the form of interpenetrating alternating bands, oriented in the direction of pin tool movement (see Figure 4, $a, b)$. Copper and nickel bands are equal to $0.3-$ 0.6 and $0.03-0.30 \mathrm{~mm}$, respectively. In these bands structure refinement takes place as a result of recrystallization processes. In copper grain size varies from 5 to 20 , and in nickel - from 5 up to $40 \mu \mathrm{m}$. Nickel band microhardness is equal to $1270 \pm 40$, and in copper it is $1140 \pm 50 \mathrm{MPa}$. Above metal mixing region in nickel, a thermomechanically affected region of up to $3 \mathrm{~mm}$ length with oriented deformation bands (Figure 4, $a, c)$ and grain size of 20 to $70 \mu \mathrm{m}$ is found. Dark bands of deformed nickel feature a higher hardness $(1610 \pm 160 \mathrm{MPa})$, compared to light spaces between them $(1290 \pm 110 \mathrm{MPa})$. Edge region of nickel - HAZ, located above the thermomechanically affected zone, has coarser grains.

In copper a recrystallization region up to $0.6 \mathrm{~mm}$ wide with fine grain of $15-20 \mu \mathrm{m}$ and up to $0.1 \mathrm{~mm}$ thermomechanically affected region with slightly deformed grain going into the base metal are observed under the mechanically stirred zone (see Figure 4, $d$ ). In both these regions, nickel inclusions are found in the form of elongated (spindle shaped) fragments with microhardness of $1300 \pm 170 \mathrm{MPa}$.

Band edges and nickel regions directly contacting copper (Figure 4, b,e, $f$ and Figure 5) are stronger etched out and have lower microhardness $(1100 \pm 60 \mathrm{MPa})$. This is attributable to copper and nickel interdiffusion along grain boundaries with formation of interlayers of these 

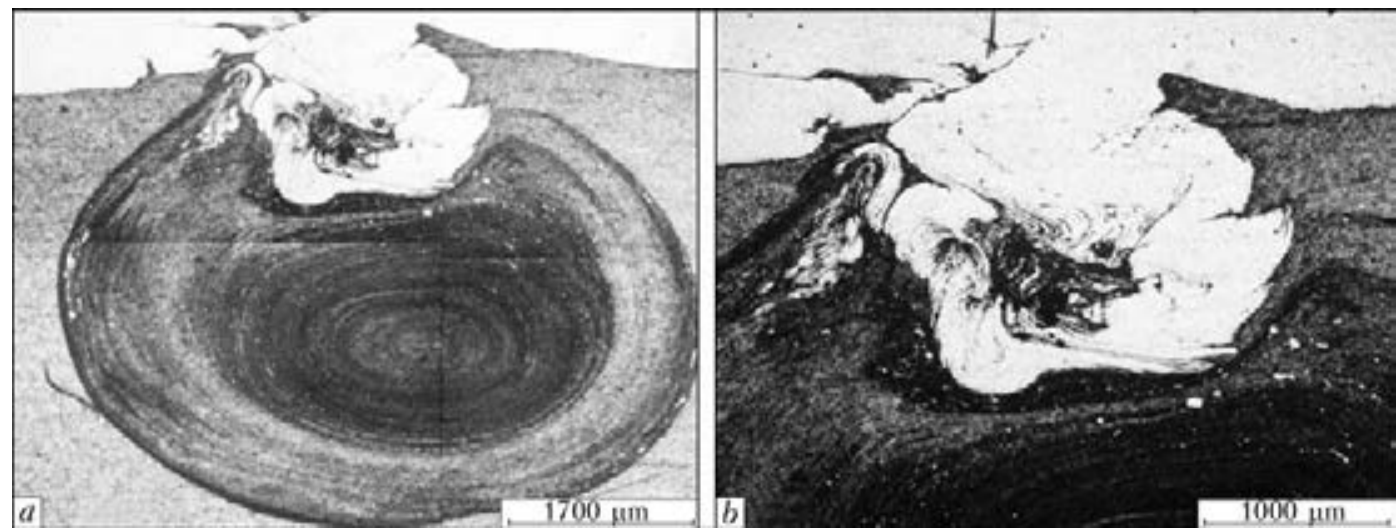

Figure 3. Microstructure of transverse microsection of $\mathrm{Ni}-\mathrm{Cu}$ welded joint produced by $\mathrm{FSW}: a-$ general view; $b-$ region of nickel mixing with copper
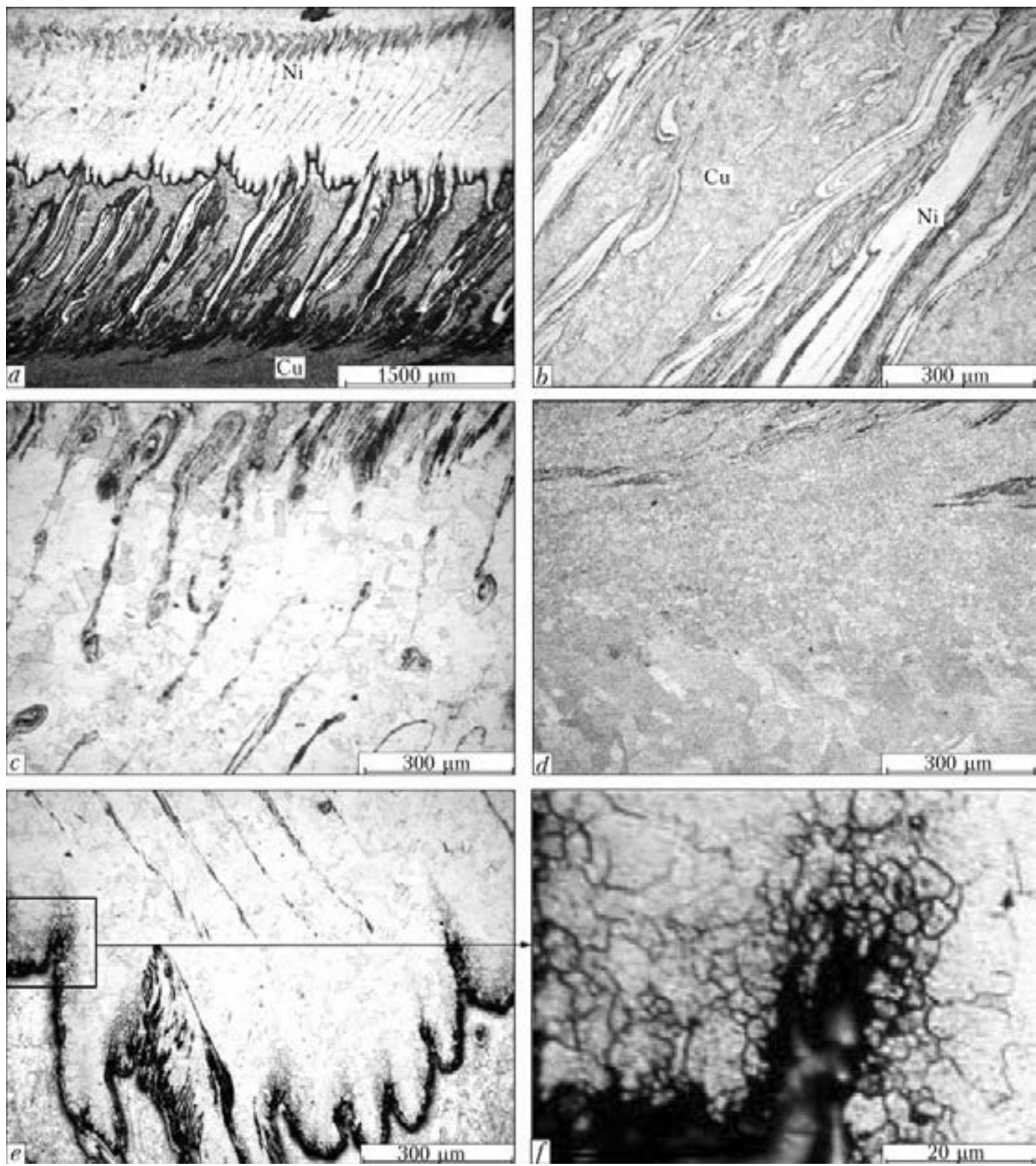

Figure 4. Longitudinal microstructure of $\mathrm{Ni}-\mathrm{Cu}$ welded joint produced by FSW: $a, b-$ zone of nickel mixing with copper; $c, d$ - thermomecanically affected zone in nickel and copper, respectively; $e, f-$ zone of copper interdiffusion in nickel 


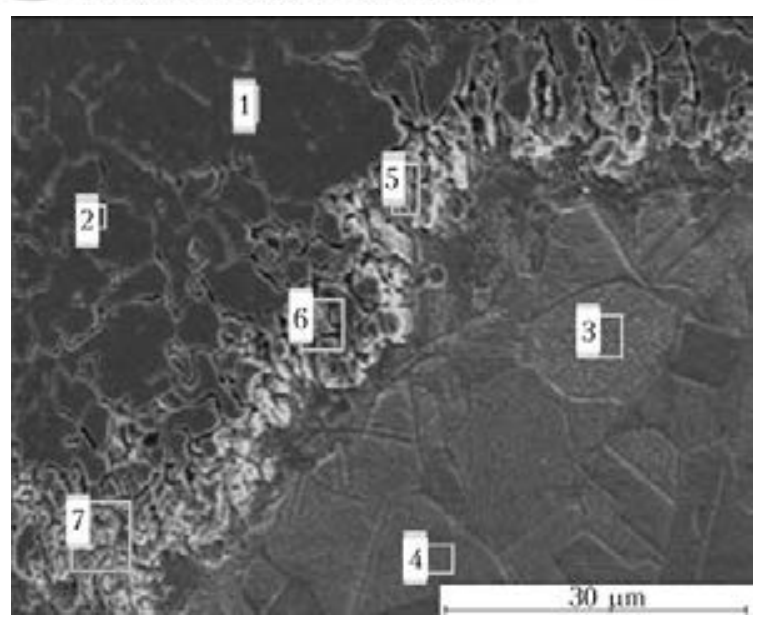

Figure 5. Microstructure of $\mathrm{Ni}-\mathrm{Cu}$ contact zone filmed in secondary electrons (here and in Figure 6, $a$ for numbers see Table 3)

metals solid solution (see Figure 4, $e, f$ ). XRMM method was used to analyze the composition of contact zone of the two metals, and it was established that copper diffusion into nickel to the depth of $10-20 \mu \mathrm{m}$ takes place along grain boundaries.

When studying the joint zone in characteristic radiation, no significant interdiffusion of elements in-depth of alternating layers of nickel and copper was found. Figure 6 and Table 3 show the results of mapping the mechanically stirred zone of metals in $\mathrm{Ni}-\mathrm{Cu}$ joint. Thus, investigation of nickel to copper welded joints showed that metal mixing in the plastic state plays the leading role in FSW processes with their interdiffusion being less important.

Copper-steel system was considered in order to study the possibility of producing by FSW joints of dissimilar metals with limited solubility of components in the solid state. According to $\mathrm{Cu}-\mathrm{Fe}$ constitutional diagram, carbon solubility in copper is practically absent in the solid state, whereas in liquid state it is equal to 0.00015 0.003 wt. $\%$ at temperatures of $1100-1700{ }^{\circ} \mathrm{C}$ [ $17-$ 19]. Carbon addition to $\mathrm{Fe}-\mathrm{Cu}$ alloys somewhat lowers copper solubility in solid iron and does not change the overall pattern. Therefore, in or-
Table 3. Composition of studied regions of $\mathrm{Ni}-\mathrm{Cu}$ joint, wt. / at. \%

\begin{tabular}{||c|c|c|}
\hline $\begin{array}{c}\text { Studied } \\
\text { region }\end{array}$ & $\mathrm{Ni}$ & $\mathrm{Cu}$ \\
\hline \multicolumn{3}{|c|}{ Acc. to Figure 5} \\
\hline 1 & 100 & 0 \\
\hline 2 & 100 & 0 \\
\hline 3 & $0.30 / 0.32$ & $99.70 / 99.68$ \\
\hline 4 & $0.37 / 0.40$ & $99.63 / 99.60$ \\
\hline 5 & $75.46 / 76.90$ & $24.54 / 23.10$ \\
\hline 6 & $91.64 / 92.22$ & $6.36 / 7.78$ \\
\hline 7 & $83.92 / 84.95$ & $16.08 / 15.05$ \\
\hline \multicolumn{3}{|c|}{ Acc. to Figure $6, a$} \\
\hline 1 & $99.23 / 99.29$ & $0.77 / 0.71$ \\
\hline 2 & $99.18 / 99.24$ & $0.82 / 0.76$ \\
\hline 3 & $4.03 / 4.35$ & $95.97 / 95.65$ \\
\hline 4 & $5.96 / 6.42$ & $94.04 / 93.58$ \\
\hline
\end{tabular}

der to analyze the process the authors considered the interaction between copper and iron. Constitutional diagram of $\mathrm{Cu}-\mathrm{Fe}$ system is given in Figure 7. Data on complete or partial solubility of iron and copper in the liquid state are contradictory. The system shows three zones of primary crystallization of $\delta, \gamma$ and $\varepsilon$ phases and three transformations (two peritectic and one eutectoid) proceeding at 1478,1094 and $850{ }^{\circ} \mathrm{C}$. Absence of delamination in $\mathrm{Fe}-\mathrm{Cu}$ system is shown. It is, however, observed in overcooled condition (100 ${ }^{\circ} \mathrm{C}$ and more). Iron solubility in copper at $1025,900,800$ and $700{ }^{\circ} \mathrm{C}$ is equal to $2.5,1.5$, 0.9 and 0.5 wt.\%, respectively [19]. At further temperature lowering, iron solubility in copper changes only slightly. Pure copper has FCC lattice so that its addition widens the range of $\gamma$-iron. Copper solubility in $\gamma$-solid solution ( $8 \mathrm{wt} . \%$ ) is higher than in $\alpha$-solid solution $(0.3$ wt.\%) and the ratios in this system are similar to $\mathrm{Fe}^{-} \mathrm{C}$ system. No intermetallics are found in this system.

FSW was performed on plates of copper and low-carbon steel (see Table 1). Pin tool impact
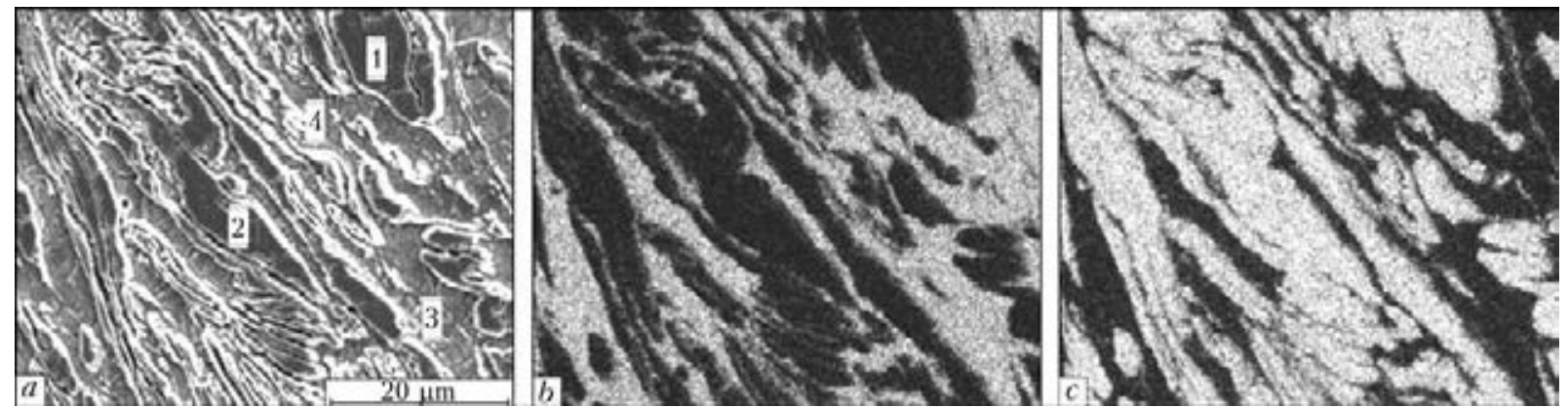

Figure 6. Image of $\mathrm{Ni}-\mathrm{Cu}$ joint zone obtained in secondary electrons $(a)$ and in characteristic radiation of copper $(b)$ and nickel $(c)$ 
was applied through $7 \mathrm{~mm}$ copper plate. Investigation of transverse and longitudinal section of copper to steel welded joint showed that it has no defects: no cracks, lacks-of-penetration or pores were detected (Figures 8 and 9). It is found that in the longitudinal direction the joint is of serrated nature. In copper wedge-like intrusions are observed, which are inclined in the welding direction (Figure 8,c). Maximum depth of their penetration was equal to $500 \mu \mathrm{m}$. This region consists of finest steel particles of 1 to $10 \mu \mathrm{m}$ size embedded into deformed copper, and microhardness of these zones is 2740 to $3020 \mathrm{MPa}$. Located above such wedge-like intrusions is incomplete recrystallization zone of copper - round-shaped grains of 30 to $100 \mu \mathrm{m}$ size, chaotically located between copper base metal grains (Figure 8, $b$ ). Their maximum quantity equal to approximately $80 \mathrm{vol} . \%$ is in direct vicinity of the zone of joint with steel. Farther from the joint zone their quantity decreases, and their size becomes smaller. Extent of the zone of incomplete recrystallization in copper is equal to $600-800 \mu \mathrm{m}$.

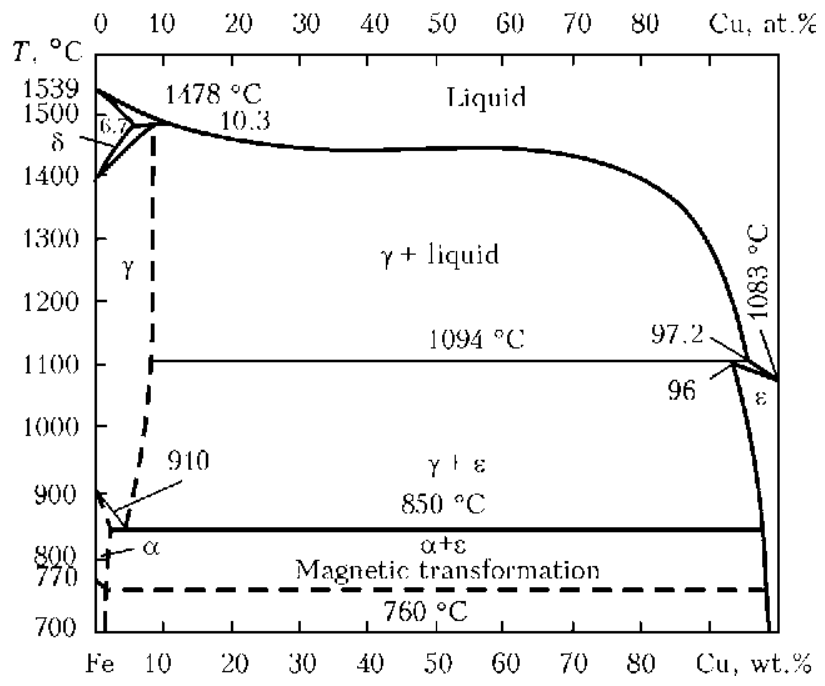

Figure 7. Constitutional diagrams of $\mathrm{Cu}-\mathrm{Fe}$ system [19]

$\mathrm{HAZ}$ width in steel is equal to $4.5 \mathrm{~mm}$. Zones of incomplete recrystallization, fine and medium grain are clearly visible (Figure $8, c^{-} e$ ). Medium grain zone is located directly in the zone of joint with copper. In the contact zone steel grain size is smaller by an order of magnitude than in the

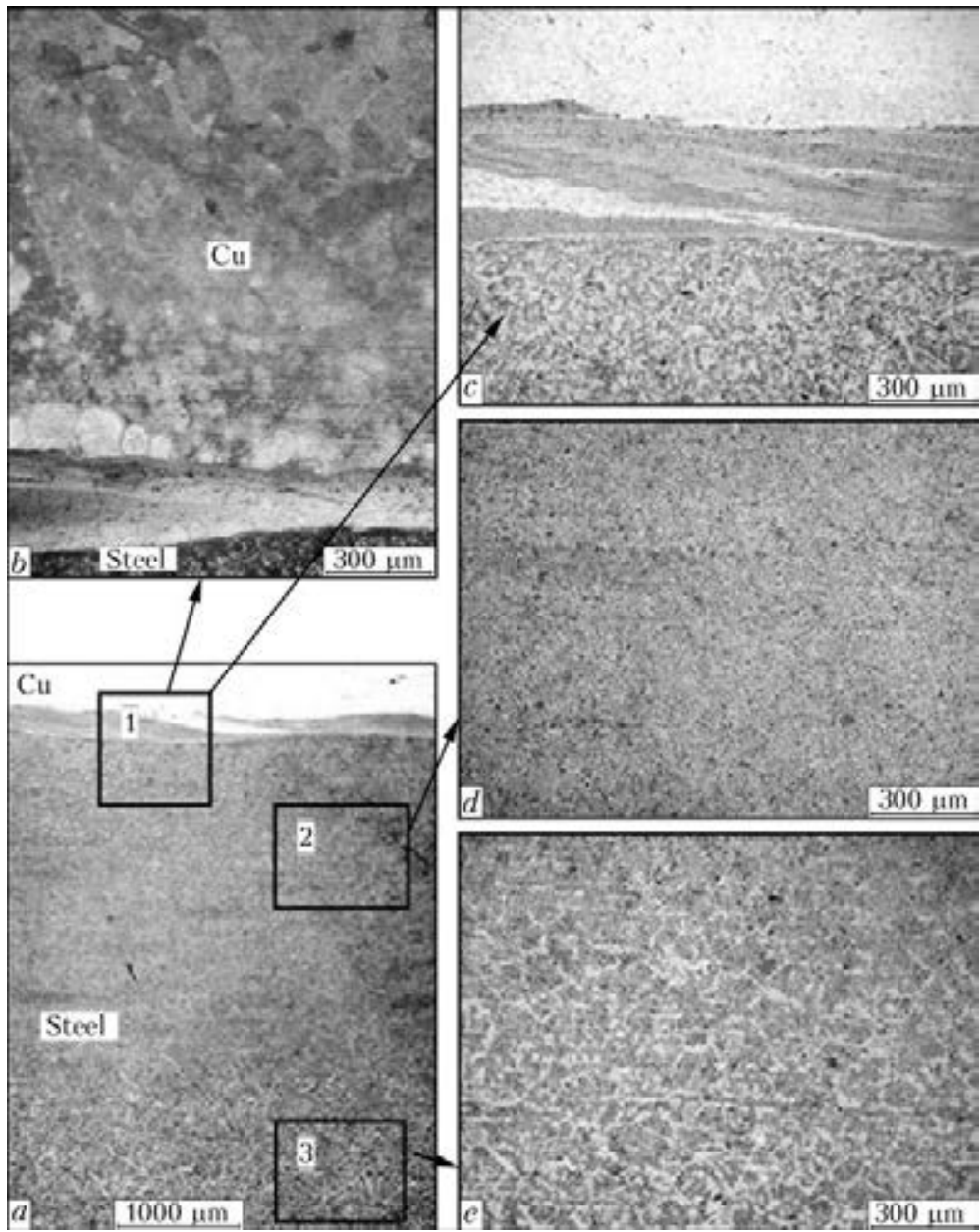

Figure 8. Longitudinal microstructure of copper-steel welded joint produced by FSW: $a-$ general view of welded joint; $b-$ zone of steel mixing with copper; $c-$ medium grain region; $d$ - fine grain region in steel HAZ; $e-$ incomplete recrystallization zone in steel (here and in Figures 10 and 11, $a$ for numbers see Table 4) 


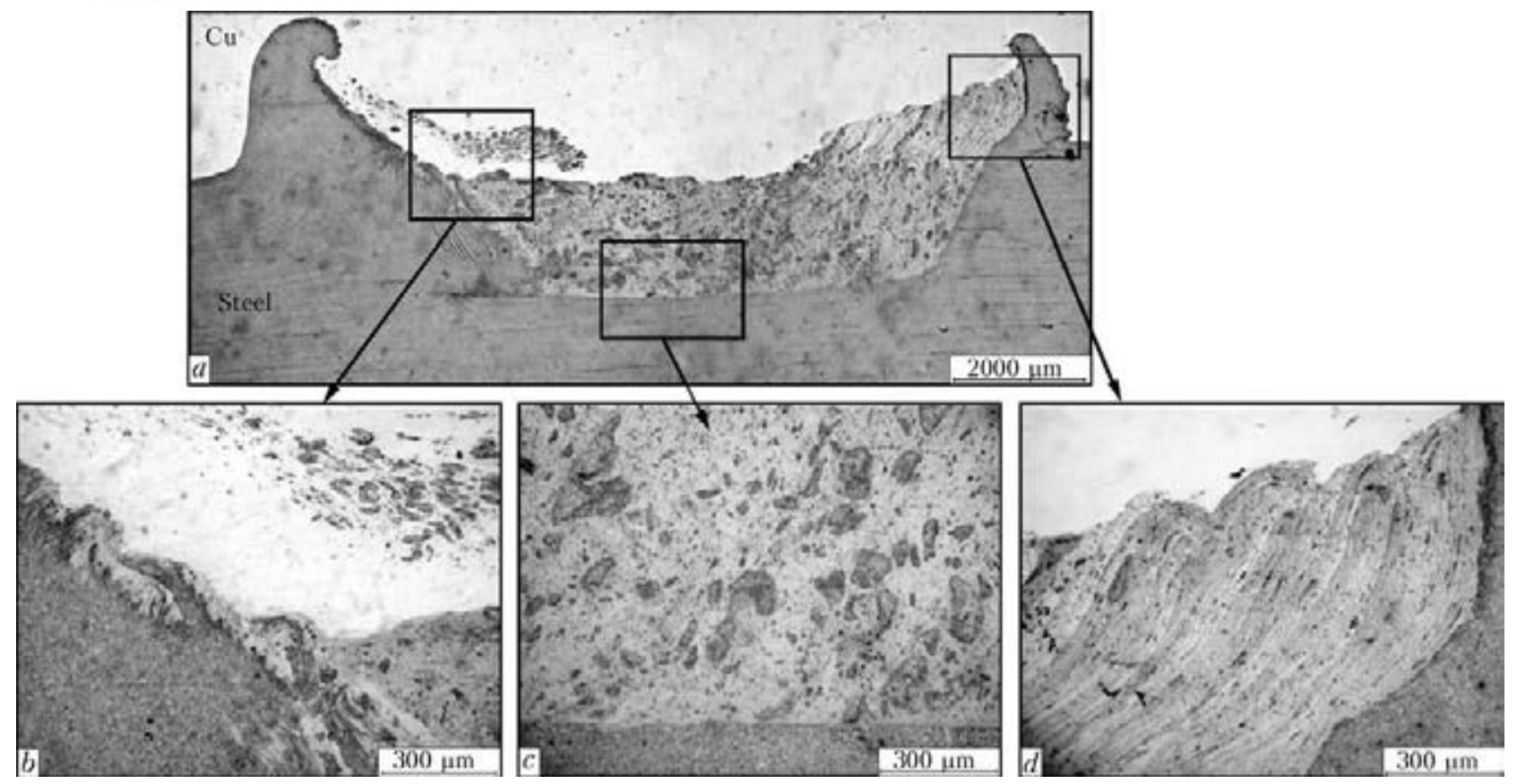

Figure 9. Cross-sectional microstructure of copper-steel welded joint produced by FSW: $a-$ general view; $b, d-$ side regions; $c$ - center of copper-steel mixing zone
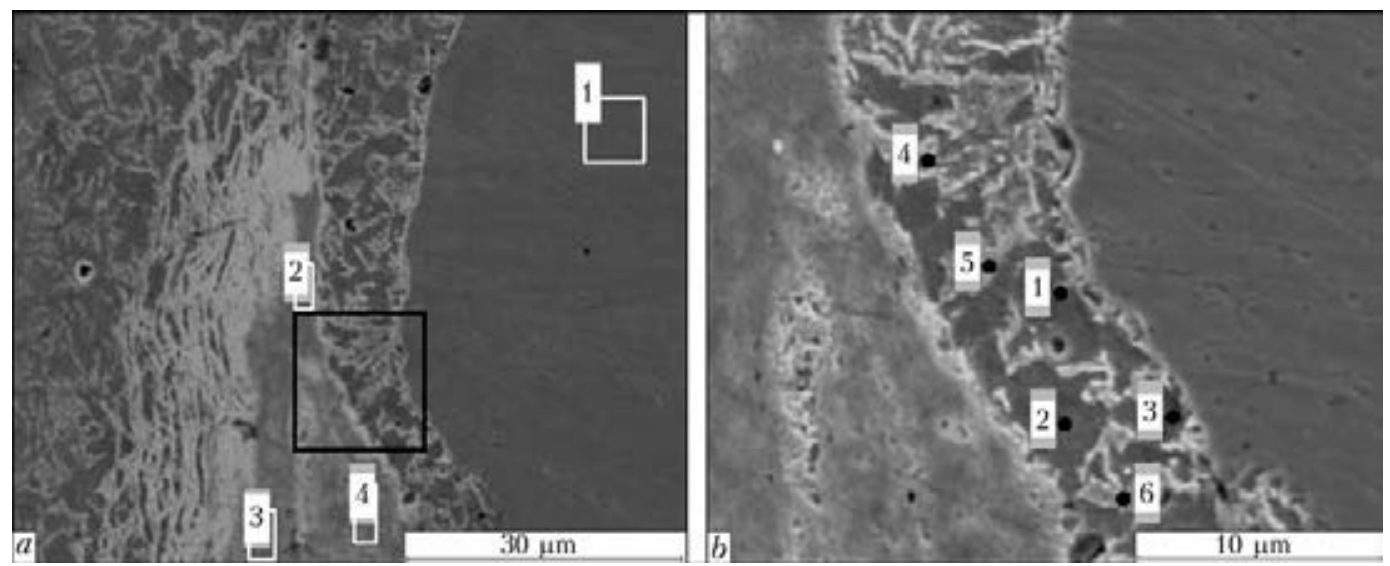

Figure 10. Microstructure of copper-steel contact zone filmed in secondary electrons

base metal. This zone microhardness is equal to $2290 \pm 120$, whereas for ferritic-pearlitic steel it is $2160 \pm 100 \mathrm{MPa}$. As steel hardness is much higher than that of copper, no formation of classical oval nugget took place in the joint zone cross-section (see Figure 9). In its upper part joint zone consists of copper, and the lower part

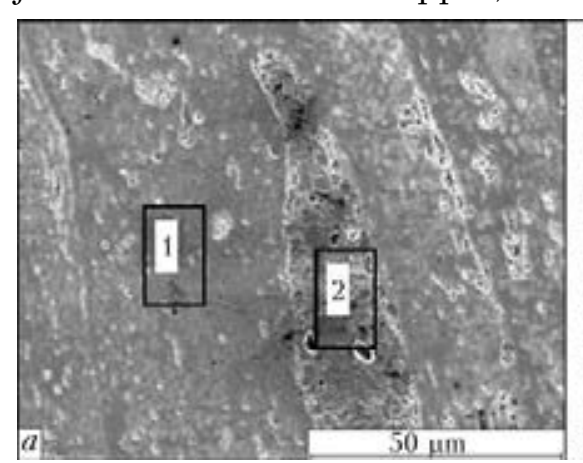

is a mixture of steel particles of different size in the copper matrix. Wedge-like intrusions of steel into copper to the depth of about 700-1000 $\mu \mathrm{m}$ limit the joint nugget. XRMM method was used to analyze different regions of the joint zone and determine their chemical composition (Figure 10, $a, b$; Table 4). As shown by investigations,

Figure 11. Copper-steel contact zone filmed in secondary electrons $(a)$ and in characteristic radiation of copper $(b)$ and

iron $(c)$
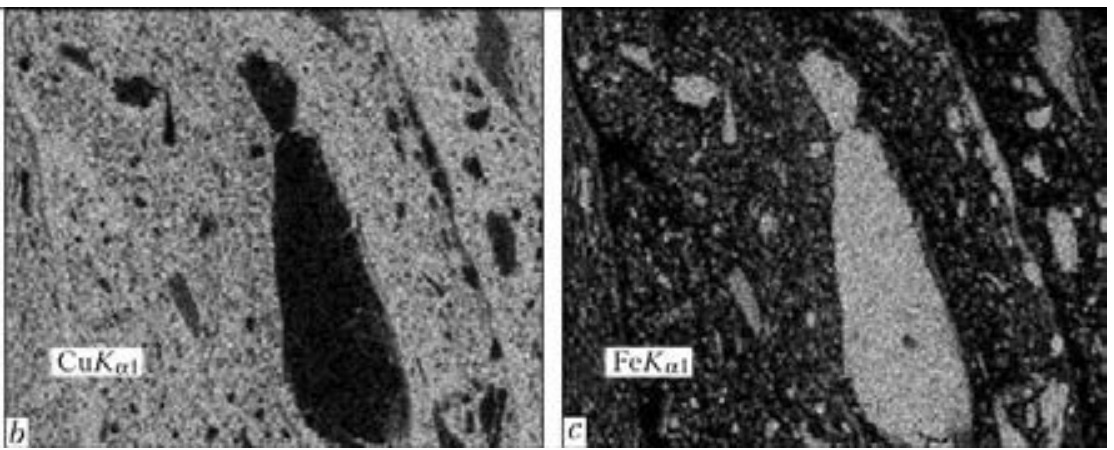
Table 4. Composition of studied regions of copper-steel joint, wt. / at.\%

\begin{tabular}{|c|c|c|c|c|}
\hline Studied region & $\mathrm{Fe}$ & $\mathrm{Cu}$ & Mn & $\mathrm{Si}$ \\
\hline \multicolumn{5}{|c|}{ Acc. to Figure $10, a$} \\
\hline 1 & $0.24 / 0.27$ & $99.76 / 99.73$ & 0 & 0 \\
\hline 2 & $21.75 / 24.02$ & $77.98 / 75.68$ & $0.27 / 0.30$ & 0 \\
\hline 3 & $30.97 / 33.79$ & $68.80 / 65.96$ & $0.23 / 0.25$ & 0 \\
\hline 4 & $31.69 / 34.41$ & $67.88 / 64.79$ & $0.43 / 0.47$ & $0.15 / 0.32$ \\
\hline \multicolumn{5}{|c|}{ Acc. to Figure $10, b$} \\
\hline 1 & $97.74 / 97.54$ & $0.74 / 0.68$ & $1.19 / 1.21$ & $0.29 / 0.57$ \\
\hline 2 & $97.44 / 97.27$ & $1.03 / 0.90$ & $1.26 / 1.27$ & $0.28 / 0.55$ \\
\hline 3 & $97.46 / 97.31$ & $1.05 / 0.92$ & $1.23 / 1.25$ & $0.26 / 0.52$ \\
\hline 4 & $97.41 / 97.30$ & $0.96 / 0.84$ & $1.42 / 1.45$ & $0.21 / 0.41$ \\
\hline 5 & $97.55 / 97.40$ & $0.83 / 0.73$ & $1.38 / 1.40$ & $0.23 / 0.46$ \\
\hline 6 & $97.58 / 97.29$ & $0.76 / 0.67$ & $1.29 / 1.30$ & $0.37 / 0.74$ \\
\hline \multicolumn{5}{|c|}{ Acc. to Figure $11, a$} \\
\hline 1 & $21.47 / 23.72$ & $78.27 / 75.99$ & $0.26 / 0.29$ & 0 \\
\hline 2 & $97.60 / 97.44$ & $0.99 / 0.87$ & $1.14 / 1.16$ & $0.27 / 0.53$ \\
\hline
\end{tabular}

wedge-like intrusions have ferritic-pearlitic structure, and contain practically no copper. In the zone of copper to steel joint, formation of a large number of iron inclusions embedded into copper as individual bands and a mechanical mixture of copper with steel is noted. In the copper matrix a considerable quantity of iron (21.7531.69 wt.\%) was found in the form of dispersed inclusions (Table 4). Having studied boundary regions of the embedded steel band (Figure 10, $b$ ) we can make the assumption that processes of metal interdiffusion with solid solution formation proceed alongside copper inclusions. Results of mapping the mixing zone in $\mathrm{Cu}$-steel 3 joints, which is a mechanical mixture of copper (base) and steel particles of different size, are given in Figure 11 and Table 4. Dispersed inclusions of copper are observed in the largest steel particles. No significant interdiffusion of elements is found during investigations in copper and iron characteristic radiation, but it cannot be ruled out in boundary regions. It is also established that during FSW of these metals a significant refinement of grains proceeds both in the recrystallization zone, and in the thermomechanically and heat affected zones. Conducted investigations show that metal mixing in the plastic state plays a major role in producing copper to steel welded joint by FSW process, and the role of diffusion processes is less significant.

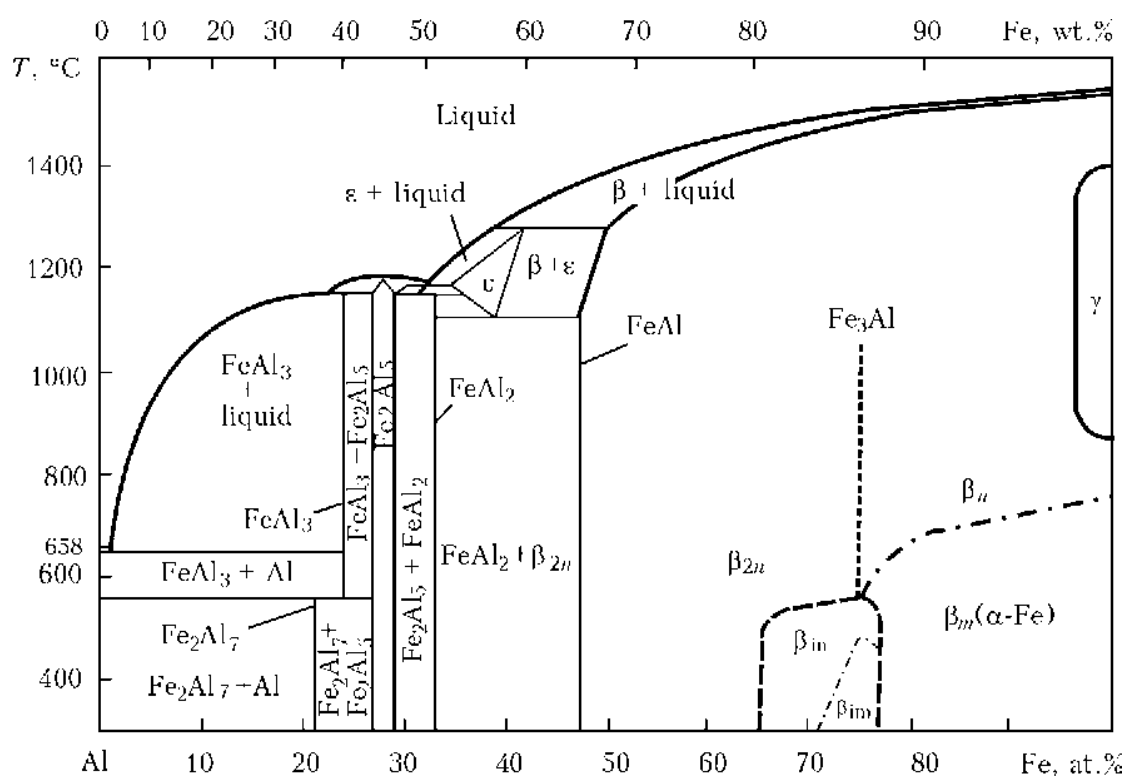

Figure 12. Constitutional diagram of $\mathrm{Fe}-\mathrm{Al}$ system [19] 
SCIENTIFIC AND TECHNICAL
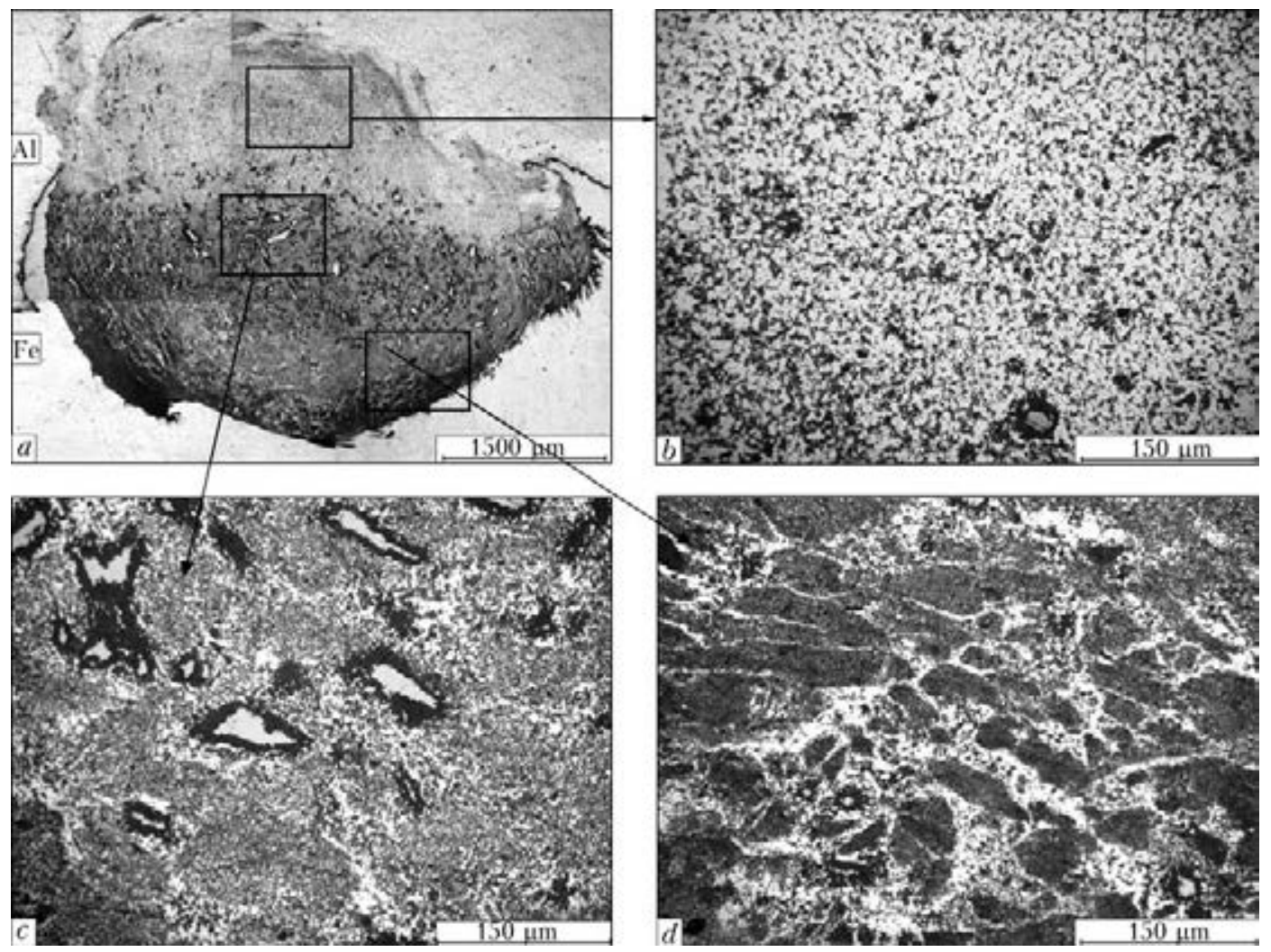

Figure 13. Cross-sectional microstructure of Fe-Al bimetal joint made by FSW: $a$ - general view; $b$ - upper; $c-$ medium; $d-$ lower part of nugget

Ability to joint dissimilar metals by FSW process in the absence of mutual solubility of elements in the solid phase was studied in the case of $\mathrm{Fe}-\mathrm{Al}$ system (Figure 12). It is known from published sources that chemical interaction of aluminium and its alloys with iron, leading to irreversible formation of intermetallics in the contact zone of the two metals, prevents making sound welded joints of these metals [19, 20]. In keeping with the constitutional diagram of $\mathrm{Fe}-\mathrm{Al}$ system solid solutions, intermetallic compounds and eutectics are formed. In the solid state iron solubility in aluminium is quite low, at temperatures of $225-600{ }^{\circ} \mathrm{C}$ it is in the range of $0.01-$ 0.22 wt.\%. Iron solubility in aluminium at eutectic temperature $\left(654{ }^{\circ} \mathrm{C}\right)$ is equal to 0.053 wt. $\%$, and at room temperature iron does not dissolve at all. At solidification of an alloy of aluminium with iron, $\mathrm{FeAl}_{3}$ crystals form already at small amounts of iron in the structure. At up to 1.8 wt.\% $\mathrm{Fe}$ content $\mathrm{Al}+\mathrm{FeAl}_{3}$ eutectic forms at $654{ }^{\circ} \mathrm{C}$. At further increase of iron content (see Figure 12), chemical compounds of the following compositions form in the alloys: $\mathrm{Fe}_{2} \mathrm{Al}_{7}, \mathrm{Fe}_{2} \mathrm{Al}_{5}$, $\mathrm{FeAl}_{2}, \mathrm{FeAl}$ and $\mathrm{Fe}_{3} \mathrm{Al}$ with $62.9,54.7,49.1,32.5$ and 13.87 wt.\% Al, respectively [20].

In this work an aluminium alloy and Armcoiron were joined by FSW in the modes given in Table 1. Pin tool penetrated through the aluminium alloy plate $5 \mathrm{~mm}$ thick to the depth of $6 \mathrm{~mm}$. At FSW of these metals a nugget of $8.2 \times$ $\times 5.4 \mathrm{~mm}$ size and a wedge-like intrusion of iron to $2 \mathrm{~mm}$ depth from both sides of the nugget form in the cross-section of the joint zone (Figure 13, a). Nugget structure is non-uniform, and consists of three zones (Figure 13, $b-d$ ). The nugget
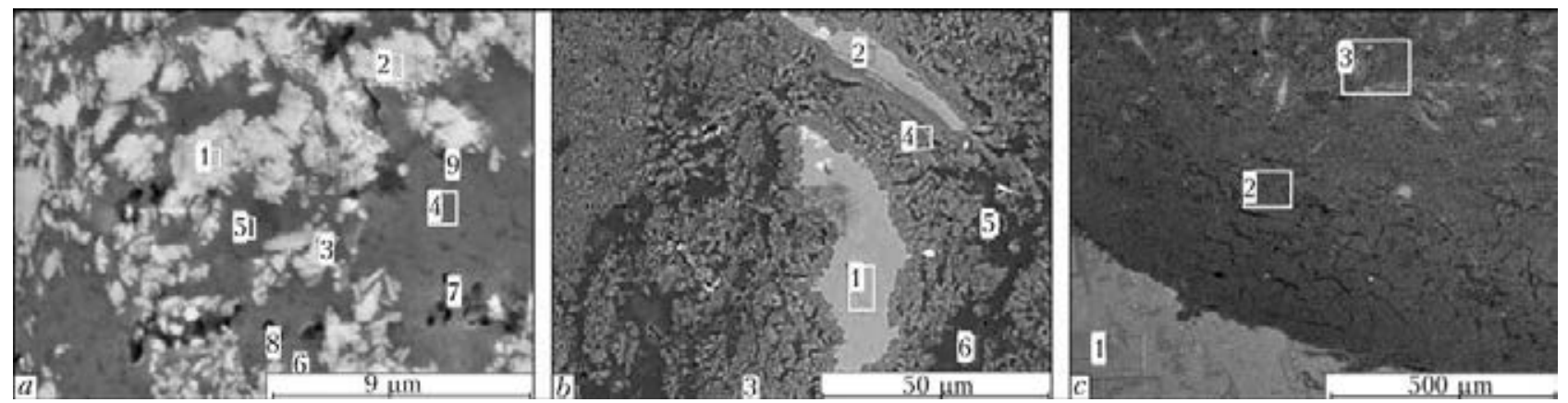

Figure 14. Microstructure of upper $(a)$, medium $(b)$ and lower $(c)$ part of nugget in Al-Fe joints, produced by FSW, filmed in back-scattered electrons (for numbers see Table 5) 
Table 5. Composition of studied regions of $\mathrm{Al}-\mathrm{Fe}$ joint, wt. / at.\%

\begin{tabular}{|c|c|c|c|c|c|}
\hline Studied region & $\mathrm{Fe}$ & $\mathrm{Al}$ & $\mathrm{Mn}$ & $\mathrm{Mg}$ & $\mathrm{O}$ \\
\hline \multicolumn{6}{|c|}{ Acc. to Figure 14, $a$} \\
\hline 1 & $31.27 / 16.91$ & $59.06 / 66.12$ & $0.28 / 0.15$ & $1.41 / 1.76$ & $7.97 / 15.06$ \\
\hline 2 & $27.18 / 14.36$ & $62.71 / 68.71$ & $0.28 / 0.15$ & $2.24 / 2.72$ & $7.59 / 14.03$ \\
\hline 3 & $24.83 / 13.09$ & $65.53 / 71.49$ & $0.68 / 0.36$ & $2.26 / 2.74$ & $6.70 / 12.32$ \\
\hline 4 & $0.87 / 0.42$ & $92.68 / 92.30$ & 0 & $5.65 / 6.22$ & $0.79 / 1.33$ \\
\hline 5 & $2.76 / 1.33$ & $90.43 / 90.91$ & 0 & $5.59 / 6.20$ & $1.22 / 2.06$ \\
\hline 6 & $4.50 / 2.21$ & $89.08 / 90.41$ & $0.32 / 0.16$ & $5.51 / 6.10$ & $0.60 / 1.02$ \\
\hline 7 & $2.11 / 1.02$ & $91.99 / 92.10$ & 0 & $5.35 / 5.94$ & $0.55 / 0.94$ \\
\hline 8 & $2.98 / 1.45$ & $90.28 / 90.89$ & $0.37 / 0.18$ & $5.76 / 6.43$ & $0.62 / 1.05$ \\
\hline 9 & $4.48 / 2.20$ & $89.25 / 90.43$ & $0.20 / 0.10$ & $5.27 / 5.93$ & $0.79 / 1.35$ \\
\hline \multicolumn{6}{|c|}{ Acc. to Figure $14, b$} \\
\hline 1 & $98.69 / 95.87$ & 0 & 0 & $0.26 / 0.57$ & $1.05 / 3.56$ \\
\hline 2 & $90.42 / 81.36$ & $8.36 / 15.56$ & $0.34 / 0.31$ & 0 & $0.88 / 2.78$ \\
\hline 3 & $23.28 / 12.25$ & $66.98 / 72.95$ & $1.07 / 0.57$ & $2.75 / 3.32$ & $5.93 / 10.90$ \\
\hline 4 & $28.67 / 15.14$ & $59.31 / 64.83$ & $0.37 / 0.20$ & $2.61 / 3.17$ & $9.03 / 16.65$ \\
\hline 5 & $1.03 / 0.50$ & $93.73 / 94.08$ & 0 & $4.47 / 4.98$ & 0 \\
\hline 6 & $0.50 / 0.24$ & $94.56 / 94.30$ & 0 & $4.94 / 5.46$ & 0 \\
\hline \multicolumn{6}{|c|}{ Acc. to Figure $14, c$} \\
\hline 1 & $99.76 / 99.51$ & $0.24 / 0.49$ & 0 & 0 & 0 \\
\hline 2 & $21.19 / 11.46$ & $74.26 / 83.23$ & $0.52 / 0.29$ & $4.03 / 5.01$ & 0 \\
\hline 3 & $25.17 / 13.93$ & $70.05 / 80.25$ & $0.38 / 0.21$ & $4.41 / 5.61$ & 0 \\
\hline
\end{tabular}

formed primarily as a result of aluminium mass transfer, as all the zones have an aluminium matrix by XRMM data (Figure 14; Table 5). A zone with the structure of Al-based alloy with $\mathrm{Fe}_{2} \mathrm{Al}_{7}$ inclusions is located in the upper part $\left(\mathrm{Fi}^{-}\right.$ gures $13, b$ and 14, $a$; Table 5). Microhardness of this zone is equal to 980-1168 MPa. Nugget middle part features the greatest non-uniformity (Figures 13, $c$ and 14, b; Table 5). Aluminium matrix contains elongated iron particles of different size and clusters of $\mathrm{Fe}_{2} \mathrm{Al}_{7}$ and $\mathrm{FeAl}_{2}$ intermetallics. At XRMM a higher content of oxygen is recorded in the studied regions, alongside $\mathrm{Fe}-\mathrm{Al}$ intermetallic formation that is indicative of simultaneous formation of intermetallics and small amount of $\mathrm{Al}_{2} \mathrm{O}_{3}$ oxide. No aluminium dif- fusion is found in the elongated iron particles, but they have higher hardness (1360-2740 MPa), probably, as a result of deformation at plastic mixing. $\mathrm{FeAl}_{2}$ intermetallic with $49 \mathrm{wt} . \% \mathrm{Al}$ is in immediate vicinity, forming an iron particle fringe, and $\mathrm{Fe}_{2} \mathrm{Al}_{7}$ is chaotically located in the aluminium matrix, increasing its microhardness up to $1260-1930 \mathrm{MPa}$. It is obvious that the interdiffusion processes develop to the depth equal to thickness of formed intermetallic particles and fringes.

In the nugget zone in direct contact with iron the main structural components are $\mathrm{Fe}_{2} \mathrm{Al}_{7}$ and $\mathrm{FeAl}_{2}$ aluminides, forming tongue-like intrusions into iron (Figures 13, $a, d$ and 14, c). Iron aluminides are located in aluminium matrix, so that
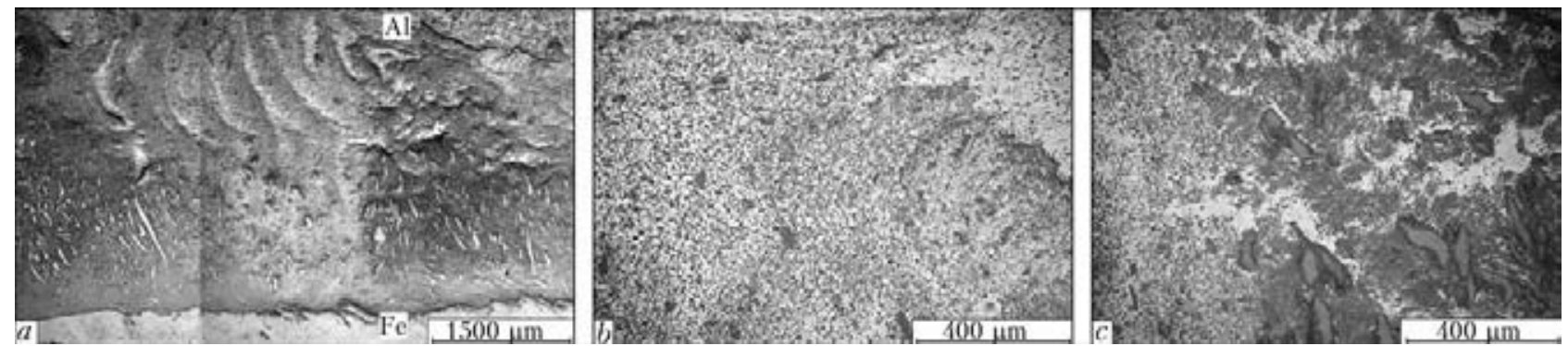

Figure 15. Microstructure of longitudinal section of Al-Fe welded joint made by FSW: $a-$ general view; $b-$ upper; $c-$ medium region of nugget 
microhardness of this zone is not high (2340$3220 \mathrm{MPa})$, compared to that of intermetallics proper $(\sim 10000 \mathrm{MPa})$. Nugget structure revealed microporosity due, obviously, to intermetallic phase formation (see Figure 14 and Table 5). By XRMM data no element interdiffusion was recorded in the aluminium alloy and in iron at 10-15 $\mu \mathrm{m}$ distance from the nugget.

When studying the longitudinal section of the joint zone (Figure 15), it was found to be continuous, without defects and having a wave-like nature, varying between 3 and $7 \mathrm{~mm}$ in width. Its structure consists of regions similar to the above-described regions of this welded joint cross-section.

Investigation of $\mathrm{Al}-\mathrm{Fe}$ joint showed that mechanical mixing with formation of $\mathrm{FeAl}_{3}, \mathrm{Fe}_{2} \mathrm{Al}_{7}$, $\mathrm{FeAl}_{2}$ compounds proceeds during FSW process. The hardest regions of the joint zone, consisting of intermetallics in aluminium matrix, are more than 3 times softer than iron aluminides.

\section{Conclusions}

1. FSW of copper to nickel leads to interpenetration of metals to the depth of down to $3 \mathrm{~mm}$. Structure refinement occurs as a result of recrystallization processes running in the bands of mechanical mixing of metals in the plastic state. Nickel regions in direct contact with copper have lower microhardness.

2. It is established that in the zone of a joint of copper to steel 3, a region of mechanical mixing of metals formed, which consists of wedge-like intrusions of steel into copper to the depth of down to $1 \mathrm{~mm}$, as well as a large number of steel inclusions of different shape of $1-10 \mu \mathrm{m}$ size. Microhardness of this mechanical mixture is 1.5 times higher than that of steel.

3. FSW of aluminium to steel resulted in formation of a joint zone of a considerable volume with aluminium penetration into iron to the depth of down to $2.5 \mathrm{~mm}$. Metal interaction takes place with subsequent formation of $\mathrm{Fe}_{2} \mathrm{Al}_{7}, \mathrm{FeAl}_{2}$ compounds. The hardest regions of the joint zone consist predominantly of iron aluminides in aluminium matrix.

4. Mechanical mixing of metals in the plastic state plays the leading role in FSW process. Role of diffusion processes is smaller. In $\mathrm{Cu}-\mathrm{Ni}$ system with unlimited solubility of components in the solid state interdiffusion is found at formation of solid solution interlayers along grain boundaries to the depth of $20 \mu \mathrm{m}$. In $\mathrm{Fe}-\mathrm{Al}$ system, when elements are not soluble in the solid state, diffusion processes proceed to the depth, equal to thickness of formed clusters of intermetallic particles and fringes down to $25 \mu \mathrm{m}$.

5. Conducted investigations allow recommending FSW process for welding dissimilar metals, having different solubility in the solid state, as well as for making bimetal joints.

1. Thomas, W.M., Nicholas, E.D., Needam, J.C. et al. Friction stir butt welding. Pat. 9125978.8 GB. Publ. Oct. 1995

2. Vill, V.I. (1970) Friction welding of metals. Leningrad: Mashinostroenie.

3. Lebedev, V.K., Chernenko, I.A., Mikhalsky, R. et al. (1987) Friction welding: Refer. Book. Leningrad: Mashinostroenie.

4. Mishraa, R.S., Ma, Z.Y. (2005) Friction stir welding and processing. Mater. Sci. and Eng., 50, 1-78.

5. Eriksson, L.G., Larsson, R. (2003) Rotation stir welding: Research and new fields of application. Tekhnologiya Mashinostroeniya, 6, 81-84.

6. Lyudmirsky, Yu.G., Kotlyshev, R.R. (2010) Friction stir welding of aluminium alloys in building industry. Nauchn. Vestnik VGASU. Stroitelstoo i Arkhitektura, 3, 15-22.

7. Nikityuk, Yu.N., Grigorenko, G.M., Zelenin, V.I. et al. (2013) Technology of reconditioning repair of slab moulds of continuous-casting machine by friction stir hardfacing. Sovr. Elektrometallurgiya, 3, 51-55.

8. Watanabe, H., Takayama, H., Yanagisawa, A. (2006) Joining of aluminum alloy to steel by friction stir welding. J. Mater. Proc. Technol., 178, 342-349.

9. Lee, W.-B., Schmuecker, M., Mercardo, U.A. et al. (2006) Interfacial reaction in steel-aluminum joints made by friction stir welding. Scripta Mater., 55, 355-358.

10. Kostka, A., Coelho, R.S., dos Santos, J. et al. (2000) Microstructure of friction stir welding of aluminium alloy to magnesium alloy. Ibid., 66, 953-956.

11. Kwon, Y.J., Shigematsu, I., Saito, N. (2008) Dissimilar friction stir welding between magnesium and aluminium alloys. Materials Letters, 62, 3827-3829.

12. Xue, P., Ni, D.R., Wang, D. et al. (2011) Effect of friction stir welding parameters on the microstructure and mechanical properties of the dissimilar $\mathrm{Al}-\mathrm{Cu}$ joints. Mater. Sci. and Eng., 528, 4683-4689.

13. Saeida, T., Abdollah-Zadehb, A., Sazgarib, B. (2010) Weldability and mechanical properties of dissimilar aluminum-copper lap joints made by friction stir welding. J. Alloys and Compounds, 490, 652-655.

14. Grigorenko, G.M., Zelenin, V.I., Kavunenko, P.M. et al. (2012) Stir friction hardfacing by nickel of copper mould walls of continuous-casting machines. In: Problems of resource and service safety of structures, constructions and machines. Kyiv: PWI, 369-372.

15. Poleshchuk, M.A., Grygorenko, G.M., Kavunenko, P.M. et al. Insert of working tool of machine for friction stir welding and surfacing. Pat. 25394 for a design, Ukraine. Publ. 10.09.2013.

16. Beckert, M.K., Clemm, H. (1988) Methods of metallographic etching: Refer. Book. Moscow: Metallurgiya.

17. Hansen, M., Anderko, K. (1962) Structure of binary alloys. Vol. 1, 2. Moscow: Metallurgizdat.

18. (1979) Binary and multicomponent systems on copper base: Refer. Book. Ed. by N.Kh. Abrikosov. Moscow: Nauka.

19. Rabkin, D.M., Ryabov, V.R., Gurevich, S.M. (1975) Welding of dissimilar metals. Kiev: Tekhnika.

20. Ryabov, V.R., Rabkin, D.M., Kurochko, R.S. et al. (1984) Welding of dissimilar metals and alloys. Moscow: Mashinostroenie. 


\title{
MODELING OF WELD POOL BEHAVIOUR IN SPOT WELDING BY PULSED LASER RADIATION*
}

\author{
A.P. SEMYONOV, I.V. SHUBA, I.V. KRIVTSUN and V.F. DEMCHENKO \\ E.O. Paton Electric Welding Institute, NASU \\ 11 Bozhenko Str., 03680, Kiev, Ukraine. E-mail: office@paton.kiev.ua
}

\begin{abstract}
Process of metal evaporation in laser welding is accompanied by dynamic impact of metal vapours on pool free surface. As this process proceeds non-uniformly over pool surface, reactive vapour pressure can differ considerably in its different sections, leading to depression of melt free surface. This work proposes a mathematical model allowing investigation of penetration dynamics and shape of weld pool free surface in laser welding of sheet metals by a stationary pulsed source (spot welding). When developing the model, we assumed that heat transfer process in the metal is due to heat conductivity and convection, and heat losses from the surface are due to metal evaporation and energy loss for heat radiation. The work gives the results of numerical modeling of weld pool penetration dynamics derived with application of the developed model. 6 Ref., 7 Figures.
\end{abstract}

Keywords: laser spot welding, sheet material, mathematical model, penetration dynamics, weld pool shape

Impact of concentrated energy sources, such as focused laser beam, on metal products being welded, may lead to intensive evaporation of metal from weld pool surface. Evaporation process is accompanied both by heat losses and dynamic impact of metal vapours on melt free surface. Under certain heating conditions, reactive vapour pressure can be quite high to cause significant depression of weld pool surface. Moreover, heating by a concentrated energy source creates a high temperature gradient along the melt free surface that is the cause for generation of $\mathrm{Ma}^{-}$ rangoni thermocapillary convection in weld pool volume. As shown by previous studies [1], thermocapillary surface forces have an essential influence on the pattern of metal flow in the weld pool and largely determine the dimensions and shape of penetration zone in different fusion welding processes.

This study proposes a mathematical model describing thermal and hydrodynamic processes in molten metal pool in spot laser welding of sheet metal. For model development it was assumed that heat transfer in the metal occurs through heat conductivity and convection, whereas heat losses from the surface are due to metal evaporation and heat radiation flow. Hydrodynamic process model used in the work is based on

\footnotetext{
${ }^{*}$ Basing on the paper presented at the Int. Conf. on Laser Technologies in Welding and Materials Processing (27-31 May 2013, Katsively, Crimea, Ukraine).
}

(๑ A.P. SEMYONOV, I.V. SHUBA, I.V. KRIVTSUN and V.F. DEMCHENKO, 2014
Navier-Stokes equations for viscous incompressible liquid and allows for capillary pressure due to curvature of molten metal free surface, as well as Marangoni thermocapillary effect. For model simplification it was assumed that all the described physical processes have the property of axial symmetry. The work analyzes the influence of various physical factors on penetration process dynamics. For this purpose comparative analysis of three models of weld pool dynamics was performed:

- heat conductivity model;

- model of convective-conductive heat transfer allowing for free surface curvature due to reactive vapour pressure;

- model of convective-conductive heat transfer allowing for reactive vapour pressure and thermocapillary Marangoni effect.

Assessment of metal movement speed. Before describing the mathematical model, let us assess the speed of melt motion in the weld pool in spot laser welding of sheet low-carbon steel. Material properties used in further calculations, are taken from work [2] and are given below:

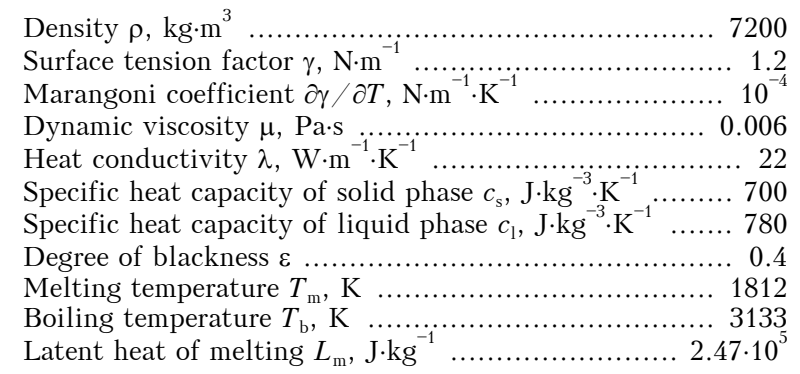

Let us write an approximate expression for tangential stresses $P_{\mathrm{m}}$ on molten metal surface $\Gamma$, assuming that the surface proper is flat: 


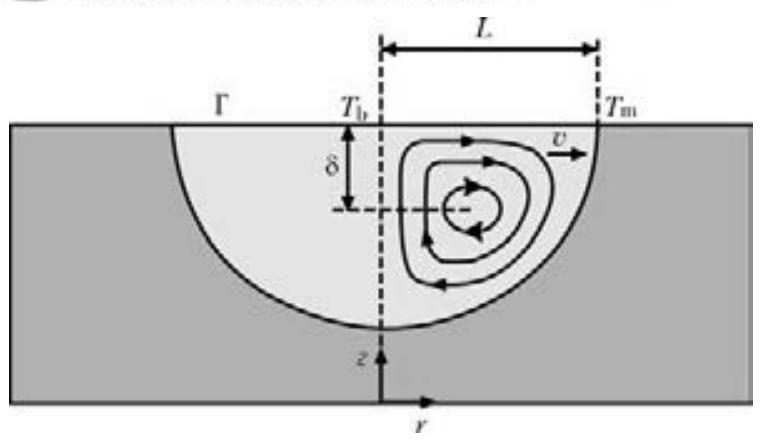

Figure 1. Characteristic flow pattern in the weld pool at thermocapillary Marangoni convection

$$
P_{\mathrm{m}}=\left.\mu \frac{\partial u}{\partial z}\right|_{\Gamma} \approx \mu \frac{u_{\mathrm{s}}}{\delta},
$$

where $\mu$ is the dynamic viscosity of liquid metal; $u_{\mathrm{s}}$ is the value of radial component of speed vector on the surface; $\delta$ is the distance from the surface to eddy center (Figure 1).

On the other hand, for value $P_{\mathrm{m}}$ we can write

$$
P_{\mathrm{m}}=\left.\frac{\partial \gamma}{\partial T} \frac{\partial T}{\partial r}\right|_{\Gamma} \approx \frac{\partial \gamma}{\partial T} \frac{T_{\mathrm{b}}-T_{\mathrm{m}}}{L},
$$

where $\gamma$ is the surface tension coefficient of liquid metal; $L$ is the weld pool radius. At derivation of (2) we assumed that temperature in the pool center corresponds to boiling point under normal conditions. We will also assume $\delta=L / 4$, then we will finally have

$$
u_{\mathrm{s}}=\frac{\delta}{\mu L} \frac{\partial \gamma}{\partial T}\left(T_{\mathrm{m}}-T_{\mathrm{b}}\right) \approx 5.5 \mathrm{~m} / \mathrm{s} .
$$

Value of Peclet number for the considered conditions $\mathrm{Pe}=u_{\mathrm{s}} L / \alpha=630$, where $\alpha$ is the coefficient of molten metal heat conductivity, indicates that convective heat transfer will have an essential influence on metal pool heat condition.

Description of mathematical model. Numerical solution procedure. To describe thermal processes in the metal being welded, we will use the equation of heat transfer in area $\Omega$ (Figure 2):

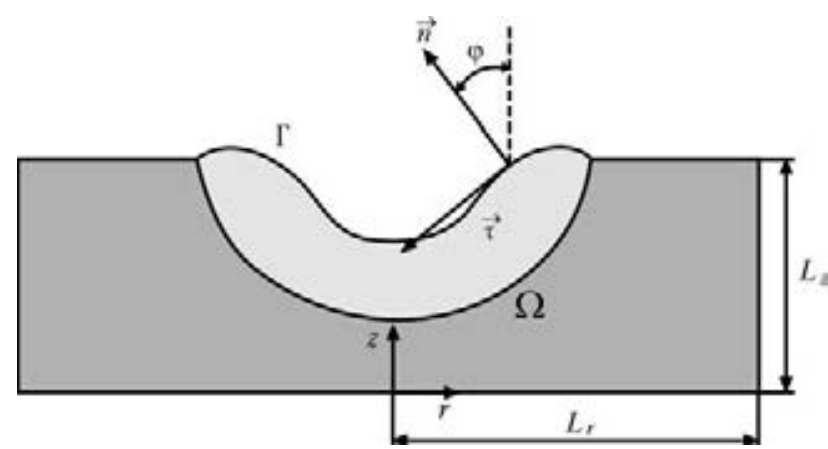

Figure 2. Schematic of calculated area

$$
\begin{gathered}
\frac{\partial H}{\partial t}+u \frac{\partial H}{\partial r}+v \frac{\partial H}{\partial z}=\frac{1}{r} \frac{\partial}{\partial r} \times \\
\times\left(r \lambda \frac{\partial T}{\partial r}\right)+\frac{\partial}{\partial z}\left(\lambda \frac{\partial T}{\partial z}\right), \\
H(T)=\int_{T_{0}}^{T} c \rho d \bar{T}+L_{\mathrm{m}} \rho \eta,
\end{gathered}
$$

where $u, v$ are the components of speed vector; $H$ is the specific enthalpy; $\eta$ is the liquid phase fraction. We will complement equation (4) by boundary and initial conditions:

$$
\begin{gathered}
\lambda \frac{\partial}{\partial} \mid=A\left(T_{\Gamma}, \varphi\right) \cos (\varphi) q_{\mathrm{S}}(r)- \\
-q_{\mathrm{ev}}\left(T_{\Gamma}\right)-q_{\mathrm{rad}}\left(T_{\Gamma}\right), \\
\left.\frac{\partial T}{\partial z}\right|_{z=0}=\left.\frac{\partial T}{\partial r}\right|_{r=0}=\left.\frac{\partial T}{\partial r}\right|_{r=L_{r}}=0, \\
T(r, z, 0)=T_{0}, \quad(r, z) \in \Omega .
\end{gathered}
$$

The following designations were introduced in condition (6): $A$ is the coefficient of laser radiation absorption by metal surface; $q_{\mathrm{s}}$ is the laser radiation power density; $q_{\mathrm{ev}}$ is the specific heat flow due to metal evaporation from pool surface; $q_{\text {rad }}$ is the specific radiant heat flow. To describe radiation power distribution in the laser beam the following dependence was used:

$$
q_{\mathrm{s}}(r)=q_{0} \exp \left(-2\left(r / r_{0}\right)^{2}\right),
$$

where $q_{0}$ is the intensity of laser radiation on beam axis; $r_{0}$ is the beam radius on item surface. At calculation of absorption coefficient it was assumed that laser radiation has random polarization. In this case

$$
A\left(T_{\Gamma}, \varphi\right)=1-\frac{R_{s}\left(T_{\Gamma}, \varphi\right)+R_{p}\left(T_{\Gamma}, \varphi\right)}{2} .
$$

Here

$$
\begin{gathered}
R_{s}\left(T_{\Gamma}, \varphi\right)=\left|\frac{\cos \varphi-\sqrt{\varepsilon_{\omega}\left(T_{\Gamma}\right)-\sin ^{2} \varphi}}{\cos \varphi+\sqrt{\varepsilon_{\omega}\left(T_{\Gamma}\right)-\sin ^{2} \varphi}}\right|^{2}, \\
R_{p}\left(T_{\Gamma}, \varphi\right)=\left|\frac{\varepsilon_{\omega}\left(T_{\Gamma}\right) \cos \varphi-\sqrt{\varepsilon_{\omega}\left(T_{\Gamma}\right)-\sin ^{2} \varphi}}{\varepsilon_{\omega}\left(T_{\Gamma}\right) \cos \varphi+\sqrt{\varepsilon_{\omega}\left(T_{\Gamma}\right)-\sin ^{2} \varphi}}\right|^{2}
\end{gathered}
$$

are the coefficients of reflection of $s$ - and $p$-polarized waves by metal surface, respectively; $\varphi$ is the angle of incidence (see Figure 2); $\varepsilon_{\omega}$ is the complex dielectric permeability of metal at laser radiation frequency. Energy losses due to heat radiation were found from Stefan-Boltzmann law: 


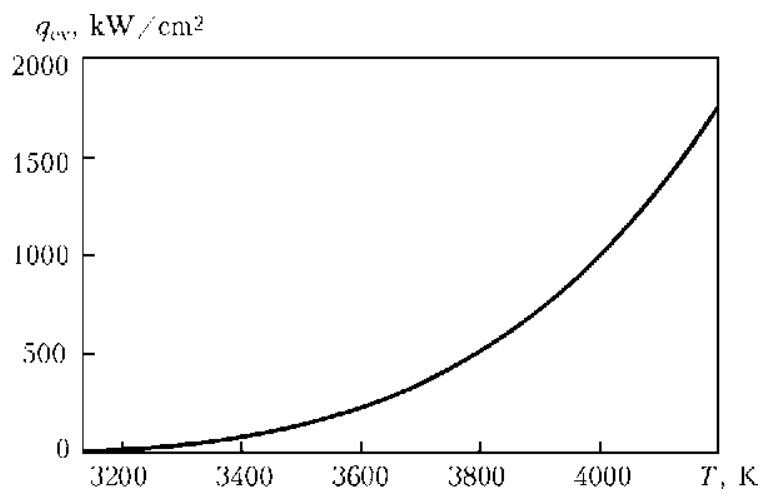

Figure 3. Temperature dependence of heat losses through evaporation

$$
q_{\mathrm{rad}}\left(T_{\Gamma}\right)=\varepsilon \sigma\left(T_{\Gamma}^{4}-T_{\infty}^{4}\right),
$$

where $\sigma$ is the Stefan-Boltzmann constant; $T_{\infty}$ is the ambient temperature.

Model of hydrodynamic processes in the weld pool is based on Navier-Stokes equations for viscous incompressible liquid:

$$
\begin{gathered}
\rho\left(\frac{\partial u}{\partial t}+u \frac{\partial u}{\partial r}+v \frac{\partial u}{\partial z}\right)=\frac{1}{r} \frac{\partial}{\partial r}\left(r \sigma_{r r}\right)+ \\
+\frac{\partial \sigma_{r z}}{\partial z}-\frac{\sigma_{\varphi \varphi}}{r}, \\
\rho\left(\frac{\partial v}{\partial t}+u \frac{\partial v}{\partial r}+v \frac{\partial v}{\partial z}\right)=\frac{1}{r} \frac{\partial}{\partial r}\left(r \sigma_{r z}\right)+ \\
+\frac{\partial \sigma_{z z}}{\partial z}-g \rho, \\
\frac{1}{r} \frac{\partial}{\partial r}(r u)+\frac{\partial v}{\partial z}=0,
\end{gathered}
$$

where

$$
\begin{gathered}
\sigma_{r r}=-P+2 \mu \frac{\partial u}{\partial r} ; \quad \sigma_{r z}=\mu\left(\frac{\partial v}{\partial r}+\frac{\partial u}{\partial z}\right) ; \\
\sigma_{z z}=-P+2 \mu \frac{\partial v}{\partial z}
\end{gathered}
$$

$\sigma_{\varphi \varphi}=-P+2 \mu \frac{u}{r}$ are the $\tilde{\sigma}$ stress tensor components; $g$ is the free fall acceleration; $P$ is the pressure in the melt. We will write boundary conditions for equations (11)-(13) in the following form:

$$
\begin{gathered}
\tilde{\sigma} \vec{n}=-\left(2 \gamma K+P_{\mathrm{ev}}\right) \vec{n}+\frac{\partial \gamma}{\partial s} \overrightarrow{\tau,} \\
\left(\vec{n},\left.\vec{V}\right|_{\Gamma}\right)=\left(\vec{n}, \vec{V}_{\Gamma}\right), \\
\left.\vec{V}\right|_{r=L_{r}}=\left.\vec{V}\right|_{r=0}=\left.\vec{V}\right|_{z=0}=0,
\end{gathered}
$$

where $\vec{n}$ and $\vec{\tau}$ are the unit vectors of normal and tangential to the surface, respectively (see Figu-

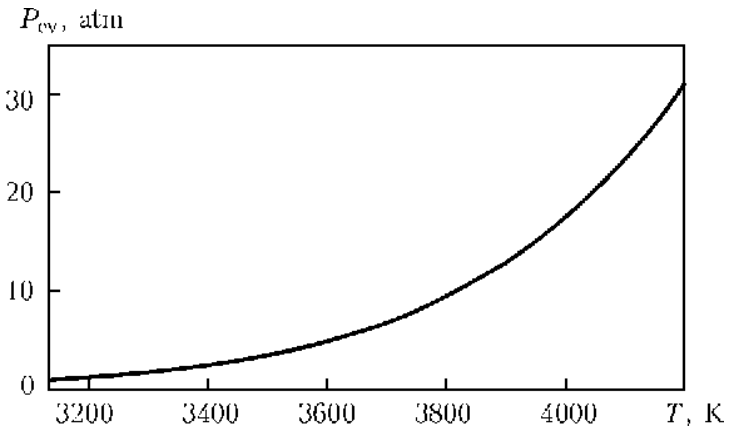

Figure 4. Temperature dependence of reactive pressure of metal vapours

re 2); $K$ is the average curvature of liquid metal surface; $\vec{V}_{\Gamma}$ is the speed of boundary movement. Equation (14) describes the balance of normal and tangential stresses on the pool free surface, whereas (15) gives the kinematic boundary conditions.

To solve problems (4)-(8) and (11)-(16) arbitrary Lagrangian-Eulerian method [3] was applied together with finite element method [4]. Calculated area $\Omega$ (see Figure 2) covers liquid metal zone, and also includes the solid phase. When solving the hydrodynamic problem, viscosity in the solid phase is assumed to be high enough $\left(10^{8}\right.$ higher than liquid metal viscosity $)$. During performance of calculation experiment, it allows suppressing metal movement in the solid phase, and eliminates the need to adapt the FE net for melting front shape and assign additional boundary conditions in the melting front. Such an approach was proposed for the first time in [5], and is found in publications under the title «effective viscosity method».

Numerical modeling results. Numerical experiments were conducted for the conditions of laser spot welding (Nd:YAG-laser) of low-carbon steel $0.3 \mathrm{~mm}$ thick. Temperature dependencies of evaporation process characteristics (heat losses through evaporation and reactive pressure of met-

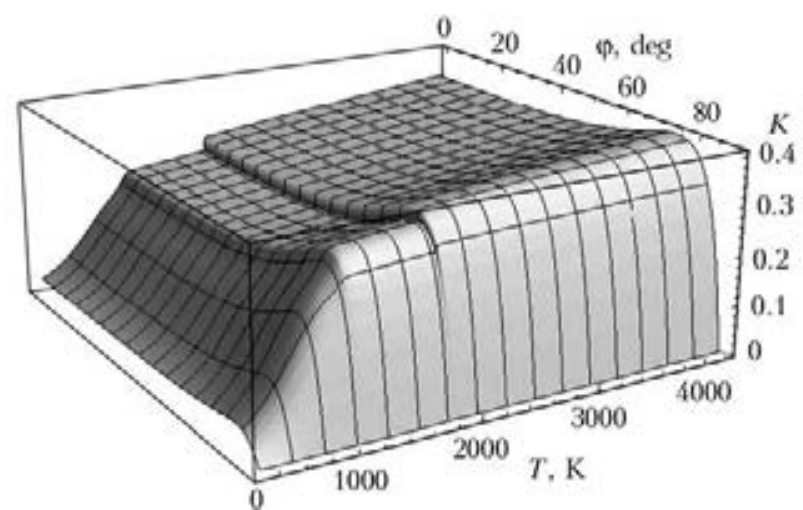

Figure 5. Dependence of coefficient of absorption of laser radiation (1.06 $\mu \mathrm{m}$ wave length) by the surface of low-carbon steel on temperature and angle of incidence 

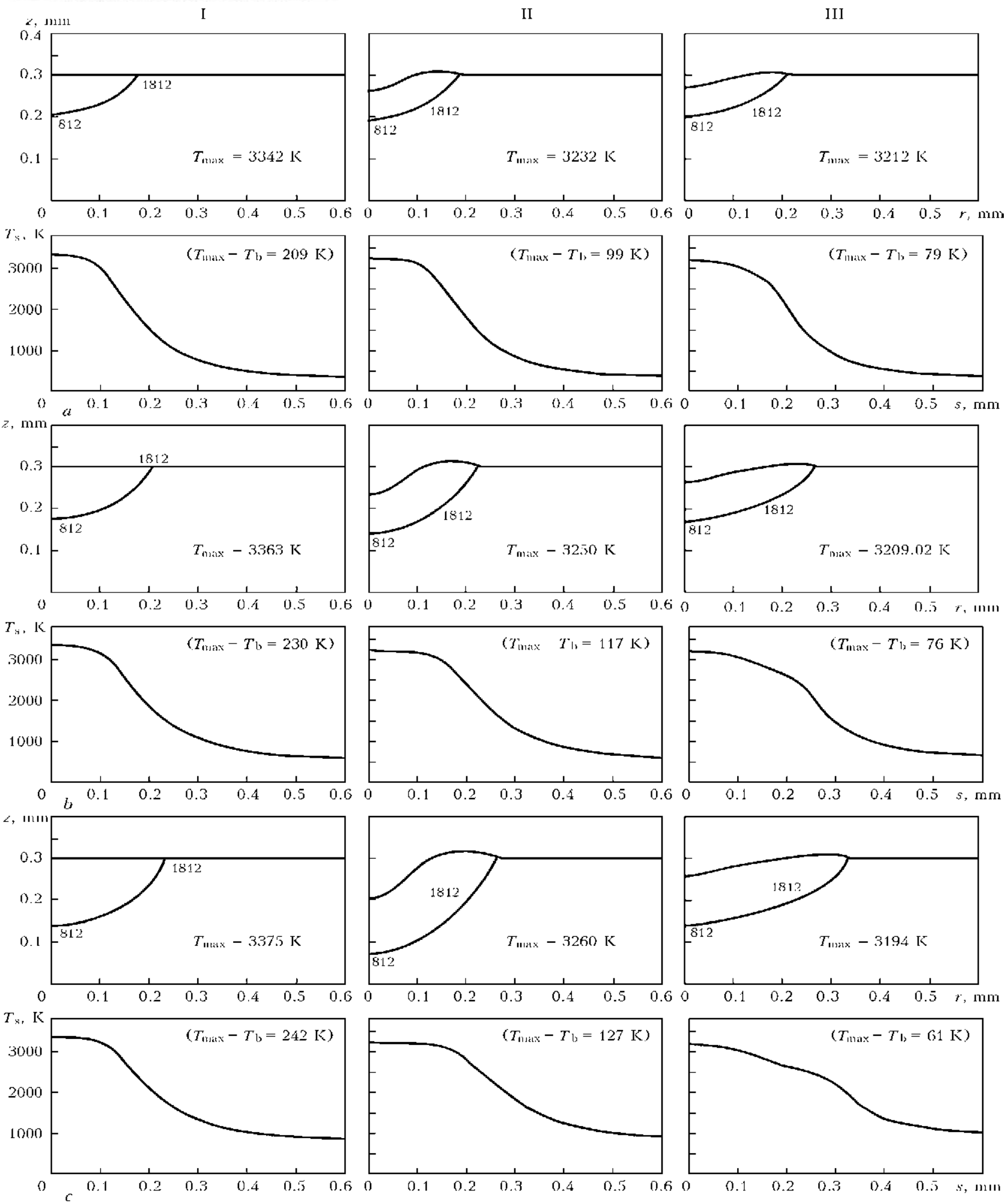

Figure 6. Dynamics of change in time $t$ of weld pool shape and temperature distribution along melt surface for modes I-III: $a-t=0.01 ; b-0.02 ; c-0.03 \mathrm{~s}$

al vapours) were derived using a model proposed in [6], and are given in Figures 3 and 4. Dependence of the coefficient of absorption for laser radiation with selected wave length on angle of incidence and metal surface temperature, determined by expression (10), is given in Figure 5 . Process parameters, used in calculations, are given below:
Welded metal thickness, $\mathrm{mm}$ 0.3 Maximum intensity of laser radiation on metal surface, $\mathrm{W} \cdot \mathrm{cm}^{-2}$

Laser beam radius on metal surface, $\mathrm{mm} \ldots \ldots \ldots . . . . .0 .2$

As shown by the results of numerical studies, calculated values of surface temperature in the center of laser heating spot, generated by model I, greatly increase boiling temperature ( $F i-$ 
1

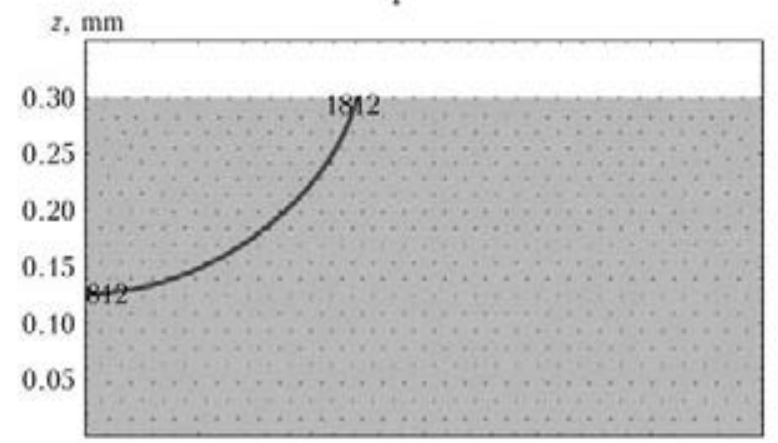

II

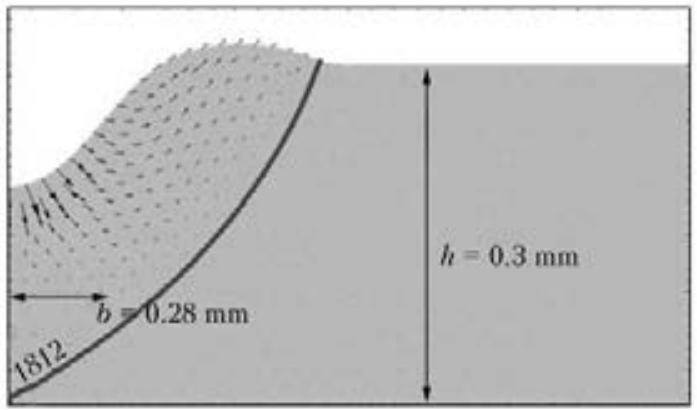

III

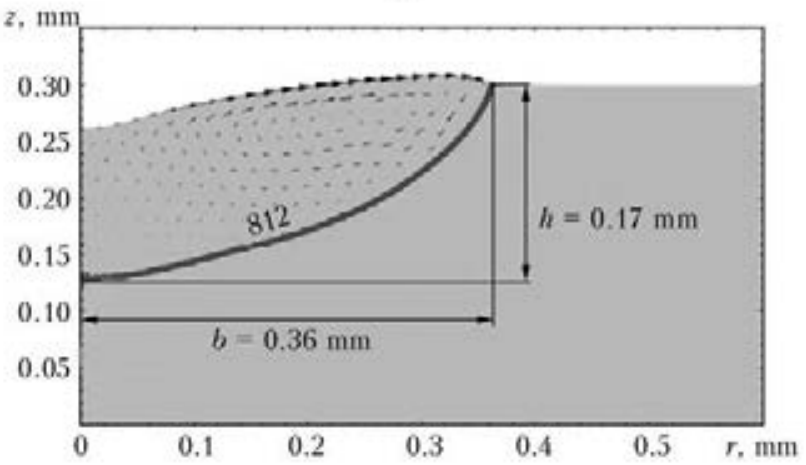

Figure 7. Comparative analysis of dimensions and shape of penetration zone produced using models I-III at $t=0.0332 \mathrm{~s}$ and maximum speed of 0 (I), 0.00285 (II) and 1.264 (III) $\mathrm{m} / \mathrm{s}$

gure 6). The smallest overheating of the surface above boiling temperature is observed with application of model III. Weld pool dimensions and shape differ accordingly. So, at one and the same time of laser radiation impact on welded metal surface $(t=0.0332 \mathrm{~s})$ depth $h$ and half-width $b$ of the penetration zone are equal to 0.17 and $0.24 \mathrm{~mm}$ for model I, 0.30 and $0.28 \mathrm{~mm}$ for model II, and 0.17 and $0.36 \mathrm{~mm}$ for model III, respectively (Figure 7).

On the whole, modeling results given in $\mathrm{Fi}^{-}$ gures 6 and 7 allow stating that Marangoni convection mainly influences the width of penetration zone, whereas pool surface depression promotes an increase of its depth. This results from increase of heat flow to the solid phase, due to reduction of thickness of liquid metal interlayer between pool surface and melting boundary.

Thus, the most adequate mathematical model of metal penetration in spot laser welding of sheet materials is that of convective-conductive heat transfer in the weld pool, allowing for reactive pressure of vapours on its surface and thermocapillary Marangoni effect (model III). This model allows in the most comprehensive manner for the processes of heat and mass transfer on the surface and in the volume of weld pool in laser welding of thin metal.

1. Kou, S. (2012) Fluid flow and solidification in welding: Three decades of fundamental research at the university of Wisconsin. Welding J., 91, 11 .

2. Hu, J., Tsai, H.L. (2007) Heat and mass transfer in gas metal arc welding. Pt 1: The arc. Int. J. Heat and Mass Transfer, 50, 833-846.

3. Donea, J., Huerta, A., Ponthot, J.Ph. et al. (2004) Arbitrary Lagrangian-Eulerian methods: Encyclop. of computational mechanics. Vol. 1. John Wiley \& Sons.

4. Zienkiewicz, O.C., Taylor, R.L. (2000) The finite element method. Vol. 1: The basis. Oxford: Butterworth-Heinemann

5. Kou, S., Sun, D.K. (1985) Fluid flow and weld penetration in stationary arc welds. Metall. Transact. $A, \mathbf{1 6}, 203-213$.

6. Knight, C.J. (1979) Theoretical modeling of rapid surface vaporization with back pressure. J. AIAA, 17, 519-523.

Received 10.01.2014 


\title{
EFFECT OF NICKEL AND MANGANESE ON STRUCTURE OF Ag-Cu-Zn-Sn SYSTEM ALLOYS AND STRENGTH OF BRAZED JOINTS
}

\author{
V.F. KHORUNOV, B.V. STEFANIV and S.V. MAKSYMOVA \\ E.O. Paton Electric Welding Institute, NASU \\ 11 Bozhenko Str., 03680, Kiev, Ukraine. E-mail: office@paton.kiev.ua
}

\begin{abstract}
It is a well-known fact that alloys of $\mathrm{Ag}-\mathrm{Cu}-\mathrm{Zn}-\mathrm{Sn}$ system are a good basis for development of cadmium-free brazing filler metals (BFM) for brazing of different materials. However, as it follows from works of different authors, the BFM of this system are insufficiently active in brazing of hard-alloy materials. This work tries to eliminate these disadvantages. Effect of nickel and manganese alloying in 1-4 wt.\% Ni and 2-6 wt.\% Mn interval is investigated using method of experiment planning. Investigated are the intervals of alloy melting, areas of spreading and wetting angles on different substrates, strength characteristics of the joints in brazing of stainless steels and hard alloys. Structure of pilot alloys is investigated using the methods of optical and electron microscopy and microX-ray spectrum analysis. It is shown that manganese and nickel alloying of $\mathrm{Ag}-\mathrm{Cu}-\mathrm{Zn}-\mathrm{Sn}$ system alloys allowed developing BFM, which provide good wetting of hard-alloy materials at the level of $\mathrm{BFM}$ of $\mathrm{Ag}-\mathrm{Cu}-\mathrm{Zn}-\mathrm{Cd}$ system at filler relationship, approximately, 1.5-2.0 Mn:1.0 Ni. Technological properties of BFM deteriorate at 1.0 Mn:1.5-2.0 Ni relationship. Development of environmentally friendly BFM of $\mathrm{Ag}-\mathrm{Cu}-\mathrm{Zn}-\mathrm{Sn}-\mathrm{Ni}-\mathrm{Mn}$ system for brazing of rock destruction and metal-cutting tool allows refusing from application of harmful BFM of $\mathrm{Ag}-\mathrm{Cu}-\mathrm{Zn}-\mathrm{Cd}$ system and significantly (per 20-50\%) increasing strength of brazed joints. 5 Ref., 4 Tables, 7 Figures.
\end{abstract}

Keywords: brazing, cadmium-free brazing filler metals, structure, melting interval, contact wetting angle, induction heating, temperature of phase transforma tions, nickel, manganese, silver brazing filler metal, joint strength

Experimental investigations were carried out in works [1,2] for the purpose of development of non-toxic brazing filler metals (BFM) containing no cadmium and having the same melting temperatures and mechanical properties as $\mathrm{Ag}^{-} \mathrm{Cu}^{-}$ $\mathrm{Sn}-\mathrm{Cd}$ system BFM. The investigations included analysis of phase composition, thermal analysis, extrusion, mechanical tests of $\mathrm{Ag}-\mathrm{Cu}-\mathrm{Zn}-\mathrm{Sn}$ system alloys. The works of authors [3, 4] show that BFM of this system provide for strength of the brazed joints close to that in using of $\mathrm{Cd}-\mathrm{con}-$ taining BFM. However, study of wetting of hardalloy plates by these BFM determined that these characteristics are not sufficient for obtaining of quality joints. In [1,2] it was noted the necessity of additional manganese and nickel alloying of the BFM of $\mathrm{Ag}-\mathrm{Cu}-\mathrm{Zn}-\mathrm{Sn}$ system for their successful application in brazing of hard-alloy tool.

Aim of the present study lies in the investigation of effect of nickel and manganese alloying of $\mathrm{Ag}-\mathrm{Cu}-\mathrm{Zn}-\mathrm{Sn}$ system alloys on structure, melting intervals, wetting of hard alloys and strength of the brazed joints. Alloy VK8 and stainless steel $12 \mathrm{Kh} 18 \mathrm{~N} 10 \mathrm{~T}$ were used as materials to be brazed.

(C) V.F. KHORUNOV, B.V. STEFANIV and S.V. MAKSYMOVA, 2014
Melting of pilot alloys of $\mathrm{Ag}-\mathrm{Cu}-\mathrm{Zn}-\mathrm{Sn}-\mathrm{Ni}-$ Mn system under laboratory conditions was carried out by induction heating using high-frequency generator of VChI4-10U4 type (frequency $440 \mathrm{kHz}$, power $10 \mathrm{~kW}$ ) with double-coil inductor. Five alloys were melted in accordance with the selected matrix of experiment planning on specified procedure [3, 4]. General losses made $0.01-0.50 \%$.

Temperature interval of alloy melting was determined with the help of differential thermal analysis on VDTA-8M unit in crucibles, manufactured from zirconium oxide. Heating and cooling was carried out in helium atmosphere at $80{ }^{\circ} \mathrm{C} / \mathrm{min}$ speed. Mass of investigated specimen made $(1.25 \pm 0.05) \mathrm{g}$. The specimens were heated twice in order to receive good fitting of sample to crucible bottom and provide accurate data on thermal effects. Therefore, thermal effects were registered according to second heating curve.

Analysis of the received data shows that nickel and manganese fillers significantly affect temperature of phase transformations and value of melting interval. Thus, only two phases are registered in $\mathrm{Ag}-\mathrm{Cu}-\mathrm{Zn}-\mathrm{Sn}-2 \mathrm{Mn}-1 \mathrm{Ni}$ alloy ( $\mathrm{Fi}$ gure 1). Solidus temperature makes $630{ }^{\circ} \mathrm{C}$, and liquidus is $694^{\circ} \mathrm{C}$. Two thermal effects are clearly registered in $\mathrm{Ag}-\mathrm{Cu}-\mathrm{Zn}-\mathrm{Sn}-6 \mathrm{Mn}-1 \mathrm{Ni}$ alloy, namely in $671-693$ and $640-671{ }^{\circ} \mathrm{C}$ intervals. $T_{S}$ makes $640{ }^{\circ} \mathrm{C}$, and $T_{L}=693{ }^{\circ} \mathrm{C}$. $\mathrm{Ag}-\mathrm{Cu}-\mathrm{Zn}-\mathrm{Sn}-$ $2 \mathrm{Mn}-4 \mathrm{Ni}$ alloy is also double phase, $T_{S}=618^{\circ} \mathrm{C}$, and $T_{L}=702{ }^{\circ} \mathrm{C}$. The second phase in $\mathrm{Ag}-\mathrm{Cu}-$ 


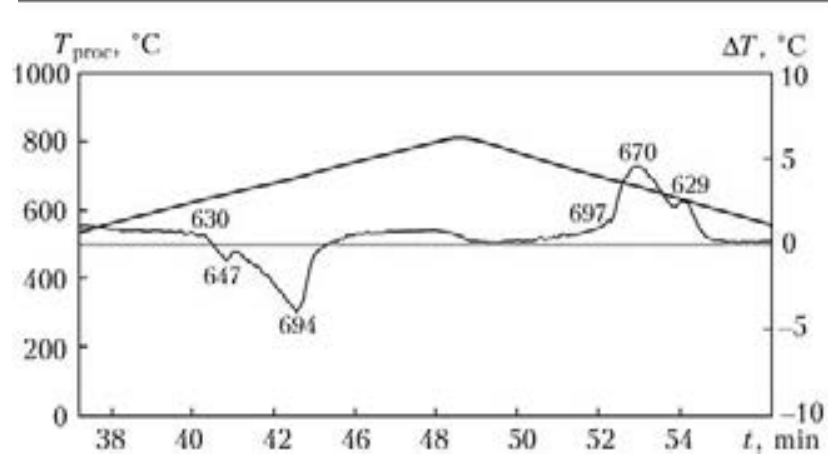

Figure 1. Results of differential thermal analysis of Ag$\mathrm{Cu}-\mathrm{Zn}-\mathrm{Sn}-2 \mathrm{Mn}-1 \mathrm{Ni}$ system alloy

$\mathrm{Zn}-\mathrm{Sn}-6 \mathrm{Mn}-4 \mathrm{Ni}$ alloy has weak thermal effect in heating, but it is clearly apparent in cooling (Figure 2). $T_{S}=640{ }^{\circ} \mathrm{C}$, and $T_{L}=720{ }^{\circ} \mathrm{C}$. $\mathrm{Ag}-$ $\mathrm{Cu}-\mathrm{Zn}-\mathrm{Sn}-4 \mathrm{Mn}-2.5 \mathrm{Ni}$ alloy is also double phase, $T_{S}=640{ }^{\circ} \mathrm{C}$ and $T_{L}=702{ }^{\circ} \mathrm{C}$. Plates from hard-alloy material VK8 of $13.5 \mathrm{~mm}$ diameter and $4.5 \mathrm{~mm}$ thickness and BFM in form of blocks $(4 \times 4 \times 4 \mathrm{~mm})$ were used as a substrate for performance of experiments on spreading.

The specimens were degreased before brazing by acetone (alcohol), the investigated BFM was placed in the middle of the specimen, and PV209 flux, reactive temperature interval of which equals $600-850{ }^{\circ} \mathrm{C}$ [5], was applied on along the whole perimeter on the specimen. Heating of the specimens was carried out using mentioned above high-frequency generator. Single-coil inductor was used for the investigations. The specimens were positioned on ceramic support having internal channel for feeding of thermocouple, measuring the temperature of specimen heating. 3-second soaking was applied after melting of the BFM and then heating was switched on. A level of solid substrate wetting by BFM was determined through evaluation of area of spreading of melted BFM (three specimens for each BFM) and contact angle, formed between the substrate and spread drop of the BFM.

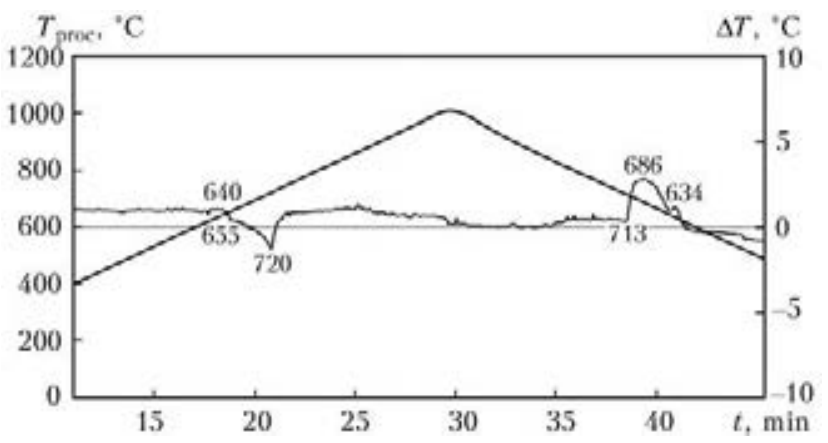

Figure 2. Results of differential thermal analysis of $\mathrm{Ag}-$ $\mathrm{Cu}-\mathrm{Zn}-\mathrm{Sn}-6 \mathrm{Mn}-4 \mathrm{Ni}$ system alloy

The contact angle was determined on microsections cut out from the specimens normal to wetting plane (Figure 3). Area of spreading of each BFM and contact wetting angle (Table 1) were calculated using AutoCard 2002 program.

Experiments on determination of strength of specimens of the brazed joint, manufactured from $12 \mathrm{Kh} 18 \mathrm{~N} 10 \mathrm{~T}$ grade stainless steel, were carried out using investigated BFM. The specimens were brazed with the help of gas heating and flux PV209. The flux was preliminary applied to the place of brazing in form of water-kneaded paste, and dried before heating. After heating to the flux melting temperature, the sample was put in the place of joining, and heating was performed up to melting of the latter and formation of the brazed joint. The brazed specimens were treated in order to remove reinforcement and break tests were carried out on MTS-20 machine.

The experiments on stainless steel were carried out according to GOST 23047-75. As can be seen from given data (Table 2), alloys of $\mathrm{Ag}-\mathrm{Cu}-\mathrm{Zn}-$ Sn system, alloyed by nickel and manganese, significantly increase shear strength of the brazed joints (from 300 to $400 \mathrm{MPa}$ ). In particular, rise of shear strength is observed in the joint, made using BFM No.5 (more than $450 \mathrm{MPa}$ ).

$\mathrm{BFM}$ of $\mathrm{Ag}-\mathrm{Cu}-\mathrm{Zn}-\mathrm{Sn}-6 \mathrm{Mn}-4 \mathrm{Ni}$, having the best indicies on wetting as well as strength char-
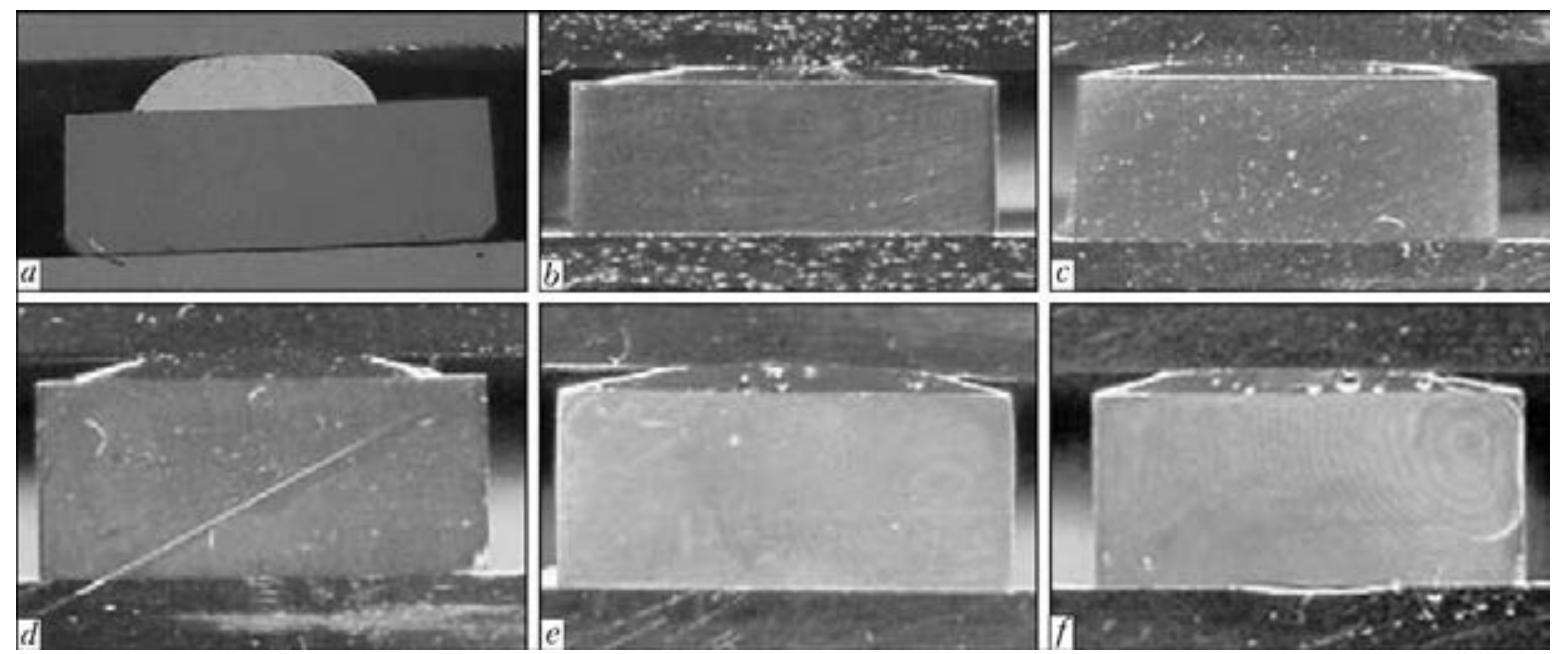

Figure 3. Cross section of specimens 1-6 (a-f) (see Table 1) after spreading test 
SCIENTIFIC AND TECHNICAL

Table 1. Melting temperature, contact wetting angle and area of spreading over hard-alloy plates of experimental alloys

\begin{tabular}{|c|c|c|c|c|c|c|}
\hline \multirow{2}{*}{ BFM number } & \multirow{2}{*}{ BFM system } & \multirow{2}{*}{$\begin{array}{l}\text { Contact wetting } \\
\text { angle } \theta, \text { deg }\end{array}$} & \multicolumn{2}{|c|}{ Temperature of melting, ${ }^{\circ} \mathrm{C}$} & \multirow{2}{*}{$\begin{array}{l}\text { Temperature of } \\
\text { BFM heating, }{ }^{\circ} \mathrm{C}\end{array}$} & \multirow{2}{*}{$\begin{array}{c}\text { Average area of } \\
\text { spreading BFM } \\
\quad S, \mathrm{~mm}^{2}\end{array}$} \\
\hline & & & $T_{S}$ & $T_{L}$ & & \\
\hline 1 & $\mathrm{Ag}-\mathrm{Cu}-\mathrm{Zn}-\mathrm{Sn}(\mathrm{BAg}-7)^{* *}$ & 50 & 618 & 651 & 750 & 51 \\
\hline 2 & $\mathrm{Ag}-\mathrm{Cu}-\mathrm{Zn}-\mathrm{Sn}-2 \mathrm{Mn}-1 \mathrm{Ni}$ & 20 & 630 & 694 & 750 & 123 \\
\hline 3 & $\mathrm{Ag}-\mathrm{Cu}-\mathrm{Zn}-\mathrm{Sn}-6 \mathrm{Mn}-1 \mathrm{Ni}$ & 17 & 640 & 693 & 750 & 136 \\
\hline 4 & $\mathrm{Ag}-\mathrm{Cu}-\mathrm{Zn}-\mathrm{Sn}-2 \mathrm{Mn}-4 \mathrm{Ni}$ & 35 & 618 & 702 & 750 & 87 \\
\hline 5 & $\mathrm{Ag}-\mathrm{Cu}-\mathrm{Zn}-\mathrm{Sn}-6 \mathrm{Mn}-4 \mathrm{Ni}$ & 10 & 640 & 720 & 760 & 144 \\
\hline 6 & $\mathrm{Ag}-\mathrm{Cu}-\mathrm{Zn}-\mathrm{Sn}-4 \mathrm{Mn}-2.5 \mathrm{Ni}$ & 12 & 640 & 702 & 750 & 143 \\
\hline
\end{tabular}

Table 2. Average strength characteristics of brazed lap joints on 12Kh18N10T steel

\begin{tabular}{||c|c|c|c|c|c|c||}
\hline \hline BFM number & BFM system & $b, \mathrm{~mm}$ & $B, \mathrm{~mm}$ & $S, \mathrm{~mm}^{2}$ & $P, \mathrm{~kg}$ & $\tau, \mathrm{MPa}$ \\
\hline 1 & $\mathrm{Ag}-\mathrm{Cu}-\mathrm{Zn}-\mathrm{Sn}(\mathrm{BAg}-7)$ & 2.35 & 20.10 & 47.23 & 1300 & 275.2 \\
\hline 2 & $\mathrm{Ag}-\mathrm{Cu}-\mathrm{Zn}-\mathrm{Sn}-2 \mathrm{Mn}-1 \mathrm{Ni}$ & 2 & 20.06 & 40.12 & 1640 & 408.7 \\
\hline 3 & $\mathrm{Ag}-\mathrm{Cu}-\mathrm{Zn}-\mathrm{Sn}-6 \mathrm{Mn}-1 \mathrm{Ni}$ & 2 & 20.06 & 40.12 & 1400 & 348.9 \\
\hline 4 & $\mathrm{Ag}-\mathrm{Cu}-\mathrm{Zn}-\mathrm{Sn}-2 \mathrm{Mn}-4 \mathrm{Ni}$ & 3 & 20.06 & 60.18 & 1860 & 309.3 \\
\hline 5 & $\mathrm{Ag}-\mathrm{Cu}-\mathrm{Zn}-\mathrm{Sn}-6 \mathrm{Mn}-4 \mathrm{Ni}$ & 2 & 20.03 & 40.06 & 1820 & 454.3 \\
\hline 6 & $\mathrm{Ag}-\mathrm{Cu}-\mathrm{Zn}-\mathrm{Sn}-4 \mathrm{Mn}-2.5 \mathrm{Ni}$ & 2 & 20.06 & 40.12 & 1658 & 413.2 \\
\hline
\end{tabular}

acteristics for stainless steel joints, was selected determination of shear strength of hard-alloy plates. $13.5 \mathrm{~mm}$ diameter, 6 and $3.5 \mathrm{~mm}$ height hard-alloy plates of VK8 type were used in determination of the brazed joint shear strength. The values of shear strength, received using special device of tensile-testing machine R-05 (V.N. Bacul Institute for Superhard Materials of the NASU), lie in 489-524 $\mathrm{MPa}$ range.

As mentioned above, the investigations were carried out using the method of experiment planning. Two-factor experiment was performed and data of two recalls were received. The results of processing of experimental data were obtained from «Statistica 6.0» program. Regression equa-

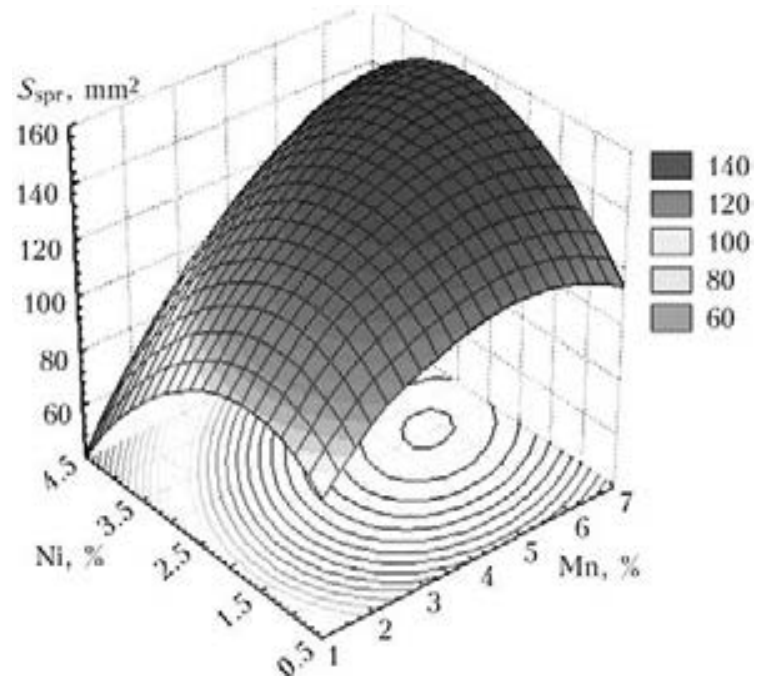

Figure 4. Dependence of BFM spreading area on manganese and nickel content tions of dependence of area of spreading and joint strength on manganese and nickel content are the following:

$$
\begin{gathered}
S_{\mathrm{spr}}=54.1014+24.5059 \mathrm{Mn}+25.061 \mathrm{Ni}- \\
-2.7492(\mathrm{Mn} \times \mathrm{Mn})+2.8052(\mathrm{Mn} \times \mathrm{Ni})- \\
-8.0526(\mathrm{Ni} \times \mathrm{Ni}) \\
\tau_{\mathrm{av}}=432.7222-12.3333 \mathrm{Mn}-15.3333 \mathrm{Ni}- \\
-2.4375(\mathrm{Mn} \times \mathrm{Mn})+17.0833(\mathrm{Mn} \times \mathrm{Ni})- \\
-10.2222(\mathrm{Ni} \times \mathrm{Ni}) .
\end{gathered}
$$

In graphic form these dependencies are shown in Figures 4 and 5. The analysis of received results allows stating that the best values of strength and area of spreading are achieved at manganese

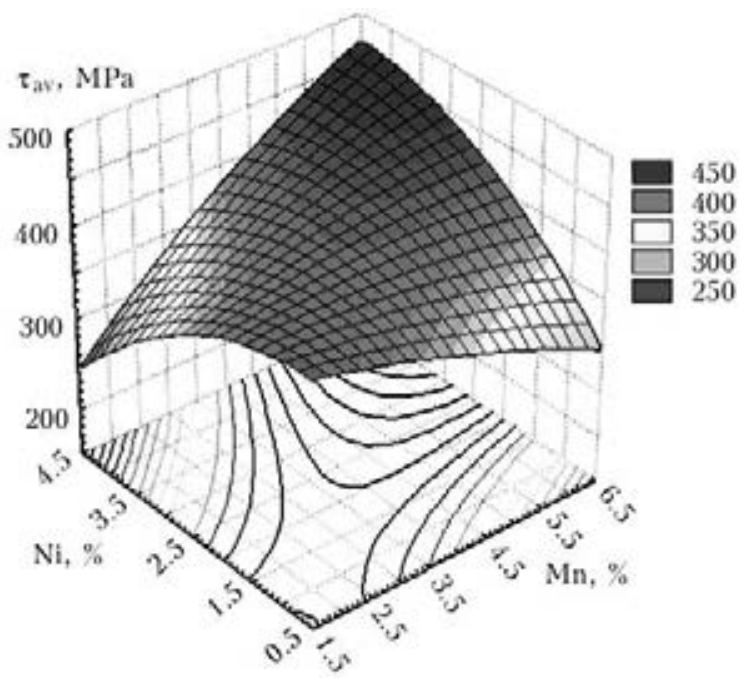

Figure 5. Dependence of BFM strength on manganese and nickel content 
Table 3. Element composition of structural constituents of $\mathrm{Ag}-$ $\mathrm{Cu}-\mathrm{Zn}-\mathrm{Sn}-2 \mathrm{Mn}-1 \mathrm{Ni}$ alloy, wt.\%

\begin{tabular}{|c|c|c|c|c|c|c|c||}
\hline $\begin{array}{c}\text { Spectrum } \\
\text { number }\end{array}$ & $\mathrm{Mn}$ & $\mathrm{Co}$ & $\mathrm{Ni}$ & $\mathrm{Cu}$ & $\mathrm{Zn}$ & $\mathrm{Ag}$ & $\mathrm{Sn}$ \\
\hline 1 & 0.35 & 0.42 & 5.76 & 61.35 & 23.66 & 8.09 & 0.37 \\
\hline 2 & 0.19 & - & 3.16 & 44.52 & 19.64 & 32.18 & 0.31 \\
\hline 3 & 0.16 & - & - & 9.41 & 12.88 & 76.69 & 0.87 \\
\hline 4 & 0.28 & - & - & 14.44 & 17.16 & 61.42 & 6.70 \\
\hline
\end{tabular}

Table 4. Element composition of structural constituents of Ag$\mathrm{Cu}-\mathrm{Zn}-\mathrm{Sn}-6 \mathrm{Mn}-4 \mathrm{Ni}$ alloy, wt.\%

\begin{tabular}{|c|c|c|c|c|c|c|c|}
\hline \hline $\begin{array}{c}\text { Spectrum } \\
\text { number }\end{array}$ & $\mathrm{Mn}$ & $\mathrm{Co}$ & $\mathrm{Ni}$ & $\mathrm{Cu}$ & $\mathrm{Zn}$ & $\mathrm{Ag}$ & $\mathrm{Sn}$ \\
\hline 1 & 8.70 & 2.25 & 26.08 & 37.32 & 21.42 & 2.74 & 1.48 \\
\hline 2 & 1.48 & - & - & 8.64 & 11.67 & 78.22 & - \\
\hline 3 & 1.76 & - & 0.36 & 15.97 & 13.52 & 65.50 & 2.89 \\
\hline
\end{tabular}

to nickel relation, approximately, 1.5:1.0 (see Tables 1 and 2).

Metallographic investigations were carried out on specimens after determination of temperature interval of melting, i.e. all alloys were cooled to room temperature at similar rate.

Structure and chemical inhomogeneity of $\mathrm{Ag}-$ $\mathrm{Cu}-\mathrm{Zn}-\mathrm{Sn}-\mathrm{Ni}-\mathrm{Mn}$ system alloys with different level of manganese and nickel alloying were investigated with the help of optic microscope MIM-8M and scanning electron microscope TescanMira3LMU. The results of investigations of alloys containing $1.5 \mathrm{Mn}: 1.0 \mathrm{Ni}$ showed that in general they can be related to the eutectic structures with larger or smaller amount of primary phase (Figures 6 and 7).

Thus, $\mathrm{Ag}-\mathrm{Cu}-\mathrm{Zn}-\mathrm{Sn}-2 \mathrm{Mn}-1 \mathrm{Ni}$ system alloy refers to the eutectic structure with small content of $\mathrm{Cu}$-based primary dendrites. This alloy has two well-defined phases with different melting temperatures, that is verified by VDTA unit results. Probably, Cu-based solid solution, containing small amount of silver and tin (see Figure 6), appears as a primary phase. Light Ag-based phase with smaller content of copper, zinc and tin from 0.87 to $6.70 \%$ (Table 3 ), is solidified around the primary dark dendrites. The $\mathrm{Ag}-\mathrm{Cu}-\mathrm{Zn}-\mathrm{Sn}-$ $6 \mathrm{Mn}-4 \mathrm{Ni}$ system alloy has the same structural constituents (see Figure 7; Table 4).

Comparison of data of the microX-ray spectrum analysis of both alloys shows significant increase of nickel, copper and tin in Cu-based solid solution (see Tables 3 and 4) in the second alloy and significant reduction of content of tin in the eutectic. The latter can explain the rise of brazed joint strength.

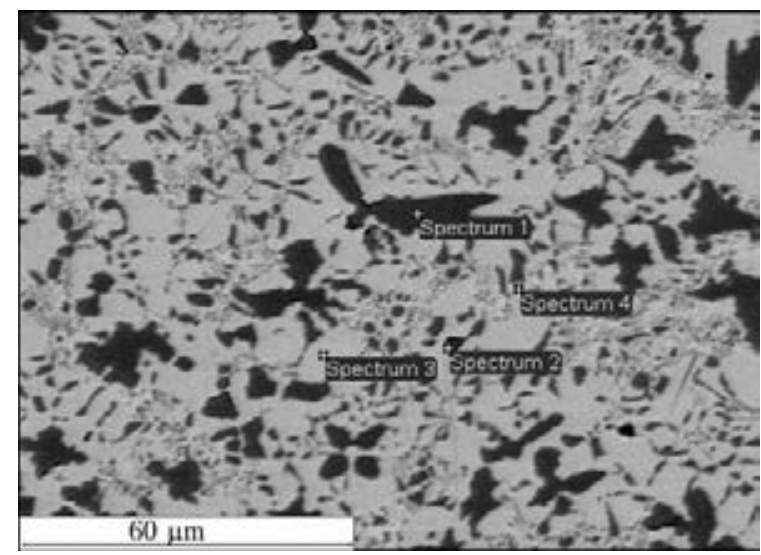

Figure 6. Microstructure $(\times 400)$ of $\mathrm{Ag}-\mathrm{Cu}^{-} \mathrm{Zn}-\mathrm{Sn}-2 \mathrm{Mn}-$ $1 \mathrm{Ni}$ system alloy

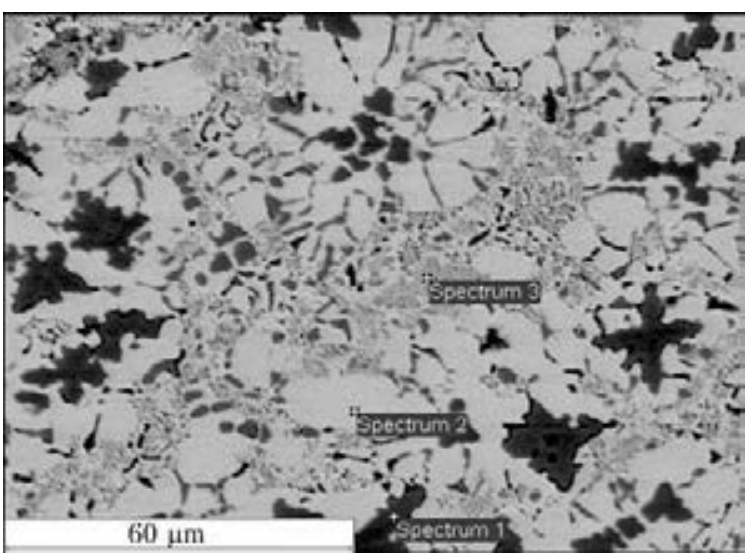

Figure 7. Microstructure $(\times 400)$ of $\mathrm{Ag}-\mathrm{Cu}-\mathrm{Zn}-\mathrm{Sn}-6 \mathrm{Mn}-$ 4Ni system alloy

\section{Conclusions}

1. Nickel and manganese alloying of $\mathrm{Ag}-\mathrm{Cu}-\mathrm{Zn}-$ Sn system alloys allowed receiving the brazing filler metals, which provide good wetting of hardalloy materials and stainless steel, and higher strength properties of brazed joints from stainless steel (up to $450 \mathrm{MPa}$ ) and hard alloys (up to $500 \mathrm{MPa})$.

2. Application of the brazing filler metals of investigated system requires no change of heating methods, flux composition, use of any special techniques and can be easily mastered in industrial conditions.

1. Roberts, P.M. (1978) Recent developments in cadmium-free silver brazing alloys. Welding J., 10, 23-30.

2. Timmins, P.F. (1994) The development of Ag-based brazing alloys. Ibid., 10, 31-33.

3. Khorunov, V.F., Maksymova, S.V., Stefaniv, B.V. (2010) Effect of tin additions on structure and technological properties of $\mathrm{BFM}$ of the $\mathrm{Ag}-\mathrm{Cu}-\mathrm{Zn}$ system. The Paton Welding J., 7, 16-21.

4. Khorunov, V.F., Maksymova, S.V., Stefaniv, B.V. (2012) Effect of palladium on structure and technological properties of $\mathrm{Ag}-\mathrm{Cu}-\mathrm{Zn}-\mathrm{Ni}-\mathrm{Mn}$ system brazing filler alloys. Ibid., 9, 20-25.

5. Klochko, N.A. (1981) Principles of technology of brazing and heat treatment of hard-alloy tool. Moscow: Metallurgiya. 


\title{
PREDICTION OF THERMODYNAMICAL PROPERTIES OF MELTS OF THE $\mathrm{CaO}-\mathrm{Al}_{2} \mathrm{O}_{3}$ SYSTEM
}

\author{
I.A. GONCHAROV ${ }^{1}$, V.I. GALINICH ${ }^{1}$, D.D. MISHCHENKO ${ }^{1}$ and V.S. SUDAVTSOVA ${ }^{2}$ \\ ${ }^{1}$ E.O. Paton Electric Welding Institute, NASU \\ 11 Bozhenko Str., 03680, Kiev, Ukraine. E-mail: office@paton.kiev.ua \\ ${ }^{2}$ I.M. Frantsevich Institute of Problems of Materials Science, NASU \\ 3 Krzhizhanovsky Str., 03680, Kiev, Ukraine. E-mail: goncharov@.paton.kiev.ua
}

\begin{abstract}
The expert evaluation of literature data was carried out and methods of calculation of thermodynamic properties of melts of the $\mathrm{CaO}-\mathrm{Al}_{2} \mathrm{O}_{3}$ system in the whole concentration range were offered. Thermodynamic activities of aluminium oxide at $0.74<x_{\mathrm{Al}_{2} \mathrm{O}_{3}}<1$ were calculated from the coordinates of the liquidus line of constitution diagram of the system $\mathrm{CaO}-\mathrm{Al}_{2} \mathrm{O}_{3}$, determined by different authors. Using calculation and experimental data on thermodynamic activity of $\mathrm{Al}_{2} \mathrm{O}_{3}$, the evaluation of thermodynamic activities of calcium oxide was carried out by integration of Gibbs-Duhem equation. It was established that they reveal great negative deviations from thermodynamic properties of perfect solutions. Basing on the established values of thermodynamic activity of calcium oxide, the liquidus line of constitution diagram of the system $\mathrm{CaO}-\mathrm{Al}_{2} \mathrm{O}_{3}$ was plotted on the side of calcium oxide. The obtained values of activity of components and liquidus temperature of the system $\mathrm{CaO}-\mathrm{Al}_{2} \mathrm{O}_{3}$ allow evaluating the thermodynamic properties of corresponding three- and four-component systems, predicting processes of interaction in the metal-slag-gaz system and creating new consumables for welding and electroslag remelting. 28 Ref., 2 Tables, 4 Figures.
\end{abstract}

$\boldsymbol{K} \boldsymbol{e} \boldsymbol{y} \boldsymbol{w} \boldsymbol{o} \boldsymbol{r} \boldsymbol{s}:$ welding, electroslag remelting, slag melts, thermodynamic activity of components, constitution diagram

Slag melts of the system $\mathrm{CaO}-\mathrm{SiO}_{2}-\mathrm{Al}_{2} \mathrm{O}_{3}-\mathrm{CaF}_{2}$ find wide application in metallurgical and welding processes. Basing on this slag system the fluxes for welding of high-alloyed steels and electroslag remelting of structural steels were created. The system $\mathrm{CaO}-\mathrm{SiO}_{2}-\mathrm{Al}_{2} \mathrm{O}_{3}-\mathrm{CaF}_{2}$ is the base of slag-forming mixtures for machines of continuous casting of billets. The scientifically grounded modification of known fluxes, development of new grades, methods of their melting and application are not possible without knowledge of physical and chemical properties, the basic of which are thermodynamic ones.

It is known that oxide-fluoride melts do not behave like perfect solutions. Thermodynamic activities of their components have deviations from the Raoult law. Therefore, the capability of components of melt to enter the chemical reactions is determined as a mole fraction of $x$ components in the melt, as well as their thermodynamic activity $a$ (hereinafter activity). To predict the metallurgical properties of slag melts the data on activity of their components are necessary.

Experimental investigations of physical and chemical properties of multi-component oxidefluoride melts are complicated due to their refractoriness and high aggressiveness. Therefore, in the last years the methods of their calculation and modeling are developed and constantly modified.

One of the prospective directions is calculations of thermodynamic properties of melts of three- and four-component systems with application of similar data for two-component ones (for the latter they are experimentally determined by different methods). In this connection, it is necessary to determine valid data from all the totality of experimental data and use them for calculation.

The aim of this work is review of existing experimental data, their expert evaluation and establishing of valid values of activities of components of oxide melts of the binary system $\mathrm{CaO}-$ $\mathrm{Al}_{2} \mathrm{O}_{3}$ in the entire concentration range.

In the nearest time the similar investigations of the system $\mathrm{CaO}-\mathrm{SiO}_{2}, \mathrm{Al}_{2} \mathrm{O}_{3}-\mathrm{SiO}_{2}, \mathrm{Al}_{2} \mathrm{O}_{3}-$ $\mathrm{CaF}_{2}, \mathrm{SiO}_{2}-\mathrm{CaF}_{2}$ and $\mathrm{CaO}-\mathrm{CaF}_{2}$ will be prepared. The groups of authors have already performed thermodynamic modeling for most of them. In spite of the fact that the known experimental data were taken as the basis, the obtained results are distinctly differed. Thus, valid thermodynamic properties of mentioned binary melts were tried to be determined using the own methods $[1,2]$.

The constitution diagram of the system $\mathrm{CaO}-$ $\mathrm{Al}_{2} \mathrm{O}_{3}$ was at the first time plotted already in 


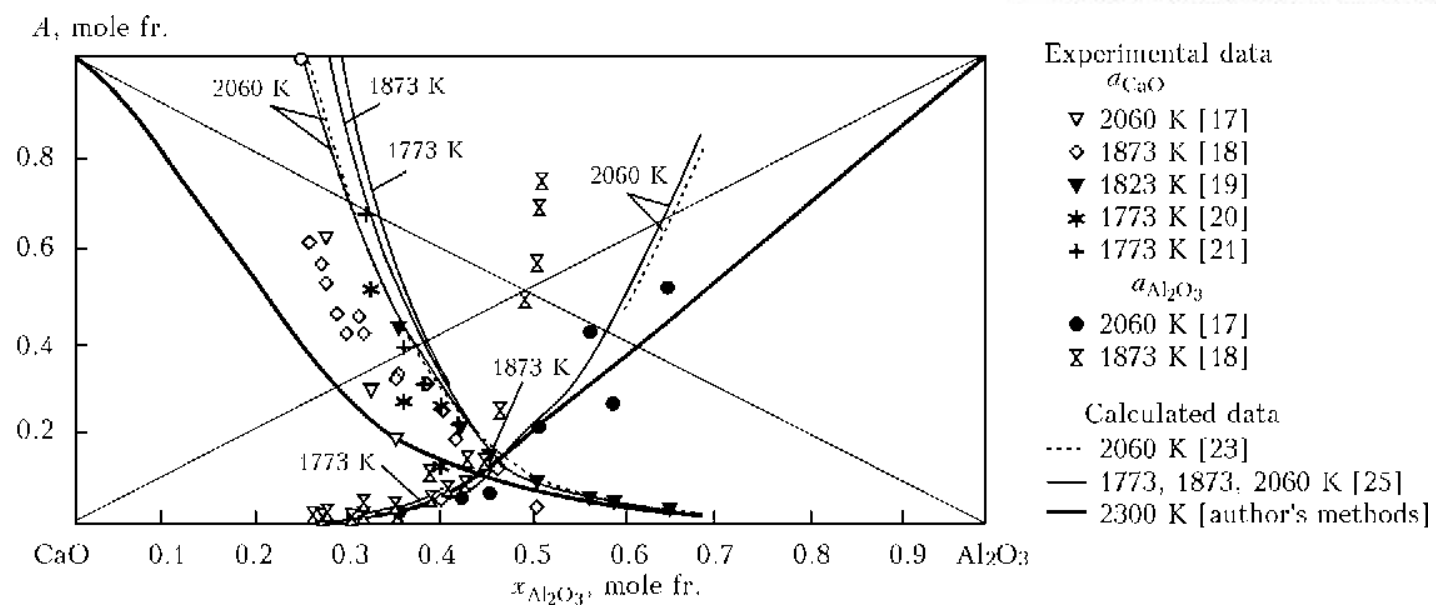

Figure 1. Activities of components of the $\mathrm{CaO}-\mathrm{Al}_{2} \mathrm{O}_{3}$ system melts

1909 [3]. In works [4-9] the description of the further investigations of phase equilibriums of the system $\mathrm{CaO}-\mathrm{Al}_{2} \mathrm{O}_{3}$ is given. However until the recent time the coordinates of liquidus line $T_{\mathrm{L}}$ of alloys of the system $\mathrm{CaO}-\mathrm{Al}_{2} \mathrm{O}_{3}$ at $0.75<$ $<x_{\mathrm{CaO}}<1$ are not determined. It is predetermined by very high temperatures of melting of these objects. Only thermochemical properties of intermediate phases of this system were experimentally investigated [10-16].

The activities of components of liquid melts of the system $\mathrm{CaO}-\mathrm{Al}_{2} \mathrm{O}_{3}$ were formerly investigated by different methods in the temperature range of 1773-2060 K (Figure 1). In the most works [17-21] the activities of calcium oxide $a_{\mathrm{CaO}}$ were determined, and activities of aluminium oxide $a_{\mathrm{Al}_{2} \mathrm{O}_{3}}-$ only in [17, 18, 22]. It should be noted that activities of components obtained using method of electromotive forces [22] reveal the highest positive deviations from the perfect solutions. It is probably predetermined by the fact that membranes in the concentration element have no the pure ion conductance. Therefore, authors did not take these data into account. As is seen from Figure 1, the activities of components are determined in the limited range of concentrations, which is predetermined by the refractoriness of $\mathrm{Al}_{2} \mathrm{O}_{3}$ and, especially, $\mathrm{CaO}$.

For the correct description of thermodynamic properties of liquid melts of the system $\mathrm{CaO}^{-}$ $\mathrm{Al}_{2} \mathrm{O}_{3}, T_{\mathrm{L}}$ of the constitution diagram in the range

Table 1. Calculation of $\mathrm{Al}_{2} \mathrm{O}_{3}$ activities according to coordinates $T_{\mathrm{L}}$ of the $\mathrm{CaO}-\mathrm{Al}_{2} \mathrm{O}_{3}$ system constitution diagram

\begin{tabular}{||c|c|c|c||}
\hline \hline$T_{\mathrm{L}}, \mathrm{K}$ & $\omega_{\mathrm{Al}_{2} \mathrm{O}_{3}}$, wt.\% & $x_{\mathrm{Al}_{2} \mathrm{O}_{3}}$, mole fr. & $a_{\mathrm{Al}_{2} \mathrm{O}_{3}}$, mole fr. \\
\hline 2140 & 84 & 0.74 & 0.60 \\
\hline 2210 & 92 & 0.86 & 0.76 \\
\hline 2280 & 95 & 0.91 & 0.91 \\
\hline
\end{tabular}

of concentrations $35-100$ wt. $\% \mathrm{Al}_{2} \mathrm{O}_{3}$ were used. According to the developed methods [1,2] the $a_{\mathrm{Al}_{2} \mathrm{O}_{3}}$ at $84-100$ wt.\% $\mathrm{Al}_{2} \mathrm{O}_{3}$ were calculated. The results of calculation are given in Table 1 . The liquidus temperature line changed in this system from 2140 to $2313 \mathrm{~K}$.

Combining these calculation results with $a_{\mathrm{Al}_{2} \mathrm{O}_{3}}$ values in melts of the system $\mathrm{CaO}-\mathrm{Al}_{2} \mathrm{O}_{3}$ [17], determined by a very precise method of Knudsen applying mass-spectrometer at $2060 \mathrm{~K}$, $a_{\mathrm{CaO}}$ was evaluated using intergration of GibbsDuhem equation. The obtained results are given in Figure 2.

It is seen that activities reveal negative deviations from the Raoult law and satisfactory correlate with the data on $a_{\mathrm{Al}_{2} \mathrm{O}_{3}}$ in the melts of the system $\mathrm{CaO}-\mathrm{Al}_{2} \mathrm{O}_{3}$ [17]. It is more distinctly shown in Figure 1.

Liquidus curve of melts of the system $\mathrm{CaO}-$ $\mathrm{Al}_{2} \mathrm{O}_{3}$ on the side of $\mathrm{CaO}$ (up to 35 wt. $\% \mathrm{Al}_{2} \mathrm{O}_{3}$ )

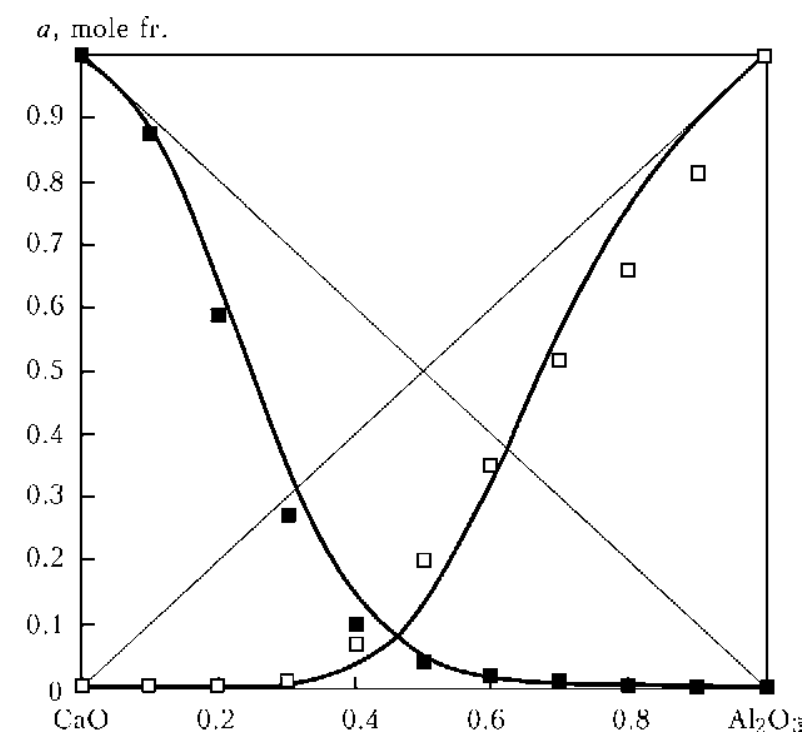

Figure 2. Activities of components of the $\mathrm{CaO}-\mathrm{Al}_{2} \mathrm{O}_{3}$ system melts at $2100-2300 \mathrm{~K}$ (spots - calculation data on the basis of $T_{\mathrm{L}}$, lines - optimized) 
$T, \mathrm{~K}$

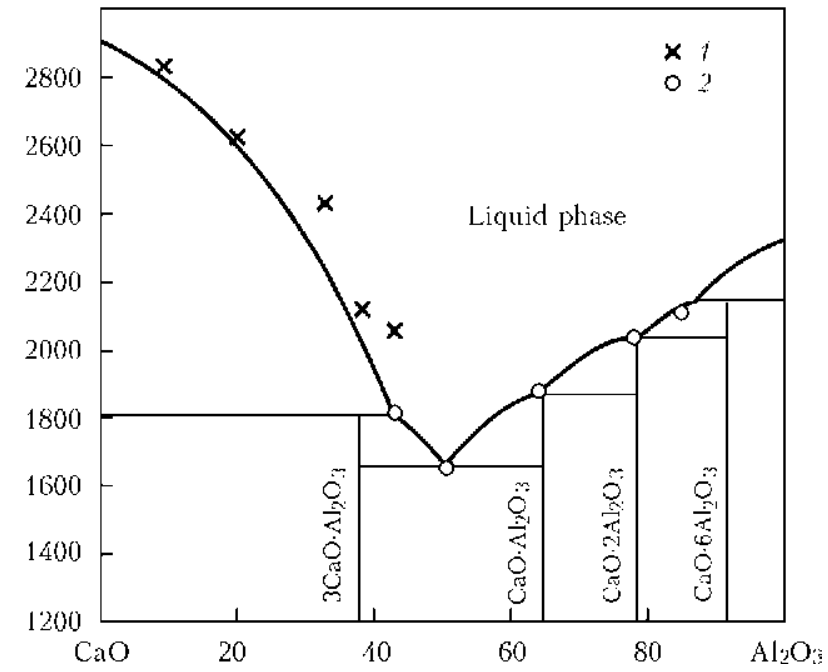

Figure 3. Constitution diagram of the system $\mathrm{CaO}-\mathrm{Al}_{2} \mathrm{O}_{3}$ : 1 - calculated data; 2 - data of work [4]

is not determined and was calculated by the authors from $a_{\mathrm{CaO}}$ in the following way:

$$
\begin{gathered}
\mu_{i}^{l}=\mu_{i}^{s_{0}}, \quad \mu_{i}^{l_{0}}+R T_{\mathrm{L}} \ln a_{i}=\mu_{i}^{s_{0}}, \\
T_{\mathrm{L}}=\frac{\mu_{i}^{s_{0}}-\mu_{i}^{l_{0}}}{R \ln a_{i}}=\frac{\Delta H_{\text {melt } i}}{R \ln a_{i}-\Delta S_{\text {melt } i}},
\end{gathered}
$$

where $\mu_{i}^{l}, \mu_{i}^{s_{0}}$ is the chemical potential of $i$-th component in liquid and solid phases, respectively; $T_{\mathrm{L}}$ is the liquidus temperature, at which solid component-solution equilibrium is considered; $a_{i}$ is the activity of $i$-th component; $\Delta H_{\text {melt } i}, \Delta S_{\text {melt } i}$ is the enthalpy and entropy of melting of $i$-th component, respectively.

The obtained results are given in Table 2 and Figure 3.

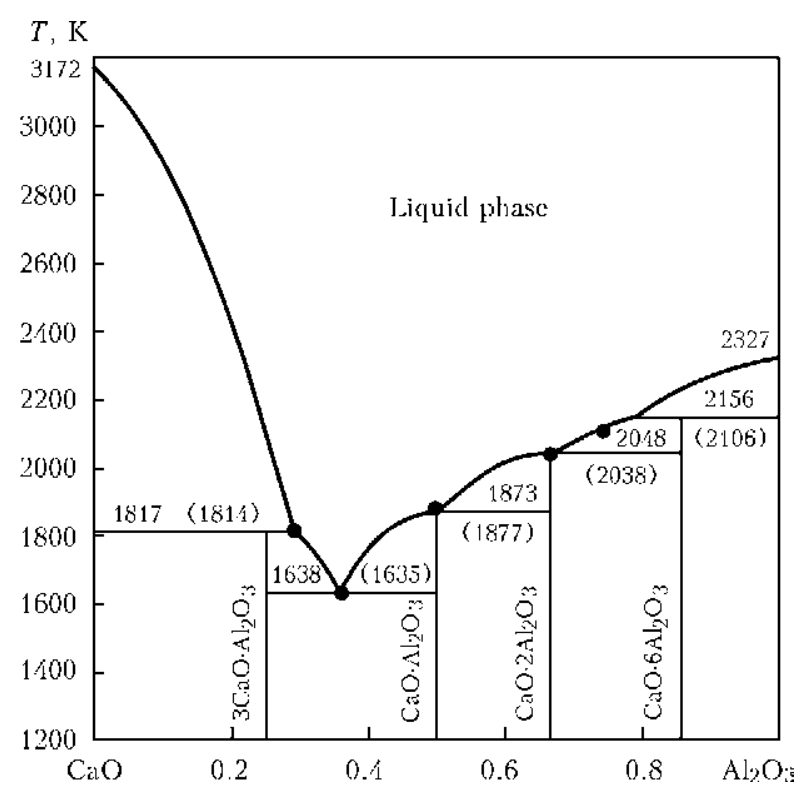

Figure 4. Constitution diagram of the system $\mathrm{CaO}-\mathrm{Al}_{2} \mathrm{O}_{3}$ modeled in work [23]
Table 2. Calculation of coordinates $T_{\mathrm{L}}$ of constitution diagram of the $\mathrm{CaO}-\mathrm{Al}_{2} \mathrm{O}_{3}$ system melts by $\mathrm{CaO}$ activities

\begin{tabular}{|c|c|c|c||}
\hline \hline$\omega_{\mathrm{Al}_{2} \mathrm{O}_{3}}$, wt.\% & $x_{\mathrm{Al}_{2} \mathrm{O}_{3}}$, mole fr. & $a_{\mathrm{Al}_{2} \mathrm{O}_{3}}$, mole fr. & $T_{\mathrm{L}}, \mathrm{K}$ \\
\hline 10 & 0.05 & 0.95 & 2838 \\
\hline 20 & 0.12 & 0.80 & 2630 \\
\hline 32 & 0.205 & 0.65 & 2424 \\
\hline 38 & 0.25 & 0.45 & 2123 \\
\hline 43 & 0.28 & 0.40 & 2040 \\
\hline
\end{tabular}

Comparison of these data with experimental results [4] showed (see Figure 3) that they are well correlated with each other.

The $\mathrm{Al}_{2} \mathrm{O}_{3}$ activities according to the results of these works were calculated using the method developed by the authors [1,2].

In the area of compositions enriched with $\mathrm{Al}_{2} \mathrm{O}_{3}$, the $T_{\mathrm{L}}$ was determined in [4, 7-9]. In the area of compositions of melts of the system $\mathrm{CaO}-$ $\mathrm{Al}_{2} \mathrm{O}_{3}$ at $0.63<x_{\mathrm{Al}_{2} \mathrm{O}_{3}}<1$, the liquidus temperature varies [4-9]. According to these data the $a_{\mathrm{Al}_{2} \mathrm{O}_{3}}$ calculation was carried out. The obtained results were compared with the data of [17], which have the best correlation with those calculated from $T_{\mathrm{L}}$ [4]. In work [11] the preference of $T_{\mathrm{L}}$ was also given established in [4].

The expert evaluation of thermodynamic properties of melts and phase equilibriums of the system $\mathrm{CaO}-\mathrm{Al}_{2} \mathrm{O}_{3}$ was carried out the most fully in [23-25]. The activities of components of alloys of the system $\mathrm{CaO}-\mathrm{Al}_{2} \mathrm{O}_{3}$ are calculated in the limited range of the compositions $0.25<x_{\mathrm{Al}_{2} \mathrm{O}_{3}}<$ $<0.7$. For $a_{\mathrm{Al}_{2} \mathrm{O}_{3}}$, the results of all these works coincide both with each other as well with experimental data [17]. As for $a_{\mathrm{CaO}}$, then they differ a little bit between themselves. This can be explained by the fact that the temperature of melting of calcium oxide in [23-25] was taken as equal to $3172 \mathrm{~K}$ (Figure 4) but not as $2900 \mathrm{~K}$, as is accepted in all the known handbooks, for example [26-28]. Consequently, the calculated in [23-25] liquidus curve of mixtures, enriched by $\mathrm{CaO}$, is located higher than that determined by us.

The modeling of activities of components of melts of the system $\mathrm{CaO}-\mathrm{Al}_{2} \mathrm{O}_{3}$ carried out in the whole concentration range, as well as liquidus temperature, will allow further evaluating of thermodynamic properties of corresponding three- or four-component systems, developing new consumables for welding and related processes with predicted metallurgical characteristics. 


\section{Conclusions}

1. Modeling of thermodynamic properties of the system $\mathrm{CaO}-\mathrm{Al}_{2} \mathrm{O}_{3}$ in the whole concentration range was carried out. Among the coordinates of liquidus line of the constitution diagram $\mathrm{CaO}-$ $\mathrm{Al}_{2} \mathrm{O}_{3}$, determined by different authors, $a_{\mathrm{Al}_{2} \mathrm{O}_{3}}$ at $0.74<x_{\mathrm{Al}_{2} \mathrm{O}_{3}}<1$ were calculated. It was established that only according to the data of constitution diagram of [4], the $\mathrm{Al}_{2} \mathrm{O}_{3}$ activities correlate with the most valid experimental results.

2 . From the calculated and valid experimental data on $a_{\mathrm{Al}_{2} \mathrm{O}_{3}}$, the $a_{\mathrm{CaO}}$ were evaluated by integration of Gibbs-Duhem equation. It was established that they reveal noticeable negative deviations from the perfect solutions.

3. From the established values of $a_{\mathrm{CaO}}$ the liquidus line on the side of calcium oxide was plotted. It is shown that in the range of experimental errors it correlates with the data of [4].

4. The obtained data on activity of components and liquidus temperature of melts of the system $\mathrm{CaO}-\mathrm{Al}_{2} \mathrm{O}_{3}$ allow evaluating the thermodynamic properties of corresponding three- and four-component systems, developing new consumables for welding and electroslag remelting with predicted metallurgical characteristics.

1. Goncharov, I.A., Galinich, V.I., Mishchenko, D.D. et al. (2011) Prediction of thermodynamic properties of melts of $\mathrm{MgO}-\mathrm{Al}_{2} \mathrm{O}_{3}-\mathrm{SiO}_{2}-\mathrm{CaF}_{2}$ system. The $\mathrm{Pa}$ ton Welding J., 10, 2-4.

2. Sudavtsova, V.S., Makara, V.A., Kudin, V.G. (2005) Thermodynamics of metallurgical and welding melts. Pt 3: Alloys based on nickel and tin, methods of modeling and prediction of thermodynamic properties. Kiev: Logos.

3. Shepherd, E.S., Rankin, G.A., Wright, F.E. (1909) The binary systems of alumina with silica, lime and magnesia. Amer. J. Sci., 28, 293-333.

4. Nurse, R.W., Welch, J.H., Majumdar, A.J. (1965) The $\mathrm{CaO}-\mathrm{Al}_{2} \mathrm{O}_{3}$ system in a moisture-free atmosphere. Transact. of British Ceramic Soc., 64, 409-418.

5. Nurse, R.W., Welch, J.H., Majumdar, A.J. (1965) The $12 \mathrm{CaO} \cdot 7 \mathrm{Al}_{2} \mathrm{O}_{3}$ phase in the $\mathrm{CaO}-\mathrm{Al}_{2} \mathrm{O}_{3}$ system. Ibid., 64, 323-382.

6. Filonenko, N.E., Lavrov, L.V. (1949) Hexaaluminate of calcium in $\mathrm{CaO}-\mathrm{Al}_{2} \mathrm{O}_{3}$ systems. Doklady $A N$ SSSR, 66, 673-676.

7. Filonenko, N.E., Lavrov, L.V. (1950) Conditions of equilibrium in $\mathrm{Al}_{2} \mathrm{O}_{3}$ angle of ternary system $\mathrm{CaO}-$ $\mathrm{Al}_{2} \mathrm{O}_{3}-\mathrm{SiO}_{2}$. Zhurnal Prikl. Khimii, 23, 1040-1046.

8. Wisnyi, L.G. (1955) The high alumina phases in the system lime-alumina: Syn. of $\mathrm{Ph}$. D. Thesis. Rutgertrs Univ. New Brunswick.

9. Roling, M., Pham, H.T. (1965) Phase diagrams of mixtures not reacting with molybdenum. Rev. Int. Hautes Temp. Refract., 2, 175-185.
10. King, E.G. (1955) Heat capacities at low temperatures and enthropies at $298.16 \mathrm{~K}$ of crystalline calcium and magnesium aluminates. J. Phys. Chem., 59, 218-219.

11. Bonnickson, K.R. (1955) High temperature heat contents of aluminates of calcium and magnesium. Ibid., 59, 220-221.

12. Gronov, E., Schwiette, H.E. (1933) The specific heats of $\mathrm{CaO}-\mathrm{Al}_{2} \mathrm{O}_{3} \cdot 3 \mathrm{CaO} \cdot \mathrm{Al}_{2} \mathrm{O}_{3}, \quad 2 \mathrm{CaO} \cdot \mathrm{SiO}_{2}$, $3 \mathrm{CaO} \cdot \mathrm{SiO}_{2}$ and $2 \mathrm{CaO} \cdot \mathrm{Al}_{2} \mathrm{O}_{3} \cdot \mathrm{SiO}_{2}$ from 20 to $1500{ }^{\circ}$ C. Z. Anorg. Allg. Chemil, 216, 185-195.

13. Coughlin, J.P. (1956) Heats of formation of crystalline $\mathrm{CaO} \cdot \mathrm{Al}_{2} \mathrm{O}_{3}, 12 \mathrm{CaO} \cdot 7 \mathrm{Al}_{2} \mathrm{O}_{3}$ and $3 \mathrm{CaO} \cdot \mathrm{Al}_{2} \mathrm{O}_{3} . J$. Chem. Soc., 78, 5479-5482.

14. Koehier, M.F., Barany, R., Kelley, K.K. (1961) Heats and free energies of formation of calcium, magnesium, sodium and lithium. U.S. Bureau of Mines Rep. of Invest., 5711. New York.

15. Geir, C.A., Kleppa, O.J., Mysen, B.O. et al. (1988) Enthalpies of formation of $\mathrm{CaAl}_{3} \mathrm{O}_{7}$ and $\mathrm{CaAl}_{12} \mathrm{O}_{19}$ (Hibonite) by high temperature, alkali borate solution calorimetry. Geochim. et Cosmochim. Acta, 52, 1729-1736.

16. Navrotsky, A., Peraudcau, G., McMillan, P.J. et al. (1982) A thermodynamical study of glasses and crystals along the joints of silica-calcium aluminate and silica-sodium aluminate. Ibid., 46, 2039-2047.

17. Allibert, M., Chatillon, C., Jacob, K.T. et al. (1981) Mass-spectrometric and electrochemical studies of thermodynamic properties of liquid and solid phases in the system $\mathrm{CaO}-\mathrm{Al}_{2} \mathrm{O}_{3}$. J. Amer. Ceramic Soc., 64(5), 307-314.

18. Zou, Y., Zou, J., Xu, Y. et al. (1982) Some aspects of the thermodynamics of melts. Acta Metall. Sinica, 18, 133-140.

19. Cameron, J., Gibbens, T.B., Taylor, J. (1966) Calcium sulphide solubilities and lime-alumina-silica system. J. Iron and Steel Inst., 204, 1223-1228.

20. Sharma, R.A., Richardson, F.D. (1961) Activities in lime-alumina melts. Ibid., 198, 386-390.

21. Edmunds, D.M., Taylor, J. (1972) Reaction $\mathrm{CaO}+$ $3 \mathrm{C}=\mathrm{CaC}_{2}+\mathrm{CO}$ and activity of lime in $\mathrm{CaO}^{-}$ $\mathrm{Al}_{2} \mathrm{O}_{3}-\mathrm{CaF}_{2}$ system. Ibid., 210, 280-283.

22. Ohtani, M., Sanbongi, K. (1952) Activity of $\mathrm{CaO}$ in the slag of $\mathrm{CaO}-\mathrm{SiO}_{2}-\mathrm{Al}_{2} \mathrm{O}_{3}$ system. Sci. Rep. Tohoku Univ., Series A, 59(4), 139-143.

23. Halstedt, B. (1993) Assessment of the $\mathrm{CaO}-\mathrm{Al}_{2} \mathrm{O}_{3}$. J. Amer. Ceramic. Soc., 73(1), 15-23.

24. Eriksson, G., Pelton, A.D. (1993) Critical evaluation and optimization of the thermodynamic properties and phase diagrams of the $\mathrm{CaO}-\mathrm{Al}_{2} \mathrm{O}_{3}, \mathrm{Al}_{2} \mathrm{O}_{3}-\mathrm{SiO}_{2}$, and $\mathrm{CaO}-\mathrm{Al}_{2} \mathrm{O}_{3}-\mathrm{SiO}_{2}$ systems. Metall. Transact. B, 24, 807-816.

25. Mao, H., Selleby, M., Sundman, B. (2004) Re-evaluation of the liquid phases in the $\mathrm{CaO}-\mathrm{Al}_{2} \mathrm{O}_{3}$ and $\mathrm{MgO}-\mathrm{Al}_{2} \mathrm{O}_{3}$ systems. Computer Coupling of Phase Diagrams and Thermochemistry, 28, 307-310.

26. (2009) Handbook of chemistry and physics. $89 \mathrm{Ed}$. (Internet version 2009). Boca Ration: CRC Press Taylor and Francis.

27. (1978) Physical-chemical properties of oxides: Refer. Book. Ed. by G.V. Samsonov. Moscow: Metallurgiya.

28. Rabinovich, V.A., Khavin, Z.Ya. (1979) Summary chemical reference book. Leningrad: Khimiya.

Received 17.01.2014 


\title{
HYBRID LASER-GMA GIRTH WELDING TECHNOLOGIES FOR TRANSMISSION PIPELINES
}

\author{
S. KEITEL and J. NEUBERT \\ Schweißtechnische Lehr- und Versuchsanstalt Halle GmbH \\ 33a Koethener Str., 06118, Halle (S.), Germany. E-mail: keitel@slv-halle.de
}

\begin{abstract}
The aim of investigation of hybrid laser-arc welding lies in accumulation of knowledges about this process applicable to producing of pipe joints. Number of aspects are considered, such as tolerances, effect of environment, mobility of equipment and procedure in irregularities of position. The main attention is paid to investigation of effect of laser welding with large penetration depth in making of high-quality joint in root face of 6-10 mm. Performed is a comparison of different positions of laser beam and arc, which can be used in hybrid welding with different types of preparation for welding. Procedure of production of pipe joints lies in downhill welding of two vertical welds, that is standard practice for pipeline construction and significantly reduces degree of freedom in positioning of laser beam and arc, necessary for obtaining technological optimum parameters during joint formation. Weld bead is elongated by means of continuous movement of torch, that allows made the first pass using hybrid welding and cover pass by arc for one welding cycle in order to obtain closed seam profile in joints of up to $12 \mathrm{~mm}$ thickness. Besides, the latter process provides positive effect on mechanical properties of the weld metal. 3 Ref., 4 Tables, 8 Figures.
\end{abstract}

Keywords: hybrid laser-arc welding, pipe joint, girth welds, equipment, welding mode parameters, experiment setup

For many years well tested and proven arc processes have been applied for welding of large diameter pipes of oil-and-gas pipelines. Depending on the length of pipeline to be produced, wall thickness and materials of individual pipes, versatile variations of these processes are used with a scope extending from manual stick electrode arc welding up to orbital MAG process. In this case, movement is not performed manually by the welder but is fully mechanized using motordriven systems and clamping rings across the entire circumference of the pipe. If permitted by length of the pipeline and profile of the ground,

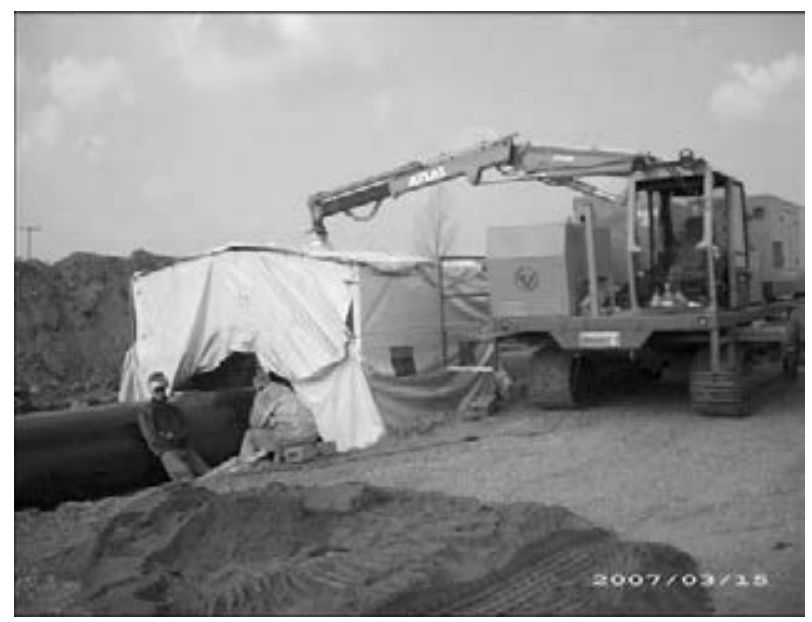

Figure 1. Building site in pipeline construction (C) S. KEITEL and J. NEUBERT, 2014 a number of these orbital units are used at the same time with every single station having been designed for one- or two-pass welding and then being displaced to the next pipe joint to produce the same weld there. Such production aggregates often rely on several welding heads per unit thus representing a high state-of-the art [1], both in relation to equipment and welding. This, however, is connected with a high expenditure on personnel and plant engineering (Figure 1).

A further increase of the performance in this area bears some problems since the arc processes applied have obtained their physical limits concerning deposition efficiency and welding speed. Here, no essential increases can be achieved by optimizing the arc welding technology.

The development of welding processes of increased performance must be carried out under the following aspects:

- reduction of the number of passes at constant and improved weld quality;

- reduction of the number of welding stations and, thus, the expenditure on equipment and personnel.

Welding processes based on laser beam, on the one hand, offer the technology and, on the other hand, the equipment needed to fulfil this demand.

Hybrid laser-GMA girth welding under conditions similar to those at construction sites. Objectives and technological approach. The objective of examinations technology and equipment described was the transfer of state of knowledge of hybrid laser-GMA welding for the pro- 
duction of pipe joints incorporating all necessary aspects such as tolerances, environmental influences, mobility of the entire equipment and welding out-of-position.

The focus of examinations was laid on the use of the laser typical deep welding effect for the production of a high quality free root pass at root faces of $6-10 \mathrm{~mm}$. To this end, the different arrangements of laser beam and arc possible for hybrid welding of butt joints were compared to the different types of joint preparation. The approach for the production of pipe joints was welding of two vertical-down seams being common practice in pipeline construction and considerably reducing the types of freedom in the arrangement of laser beam and arc required for the technological optima of the weld formation.

For the generation of a closed seam profile the welding head was extended by a further arc torch, thus enabling to weld the first pass using hybrid welding and the cover pass using GMA welding during one welding run. The objective was to produce a closed seam profile on a plate $12 \mathrm{~mm}$ thick in one rotation. Further, this trailing process is a good opportunity to have a positive influence on the mechanical-technological properties of the weld metal.

Equipment. In order to verify the principal feasibility of the laser-GMA process during girth welding the proven techniques were used. The equipment for examinations was the Gullco commercially available system for pipe welding.

This system was equipped with a tractor on a ring guide for girth welding, as well as with a contact seam tracking and scanning system based on two control axes for the transverse and height positioning of the components to the groove. The arrangement of the contact sensor forwarding the welding process was executed in direction of movement. Equipped with various stiffening elements the adaptation of the welding head to the control axles for height control was executed. For transferring the possible serial types of arrangement of laser beam and welding arc are shown in Table 1, the head for hybrid welding was equipped with additional degrees of freedom.

As shown in this Table, either the laser or the arc was considered at neutral position each, for reasons of simplification. No intermediate levels were used.

Two different fiber lasers were used as laser beam sources. In the first phase with the focus of investigation on root faces up to $6 \mathrm{~mm}, 4.5 \mathrm{~kW}$ output system was used, and for second phase at root face of $8 \mathrm{~mm}$, the SLV Mecklenburg-Vorpommern mobile $10 \mathrm{~kW}$ laser was integrated to
Table 1. Serial arrangements of laser beam and arc

\begin{tabular}{||c|c|c|c|}
\hline \multirow{3}{*}{ Variation } & $\begin{array}{c}\text { Neutral } \\
\text { process }\end{array}$ & Second process & $\begin{array}{c}\text { Schematic } \\
\text { beam } \\
\text { representation }\end{array}$ \\
\hline 2 & & $\begin{array}{c}\text { Arc forward } \\
\text { travelling }\end{array}$ & Arc trailing \\
\hline \multirow{2}{*}{3} & Arc & $\begin{array}{c}\text { Laser beam } \\
\text { forward travelling }\end{array}$ \\
\hline \multirow{2}{*}{4} & Laser beam trailing
\end{tabular}

the test built-up. The $4.5 \mathrm{~kW}$ fiber laser from the year 2003 was one of the first sources for welding within this performance class having proven its long standing stability in many applications.

Figure 2 shows the completed welding head with equipment for hybrid welding and integrated second arc torch for welding the cover pass during one vertical-down movement.

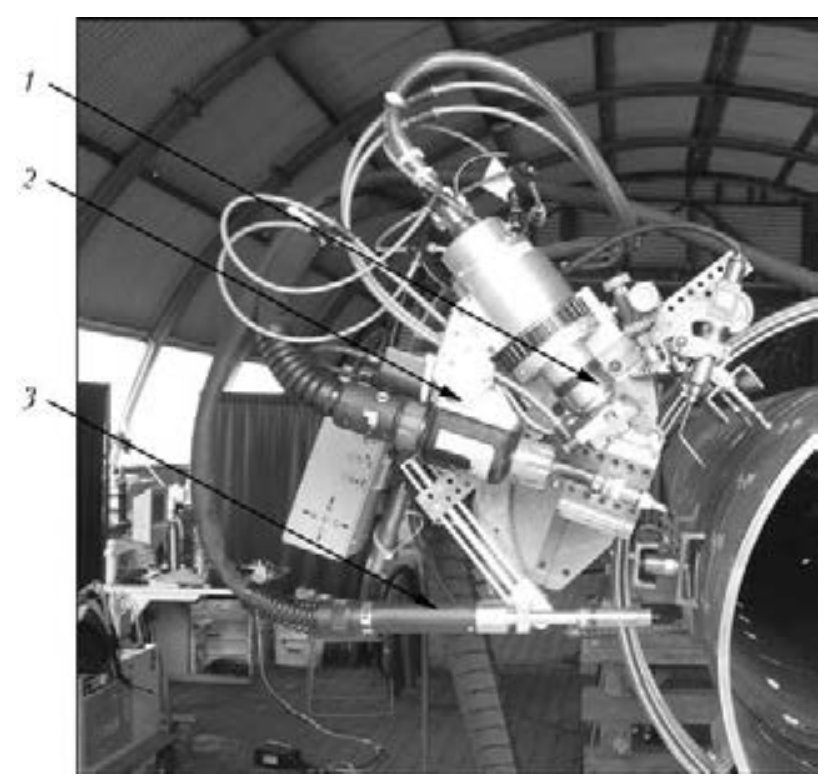

Figure 2. Welding head with hybrid equipment for root pass and arc torch for filling the groove: 1 - laser optics; 2 - hybrid arc; 3 - torch for filler pass welding 


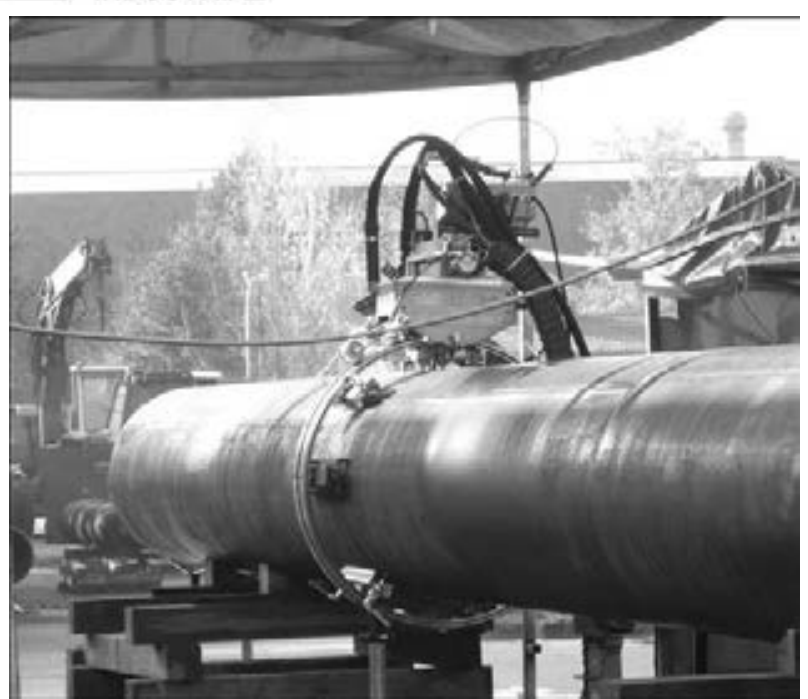

Table 2. Edge preparation and hybrid-welded joints macrosections

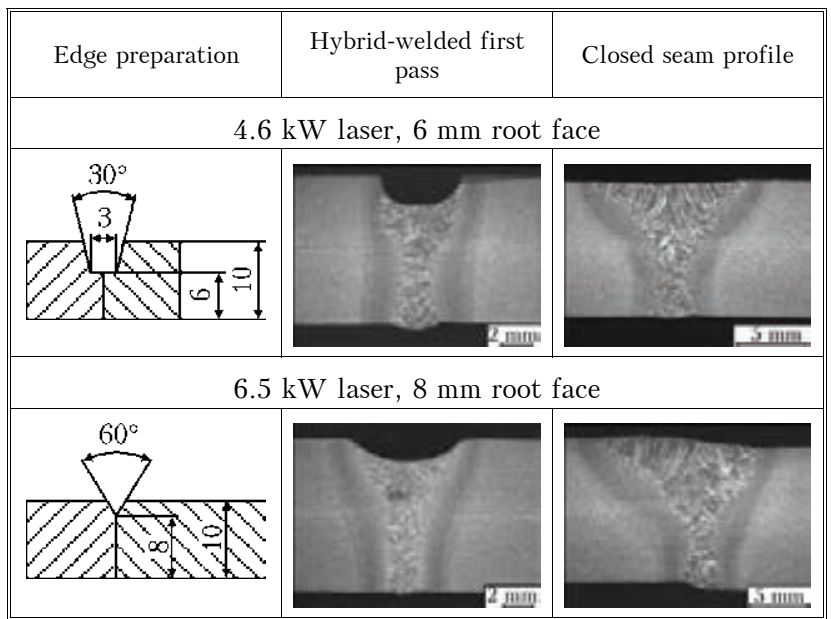

Figure 3. Entire test built-up on the pipe

Welding was performed on pipe pieces at lengths of up to $6 \mathrm{~m}$. In this case larger tolerance results compared to pipe with calibrated ends, in particular, with regard to quality and misalignment of edges.

Through the integration of the components described the entire test set-up, shown in $\mathrm{Fi}_{-}$ gure 3, was realized.

Execution and results of the technological examinations. The test was performed using two laser beam sources of different output. In doing so, first the principal test series for determining the basic parameters for hybrid arc and for determining the tolerance susceptibility of hybrid process at continuously changing welding positions across the pipe circumference was performed in first phase using the $4.5 \mathrm{~kW}$ fiber laser. Second test phase served to estimate the potential of hy-

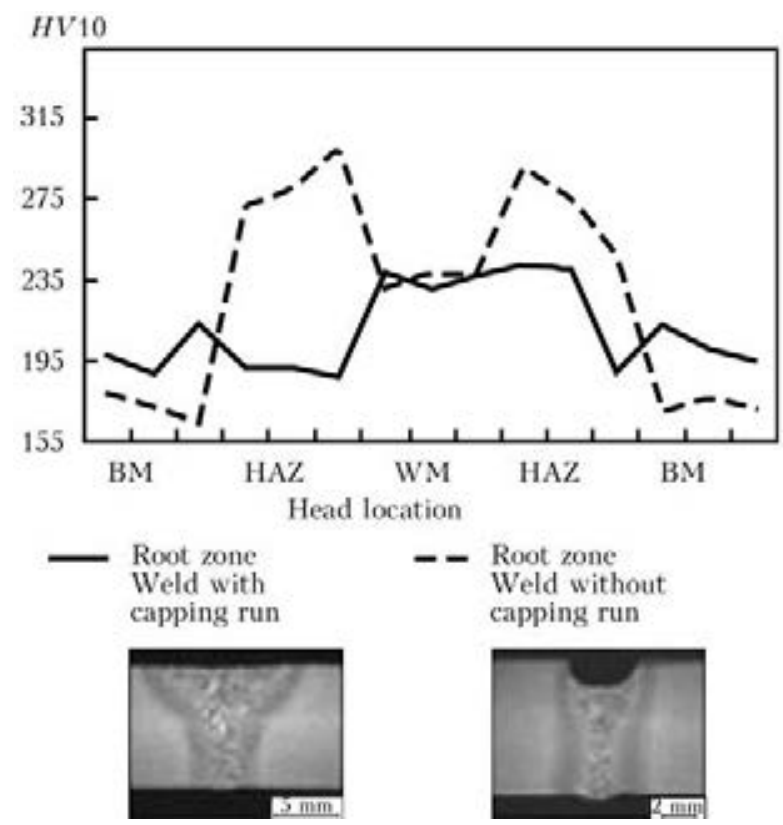

Figure 4. Influence of hardness distribution in the root zone on welding head location [2]

brid process at higher laser performance at simultaneous increase of root faces for the root pass of 6-8 $\mathrm{mm}$. To his end, the $10 \mathrm{~kW}$ fiber laser system was used.

In the following the results are shown in the form of macrosections both for the first hybrid pass and the closed seam profile, performed by trailing arc at different variation of edge preparation at laser output of 4.6 and $6.5 \mathrm{~kW}(\mathrm{Ta}-$ ble 2). Through the tolerances, measured at pipe joints and welding parameters assigned today, there are considerable results on the different tolerances of the process.

The examinations were concluded by the determination of hardness distribution, in particular in the root area of welds, since this obviously laser beam dominated area in HAZ could be susceptible to increased hardening. During these examinations, pure root welding without cover pass was compared to welding with closed seam profile through the trailing arc. Obtained results are shown in Figure 4.

A decisive object of investigation was the determination of typical tolerances in pipeline construction and the examination of influence of these tolerances on the hybrid welding process. During the trials the pipe joints were positioned and fixed using typical tools, and methods resulting in tolerances typical of pipeline construction. In order to draw conclusions from these tolerances during the future evaluations, the joining edges and welded joints were measured.

Further development of equipment and technology. The major objective of the investigations shown was to prove the principal suitability of hybrid welding for pipeline construction with regard to the more rough climatic conditions in this field of application. Here, important information 
with a great influence on the structural design of equipment was obtained. The specialized prototype developed on the basis of this for realization of girth movement in hybrid laser-GMA welding (Figure 5) has the following technical data: up to $6 \mathrm{~m} / \mathrm{min}$ travelling speed at positioning and up to $3 \mathrm{~m} / \mathrm{min}$ in welding; processed pipe diameters of $500-700 \mathrm{~mm}$; change of parameters depending on position; seam tracking and guidance system.

The integrated laser working head allows coupling with all fiber-guided solid-state lasers of up to $20 \mathrm{~kW}$ outputs.

The focus of the examinations, on the one hand, was directed to investigate the possibilities of formation of the weld and root with the laser output available and, on the other hand, on the overlapped areas at the weld start obligatory when welding two vertical-down seams at the circumference of pipe.

This phase of examinations was concluded by the performance on material tests for determining the mechanical-technological characteristic values for the L360NB test steel. The results of tensile test and $\mathrm{V}$-notched bar impact test at temperature of $0{ }^{\circ} \mathrm{C}$ is shown in Table 3 .

Laser girth welding and in-process testing of small diameter pipe joints with wall thickness of $3-\mathbf{5} \mathbf{~ m m}$. The objective of the second research project was a prototype for laser welding that should be developed and will allow a combined solution for the welding and testing of small diameter steel pipes with the aid of orbital process. The development effort in this situation consists of the combining different test techniques, in order finally to achieve a degree of reliability of results appropriate to the area of application.

Right from the start, the prototype was to be based on a design, which was as easy to handle as possible, and as space-saving as could be achieved. With an eye to the areas of application, which have already been described, as a first step a rated wall thickness range of the steel pipes from 3 to $5 \mathrm{~mm}$ was covered, this finally corresponds to the application range of pipe external diameters from 100 to about $400 \mathrm{~mm}$. The per-

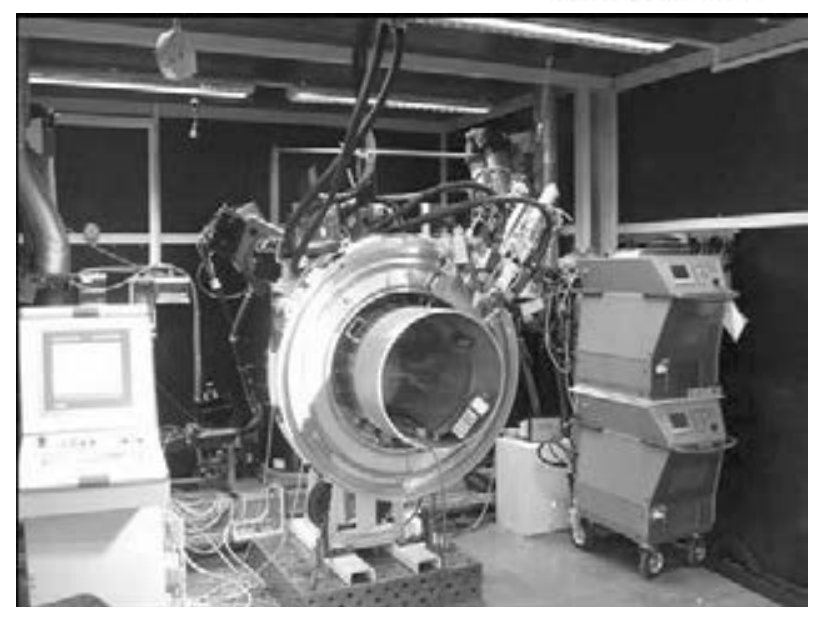

Figure 5. Specialized prototype equipment for pipeline welding

missible tolerances for welding gap and detectable sizes of irregularities, acquired by the test technology, are to be determined.

The construction equipped with testing and welding technology for the pipe joining is to be kept distinct from the equipment required for generation of the welding energy and for processing the measurement signals. The connection is to be produced by an appropriately arranged service line. In this way, even considerable distances can be covered between the equipment technology and actual workplace. This means that, depending on the area of application, the equipment can be installed on a site vehicle.

Experimental setup and procedure. To resolve the basic task successfully, it was, first of all, necessary to design the device for carrying out the circumferential movement of laser optics, as well as the device had to provide sufficient space for the sensor system for process monitoring and non-destructive testing. In this context, the focus of the investigations was set on creation of unitary monitoring and testing strategy, which would provide an analysis of weld quality, achieved directly after the welding completion. The information required for this can be acquired before, during and after the welding process in the form of different signals. The analysis of irregularities in laser-welded joints shows that the majority of these are attributable to interference in the process sequence. The cause of these, in turn, is the

Table 3. Mechanical properties of the L360NB steel welded joints

\begin{tabular}{|c|c|c|c|c|c|c|c|c|c|c|}
\hline \multicolumn{5}{|c|}{ Tensile test } & \multicolumn{6}{|c|}{$\mathrm{V}$-notched bar impact test at $T=0{ }^{\circ} \mathrm{C}$} \\
\hline \multirow{2}{*}{$\sigma_{0.2}, \mathrm{MPa}$} & \multirow{2}{*}{$\sigma_{t}, \mathrm{MPa}$} & \multirow{2}{*}{$\delta, \%$} & \multirow{2}{*}{$\psi, \%$} & \multirow{2}{*}{ Fracture site } & \multicolumn{2}{|c|}{ Dimensions, mm } & \multicolumn{4}{|c|}{$K C V, \mathrm{~J}$} \\
\hline & & & & & Width & Height & 1 & 2 & 3 & Mean \\
\hline 345 & 532 & 42 & 71 & BM & 7.5 & 8.0 & 201 & 128 & 77 & 136 \\
\hline 368 & 539 & 39 & 69 & $\mathrm{BM}$ & 7.5 & 8.0 & 180 & 181 & 169 & 177 \\
\hline
\end{tabular}




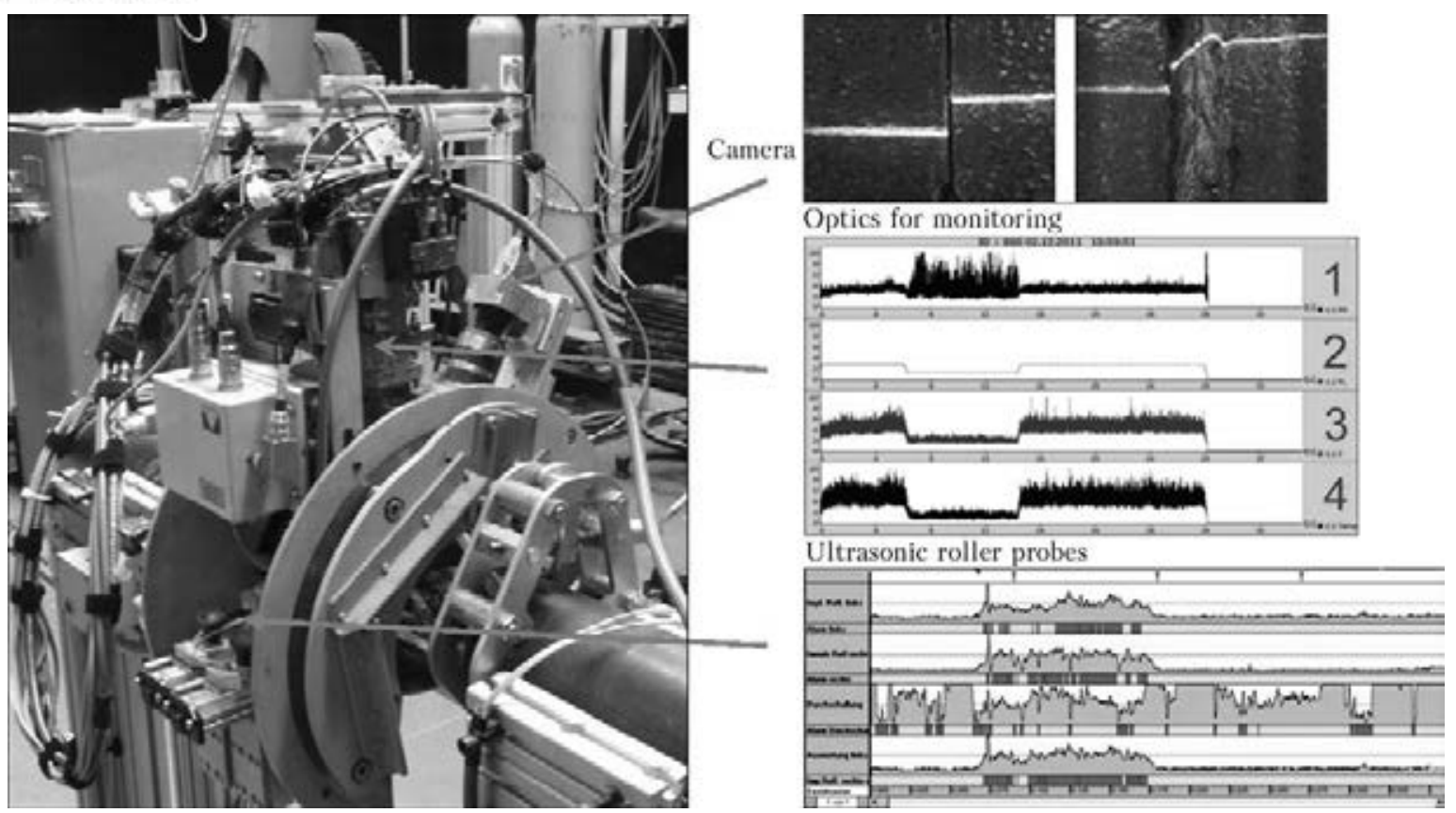

Figure 6. Specialized prototype equipment with camera, laser optics and ultrasonic test device

quality of the joint preparation with regard to geometry (presence of gap or poor edge alignment) and the standard of cleanliness.

As the first step, design and layout of the suitable construction was developed, for transforming the circumferential movement of the laser optics on pipe, including the clamping technique, required for joining and fixing the pipes of rated diameter from 80 to $150 \mathrm{~mm}$ with wall thicknesses of $2-5 \mathrm{~mm}$.

The construction consists of four ring-shaped plates, open downwards in order for joined pipes to be laid on them. Two outer plates are each

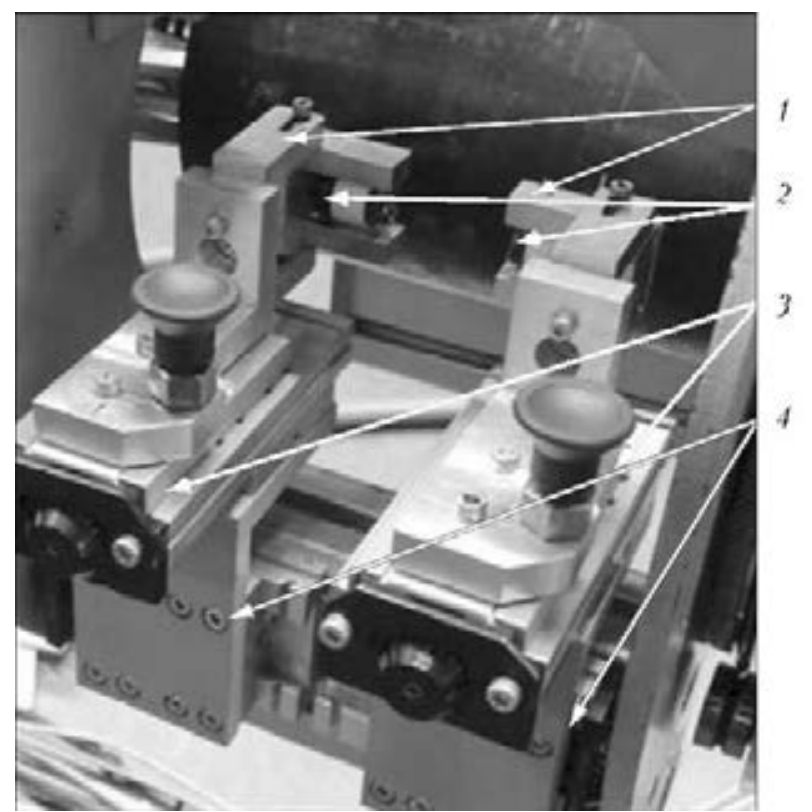

Figure 7. Ultrasonic test device: 1 - holding device for ultrasonic probes; 2 - ultrasonic roller probes; 3 - axes for coarse height adjustment; 4 - axes for adjusting distance to the welded joint connected to one of the pipes by means of clamping device. Two inner rings are guided along them, so that circular movement around the pipes can be carried out. Two inner rings are rigidly connected to one another. Arranged between these rings are all the components, which carry out the joining and testing procedures (Figure 6).

The core of experimental arrangement is the Precitec transmitting processing optical unit of YW30 type, from with sensor array, integrated coaxially to the path of beam, for photo-optical acquisition of relevant emissions from laser welding process. This processing optical array was adapted to the construction for the purpose of experiment.

For the assessment of weld, in particular with regard to edge alignment and gap, the bead, produced by line laser transverse to the joint, is recorded by camera. The camera and line laser are located close to the laser optic centrally between two inner plates of the carrier system, and are guided around the pipe with circumferential movement. Following the welding process, the same camera is used to record the topography of weld. In this situation, particular attention is paid to the gap and edge alignment at preparation for welding, geometrical seam irregularities and welding defects open to the outside.

The ultrasonic inspection equipment, used in investigations, is made up of actual ultrasonic testing instrument and roller angle beam probes. The testing instrument is a multi-channel ultrasonic system with five channels, separated from one another with the aid of a multiplexer. In 

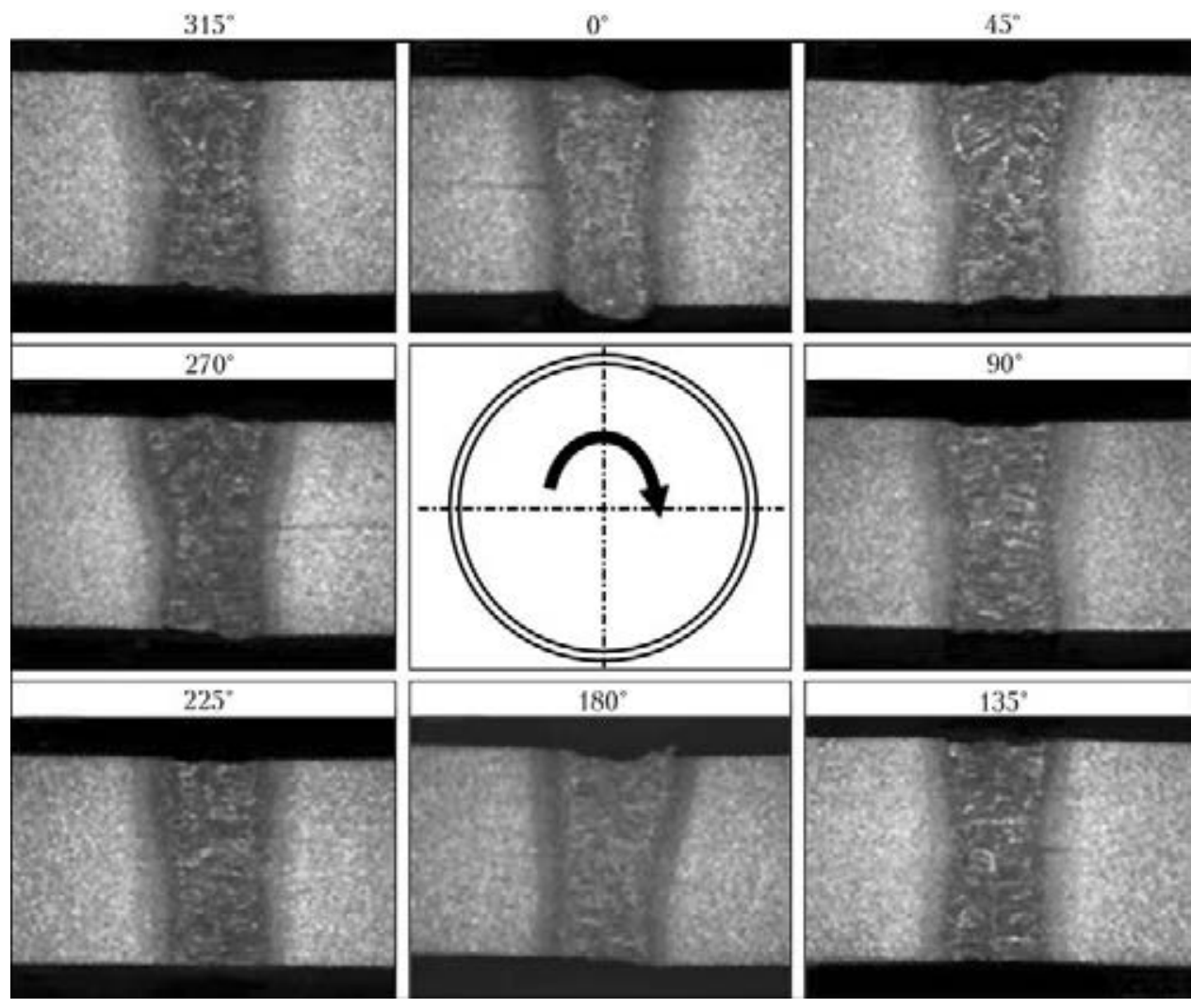

Figure 8. Macrosections of welded joint specimens with various pipe bend angle (3.5 times magnification)

addition, special roller angle beam probes are used for oblique application of ultrasonic with $55^{\circ}$ angle and $6 \mathrm{MHz}$ frequency. These probes are characterized in that the effective coupling is carried out not with the aid of couplants but by way of silicone tyre. The probe is moved on this tyre above the component, whereby only a movement parallel to the seam can be carried out.

In the final project phase, the individual systems, which had been developed consisting of welding optics, camera for recording the joint topography and process monitoring, as well as arrangement for the ultrasonic roller probes were all brought together to form a complete prototype solution.

For the direct evaluation of internal weld irregularities, two ultrasonic roller probes are guided around the pipe at defined interval from one another, left and right of the seam. Figure 7 shows the arrangement of ultrasonic test device.

Contact between the ultrasonic roller probes and the pipe is maintained by means of spring tension. Height adjustment is possible for different pipe diameters.

Results of material testing. In order to determine the mechanical-technological characteristic values of the laser-welded pipe joint, a series of experiments were carried out under ideal conditions for pipe edge preparation and without any provoked defect settings. After the produc-
Table 4. Mechanical properties of the L360NB steel welded joints

\begin{tabular}{|c|c|c|c|c|c|}
\hline \multirow{2}{*}{\multicolumn{2}{|c|}{$\begin{array}{l}\text { Specimen } \\
\text { location }\end{array}$}} & \multicolumn{2}{|c|}{ Dimensions, mm } & \multicolumn{2}{|c|}{$K C V, \mathrm{~J}$} \\
\hline & & Width & Height & Individual & Mean \\
\hline \multicolumn{6}{|c|}{ Charpy impact test at $T=0{ }^{\circ} \mathrm{C}$} \\
\hline \multirow{6}{*}{\multicolumn{2}{|c|}{ Weld }} & 3.4 & 8.0 & 59 & 62 \\
\hline & & 3.4 & 8.0 & 75 & \\
\hline & & 3.4 & 8.0 & 53 & \\
\hline & & 3.4 & 8.0 & 79 & 71 \\
\hline & & 3.4 & 8.0 & 66 & \\
\hline & & 3.4 & 8.0 & 68 & \\
\hline \multicolumn{6}{|c|}{$\mathrm{V}$-notched bar impact test at $T=0{ }^{\circ} \mathrm{C}$} \\
\hline \multirow[t]{6}{*}{ HAZ } & & 3.4 & 8.0 & 63 & \multirow[t]{3}{*}{55} \\
\hline & & 3.4 & 8.0 & 56 & \\
\hline & & 3.4 & 8.0 & 45 & \\
\hline & & 3.4 & 8.0 & 40 & \multirow[t]{3}{*}{41} \\
\hline & & 3.4 & 8.0 & 42 & \\
\hline & & 3.4 & 8.0 & 41 & \\
\hline \multicolumn{6}{|c|}{ Transverse tensile test } \\
\hline Specimen & $\sigma_{\mathrm{y}}, \mathrm{MPa}$ & $\sigma_{\mathrm{t}}, \mathrm{MPa}$ & $\delta, \%$ & $\psi, \%$ & $\begin{array}{c}\text { Fracture } \\
\text { site }\end{array}$ \\
\hline 1 & 448 & 487 & 20.1 & 70 & $\mathrm{BM}$ \\
\hline 2 & 418 & 467 & 24.5 & 70 & $\mathrm{BM}$ \\
\hline 3 & 416 & 466 & 21.6 & 67 & $\mathrm{BM}$ \\
\hline 4 & 413 & 463 & 25.8 & 62 & $\mathrm{BM}$ \\
\hline
\end{tabular}


tion of this reference sample, metallographic specimens were taken in increments of $45^{\circ}$, divided over the circumference. These are shown in Figure 8, related to the pipe angle in each case.

As can clearly be seen, for the parameters selected no influence derives from the orbital constantly changing welding position, which supports the constant signal level of the process monitoring system. This analysis relates both to the weld geometry in respect of its upper and lower side, as well as to the occurrence of internal weld irregularities. As a result it can be estimated that, under the conditions chosen, an evaluation group B according to DIN EN ISO 13919-1 is fulfilled.

The investigations for determining the static weld strength and toughness, making reference to the DVGW Worksheet GW 350, likewise did not reveal any anomalies. The values, determined accordingly in the tensile and $\mathrm{V}$-notched bar impact test (undersize samples) for L360NB steel $5 \mathrm{~mm}$ thick are given in Table 4 .

\section{Summary}

In order to increase efficiency in pipeline construction, examinations of new welding processes for joining of pipes are indispensable with the focus on increasing the welding speed at a reduced number of passes. Possible alternatives are the laser and hybrid laser-GMA welding processes since due to development of fiber laser, the beam source with new fields of application is available [2].

The objective of investigations presented was to prove the principal suitability of laser-based processes for pipeline construction, as well as the behaviour of those processes in out-of-position welding, which is required for its application.

The results distinctively show the potential of laser welding technology at high laser output and with brilliant beam qualities.
As an alternative of the existing approaches [3] there is the idea of using the hybrid process for production of high quality root pass at 12$15 \mathrm{~mm}$ root faces. This approach is the basis of examinations currently performed.

As a result of the work presented for the development of in-situ testing and monitoring strategy for laser-based pipe welding, the function and suitability have been proved at the laboratory level. In specific terms, this means that the ability to test laser-welded joints by means of ultrasonic technology can also be achieved in the $3-5 \mathrm{~mm}$ range of wall thicknesses for critical irregularities, such as lack of fusion, root defects (lack of penetration), and porosity. In the final arrangement of equipment, it was shown that the interaction of individual systems of the camera, photooptical process monitoring and ultrasonic testing is indeed achieved. This was proved in the error simulations. Further optimization of the assessable sizes of irregularities in the weld is foreseeable in the further course of the work.

Acknowledgements. The authors gratefully acknowledge funding of the German Federal Ministry of Economics and Technology.

1. Blackman, D., Dorling, V., Howard, R. (2002) High-speed tandem GMAW for pipeline welding. In: 4th Int. Pipeline Conf. Proc. (Calgary, Alberta, Canada), 517-523.

2. Keitel, S., Neubert, J., Stroefer, M. (2009) Laserbased girth welding technologies for pipelines GMAW gets support. In: Proc. of IIW Int. Conf. on Advances in Welding and Allied Technologies (Singapore), 289-294.

3. Gumenyuk, A., Gook, S., Lammers, M. et al. (2009) High power fibre laser welding for pipeline applications. In: Proc. of 5th Int. Congress on Laser Advanced Materials Processing. 


\title{
PERCUSSION CAPACITOR-DISCHARGE WELDING OF WIRE OF COMPOSITE SUPERCONDUCTING ALLOY
}

\author{
D.M. KALEKO \\ E.O. Paton Electric Welding Institute, NASU \\ 11 Bozhenko Str., 03680, Kiev, Ukraine. E-mail: office@paton.kiev.ua
}

\begin{abstract}
Urgency of application of superconducting wires in medical and experimental equipment requires, considering limited length of wire and its high cost, development of joining methods, preserving service characteristics of a base metal. Structure of composite wire, consisting of several dozens of threads from superconducting alloy in copper matrix, allows application of only solid-phase methods of welding. Percussion capacitor-discharge welding is the most perspective for butt joining of such small diameter wires. It provides the possibility of simultaneous welding of threads and matrix, having extremely different thermal-physical characteristics. It is shown that this method allows producing of the joints of commercial composite wires of 0.85 and $1 \mathrm{~mm}$ diameter from NT-50 niobium-titanium alloy in copper matrix without significant reduction of critical current in up to $80 \mathrm{kOe}$ fields. 2 Ref., 2 Tables, 4 Figures.
\end{abstract}

$\boldsymbol{K} \boldsymbol{e} \boldsymbol{y} \boldsymbol{w} \boldsymbol{o r d} \boldsymbol{s}:$ percussion capacitor-discharge welding, composite wire, superconducting wire, niobium-titanium alloy

Production of superconducting materials based on $\mathrm{Nb}-\mathrm{Ti}$ alloy and $\mathrm{Nb}_{3} \mathrm{Sn}$ intermetallic was expanded in recent years due to works on project of the International Thermonuclear Experimental Reactor. $\mathrm{Ni}-\mathrm{Ti}$ alloy $(\mathrm{Nb}-47.5 \% \mathrm{Ti})$ due to high technological characteristics, namely strength and ductility, is the basic material for technical application of superconductors, main of which are coils of tomopgraphs for magnetic resonance therapy and nuclear magnetic resonance. The superconductors have also found application in the magnets of research power installations of Tokamak type, in the pilot models of superconducting induction energy storages, cables, magnetic separators etc.

At present time series of companies, including Supercon (USA), Western Superconducting Technologies (China), Chepetsky Mechanical Plant of TVEL Corporation (Russia) and others, mastered manufacture and propose for sale $\mathrm{Ni}-\mathrm{Ti}$ wire of 0.3 to $2.0 \mathrm{~mm}$ diameter.

A structure of wire - thread of $\mathrm{Nb}-\mathrm{Ti}$ alloy in copper matrix - is determined by the requirements of preservation of superconducting characteristics in magnetic field of up to $10 \mathrm{~T}$ value. For this, the $\mathrm{Ni}-\mathrm{Ti}$ rods are laid in the cylindrical channels of copper semi-product and such a composition is treated by pressure and drawn in a wire. Cold deformation results in appearance of high dislocation density and structural defects, which serve as centers of locking of magnetic vortexes (so called pinning), and this, after cor- responding annealing, provides for necessary current density at high magnetic field intensity [1].

One more condition for successful operation of $\mathrm{Ni}-\mathrm{Ti}$ composite superconductor is spiral twisting of the Ni-Ti threads (twisting). Such peculiarity of the structure results in change of orientation of applied field, that allows reducing time of attenuation of loop-forming screen currents by passing along one side of the conductor and returning through the copper matrix to opposite side. Step of twisting, in general, depends on conditions of wire operation and have order of several centimeters. Figure 1 shows cross-section of the superconducting $\mathrm{Ni}-\mathrm{Ti}$ wire.

Manufacture of the devices, using superconducting wires, requires joining wires between

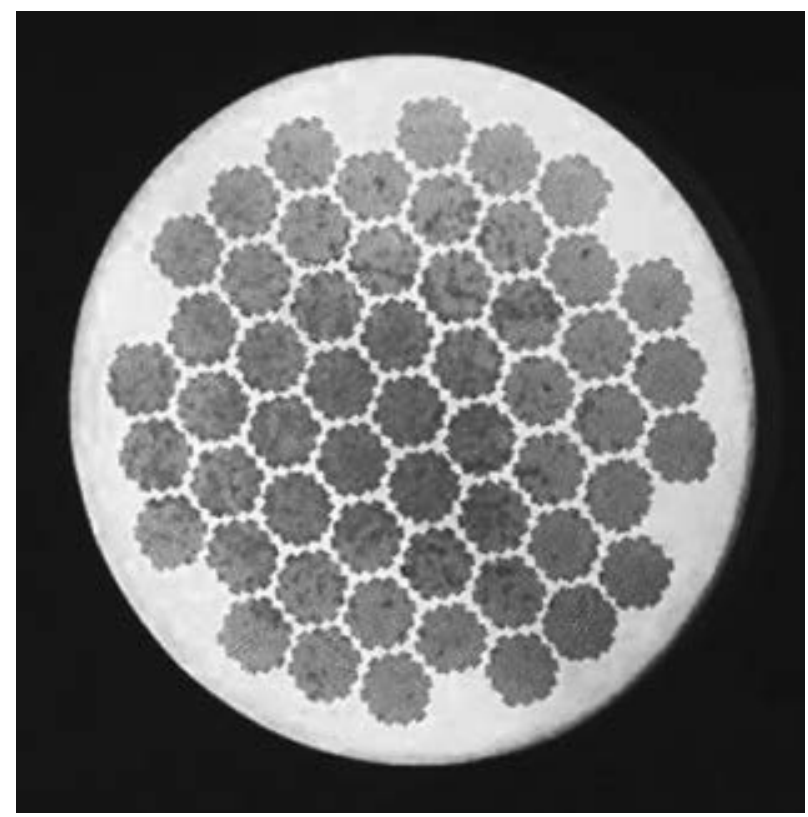

Figure 1. Cross-section of NT-50 alloy wire of $1 \mathrm{~mm}$ diameter 


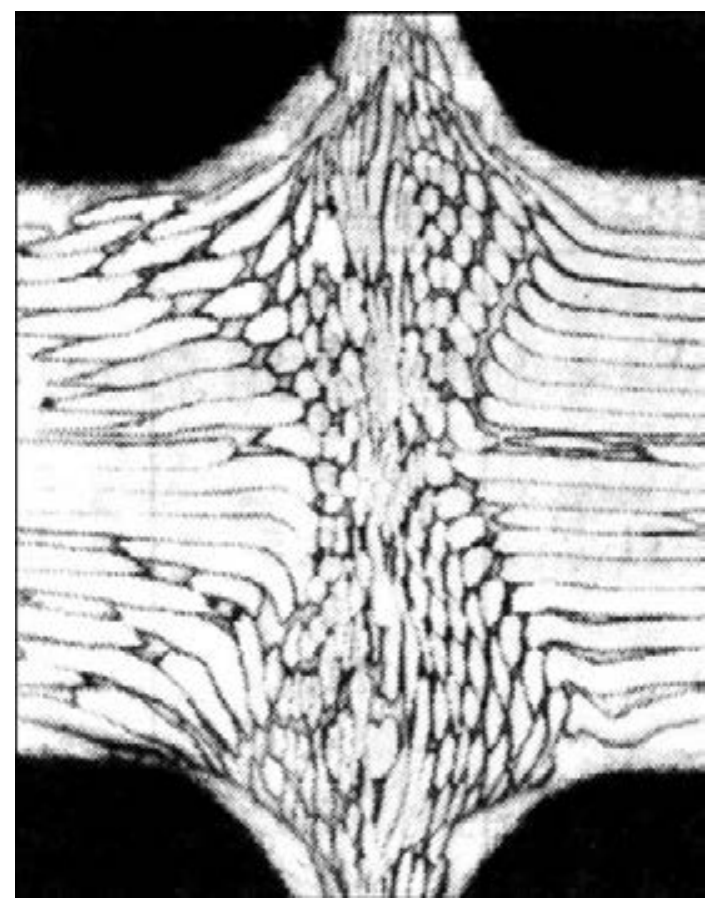

Figure 2. Macrostructure of cold-welded joint of composite superconducting wire [2]

each other, considering its high cost and length, limited by production technology. Now it is performed by parallel laying of ends of the wires being joined with subsequent brazing-on of copper matrix along the significant length, since it is necessary to provide not only joint strength, but also the possibility of conduction of current in several tens of kiloamperes through copper, keeping electrical resistance.

Experiments were carried out on joining of fragments of wire by removing (etching) the copper matrix from superconducting alloy threads with subsequent covering of the welded joint by copper [2]. It is shown in this work that the best result is received in joining of the threads without flashing, for example, at pressing by copper tube

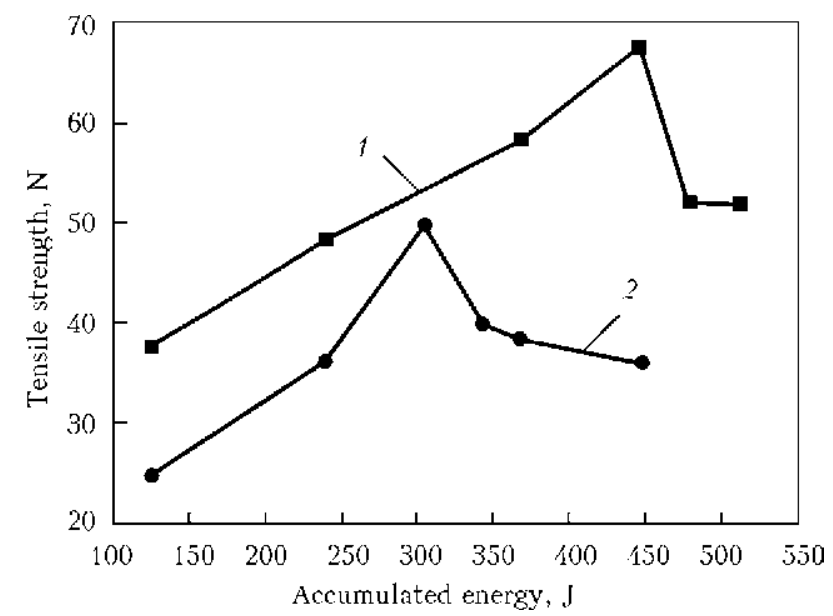

Figure 3. Dependence of joint strength of composite superconducting NT-50 wires in copper matrix, made by percussion capacitor-discharge welding, on accumulated energy (diameter of wires being joined 1 (1) and 0.85 (2) $\mathrm{mm}$ of the composition of threads, which mutually come into fragments of wire being joined. At that, the experiments with electron beam welding of threads showed significant (by 2 orders) reduction of critical current passing through the joint.

Laboriousness of described operation of mechanical joining provokes searching of the methods for butt joining of the wires in a way to provide simultaneous welding of threads of superconducting material and copper matrix. Obviously, that searching can be carried out only among the methods of solid-phase welding. Considering form of the joint, cold and percussion capacitor-discharge welding can be referred to such. Advantage of the latter lies in low level of deformation and, due to this, preservation of composite structure. Cold welding requires application of significant forces, which result in breaking of the threads of superconducting material and their distortion (Figure 2). Therefore, percussion capacitor-discharge welding is more preferable for joining of composite wire.

Joining in percussion capacitor-discharge welding takes place in upsetting of wires being joined after cleaning and heating of welded surfaces by arc burning at capacitor discharge. Compression of the wires results in removal of molten metal in flash and formation of metallic bonds of the surfaces being joined. Initial characteristics of the metal are preserved due to this, and certain increase of joint area makes it full-strength with the base metal.

The experiments were carried out using wires of composite alloy NT-50 (47.5 wt.\% Ti, the rest is $\mathrm{Ni}$ ) in the copper matrix of $1 \mathrm{~mm}$ diameter (quantity of threads $n=37$, space factor $F_{\mathrm{s}}=$ $=45.4 \%), 0.85 \mathrm{~mm}\left(n=37, F_{\mathrm{s}}=46.38 \%\right)$ and $0.5 \mathrm{~mm}\left(n=24, F_{\mathrm{s}}=32.12 \%\right)$. Welding was performed on universal machine A-1091 for arc methods of capacitor-discharge welding. Modes of welding are shown in Table 1. Satisfactory quality of joints of $0.5 \mathrm{~mm}$ diameter wire was not succeeded.

Figure 3 shows effect of mode parameters on tensile strength of the joint. The mode of welding, at which the specimens fracture along the solid

Table 1. Modes of percussion capacitor-discharge welding of composite superconducting $\mathrm{Ni}-\mathrm{Ti}$ wire (resistance of discharge loop $1.2 \mathrm{Ohm}$ )

\begin{tabular}{||c|c|c|c||}
\hline $\begin{array}{c}\text { Wire diameter, } \\
\mathrm{mm}\end{array}$ & $\begin{array}{c}\text { Capacity of } \\
\text { capacitors, } \mu \mathrm{F}\end{array}$ & $\begin{array}{c}\text { Charging } \\
\text { voltage of } \\
\text { capacitors, } \mathrm{V}\end{array}$ & $\begin{array}{c}\text { Percussion } \\
\text { force, } \mathrm{N}\end{array}$ \\
\hline 1 & 1500 & 770 & 10 \\
\hline 0.85 & 1400 & 660 & 8 \\
\hline
\end{tabular}


Table 2. Values of current in liquid helium

\begin{tabular}{||l|c|c|c||}
\hline \multirow{2}{*}{ Specimen } & \multicolumn{3}{|c|}{$\begin{array}{c}\text { Critical average current, A, in } \\
\text { magnetic field, kOe }\end{array}$} \\
\cline { 2 - 4 } & 50 & 60 & 70 \\
\hline $\begin{array}{l}\text { Initial material of 1 mm } \\
\text { diameter }\end{array}$ & - & 582 & 438 \\
\hline Welded specimen & - & 577 & 427 \\
\hline $\begin{array}{l}\text { Initial material of } 0.85 \mathrm{~mm} \\
\text { diameter }\end{array}$ & 414 & 326 & 257 \\
\hline Welded specimen & 389 & 299 & 246 \\
\hline
\end{tabular}

wire far from place of welding, was taken as the optimum one. Such a choice was verified by measurement of operating characteristics.

Microstructure of the welded joints of superconducting composite wire NT-50 of $1 \mathrm{~mm}$ diameter (Figure 4) shows performance of the joints of separate threads of superconducting alloy as well as copper matrix in the process of percussion capacitor-discharge welding. Inhomogeneity of NT-50 threads out of the joint, which can be seen in microsection photo, is explained by non-parallelism of «twisted» thread and microsection plain.

Since it is impossible to adjust accurately the threads of stranded fragments of composite wire being joined during welding, welded joints of superconductor with copper matrix appear in the butt. Based on data of metallographic analysis, possibility of joining of separate threads between each other makes around $80 \%$.

Measurements of electric resistance in $5 \mathrm{~m}$ length specimens of $1 \mathrm{~mm}$ diameter NT-50 wire having 20 butts, carried in the I.V. Kurchatov Institute of Atomic Energy, at $4.2 \mathrm{~K}$ temperature in $80 \mathrm{kOe}$ intensity magnetic field, showed value around $0.1 \mu \mathrm{Ohm}$. The critical currents in liquid helium, measured in the All-Russian Research Institute of Cable Industry, are given in Table 2.

The Table shows that the welded joint critical current, which is one of the main characteristics

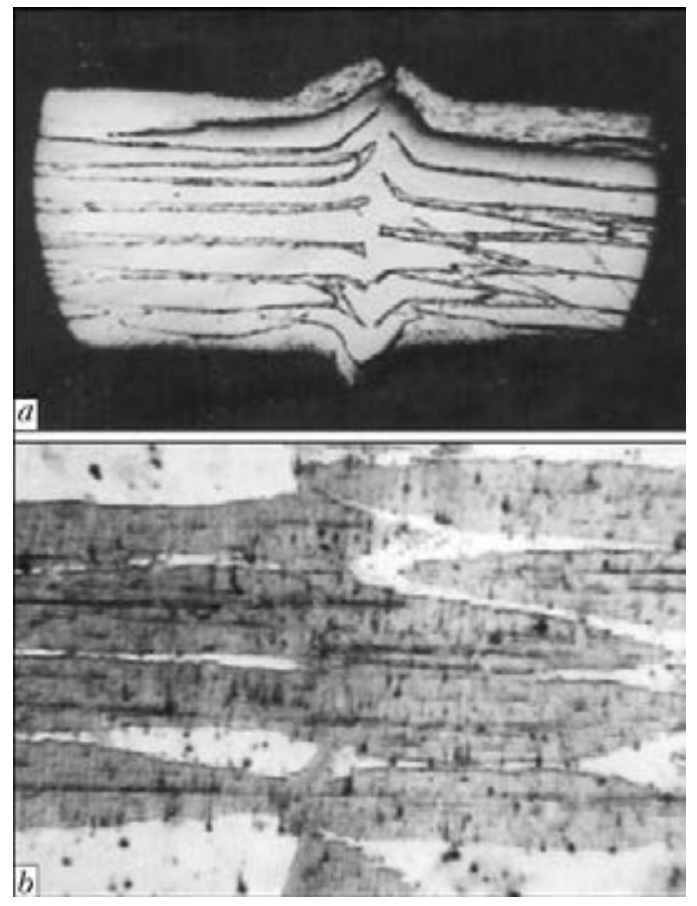

Figure 4. Microstructure of welded joints of superconducting composite wire NT-50 of $1 \mathrm{~mm}$ diameter: $a$ - without etching $(\times 30) ; b-$ after microsection etching $(\times 150)$

of superconducting wire, reduces not more than per $10 \%$, that allows recommending the methods of percussion capacitor-discharge welding for joining of composite wires of superconducting $\mathrm{Ni}-\mathrm{Ti}$ alloy in copper matrix.

Therefore, percussion capacitor-discharge butt welding of superconducting composite wire of $\mathrm{Ni}-\mathrm{Ti}$ alloy in copper matrix allows producing the joints with the properties close to that of the base metal.

1. Chyorny, O.V., Reshetnyak, E.N., Stetsenko, A.N. et al. (2002) Structure and superconducting characteristics of $\mathrm{Nb}-\mathrm{Ti} / \mathrm{Ti}$ superlattice. Voprosy Atom. Nauki i Tekhniki, 1, 84-87.

2. Shibuya, J., Mizutame, M., Nakanishi, K. (1987) Joining process and its feature of superconducting materials. J. JWS, 56(2), 12-16.

Received 29.01.2014 


\title{
PRODUCING OF BIMETAL JOINTS BY LASER WELDING WITH FULL PENETRATION
}

\author{
M. SCHMIDT ${ }^{1}$ and S.V. KURYNTSEV ${ }^{2}$ \\ ${ }^{1}$ Fridrich-Aleksandr University, Erlangen, Germany \\ ${ }^{2}$ A.N. Tupolev Kazan National Research Technical University \\ 10 K. Marks Str., Kazan, 420111, RF. E-mail: kuryntsev16@mail.ru
}

\begin{abstract}
Current level of development of technologies for treatment of metallic materials is impossible without using of lasers, which have found application in such processes as cutting, heat treatment, welding, engraving and brazing. This paper describes investigation of process of production of stainless steel-brass bimetal joint using laser welding with full penetration. The specimens were welded on equipment of IPG «IRE-Polus» Ltd. This company manufactures machines for laser welding using tongs. Thickness of specimens from $12 \mathrm{Kh} 18 \mathrm{~N} 10 \mathrm{~T}$ steel and L63 brass made $3 \mathrm{~mm}$. Welding was carried out at different modes, and influence of postweld heat treatment on mechanical properties of the joints was evaluated. Performed are metallographic investigations, and microhardness of different zones of welded joint is measured. It is determined that application of laser welding with full penetration for production of bimetal joints is possible under condition of more accurate adjustment of welding modes and postweld heat treatment. 8 Ref., 2 Tables, 6 Figures.
\end{abstract}

Keywords: laser welding, tongs, full penetration weld, bimetal joint, microhardness, metallography

Application of composite metallic materials, in particular bimetals, allows combining valuable service and physical-mechanical properties, typical for dissimilar metals, such as corrosion resistance and mechanical strength, tribotechnical characteristics and corrosion resistance, tribotechnical characteristics, heat resistance, and high-temperature strength in one product. Bimetals find wide application in machine-, ship-, aircraft building, chemical industry and production of power installations.

Joining of some pairs of metals by fusion welding is impossible since they are metallurgically incompatible or due to formation in a fusion line of intermetallics, which have negative effect on mechanical and electrophysical properties of the joints.

There are number of methods for production of bimetals, in particular, pouring of molten metal on moving steel strand, metallic powder sintering, arc surfacing [1, 2], magnetic-pulse welding, roll welding [3], explosion welding [4], linear friction welding, ultrasonic welding and diffusion welding [5]. All this methods have a series of technological disadvantages, namely complexity of manufacture, low indices of process ecological compatibility, maximum efficiency only in bulk production, high energy intensity of the processes, low productivity, narrow specializing of used equipment, labouriousness and irregular repeatability of the technological process. Therefore, implementation into commercial production of more advanced technologies providing high indices of energy efficiency, repeatability of the technological process, automation and robotization of the technology is relevant. At present time, laser technologies are state-of-the-art in the world practice and fulfill current requirements.

At the same time, the disadvantages, typical for laser technologies, can be outlined. Among them is an insufficiently studied mechanism of formation of vapour-gas channel due to the fact that generation of pores in the welded joints is connected with it. Works [6, 7] study the issue of groove preparation for gas-shielded welding. Work [8] proposes a technology of laser-arc hybrid welding with full penetration and represents the results of influence of surface pre-treatment, level of pressing of semi-products to each other, modes of hybrid process, fluxes, shielding gases and filler wire on joint formation and thermal cycle of welding.

The present paper considers application of laser welding with the help tongs for production of bimetal semi-products as an alternative to widely used methods.

Laser welding using tongs is the process of production of permanent joint by means of creation of interatomic bonds between two or more flat semi-products. As a result of influence of laser beam, traveling on specific trajectory, on a surface of one of semi-products, a joint is formed due to remelting of boundaries of two surfaces, 
Table 1. Modes of production of $12 \mathrm{Kh} 18 \mathrm{~N} 10 \mathrm{~T}$ steel $+\mathrm{L} 63$ brass specimens

\begin{tabular}{||c|c|c|}
\hline \hline Mode & $N, \mathrm{kV}$ & $v_{\mathrm{w}}, \mathrm{mm} / \mathrm{s}$ \\
\hline 1 & 3.0 & 25 \\
\hline 2 & 2.5 & 25 \\
\hline 3 & 2.5 & 15 \\
\hline
\end{tabular}

possibly with complete and incomplete penetration (Figure 1). The welding technology is the following. The semi-products to be welded are placed between clamping collets of the tongs (Figure 1,b) that provides sufficiently tight pressing. A shielding gas is fed into the hollow tongs and a laser beam is directed, virtually, simultaneously normal to the semi-products being welded through the upper collet clamp.

Below are given the characteristics of laser welding process with full penetration:

Weight of tongs, $\mathrm{kg}$ 45

Pressing force, $\mathrm{kN}$ $0.6-0.3$

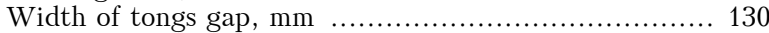

Length of welding zone, $\mathrm{mm}$.................................. $0-40$

Amplitude of beam oscillation, $\mathrm{mm}$......................... 2

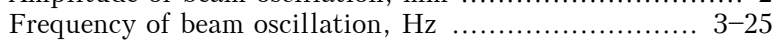

Welding speed, $\mathrm{mm} / \mathrm{s}$............................... max 80

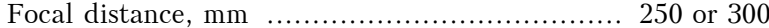

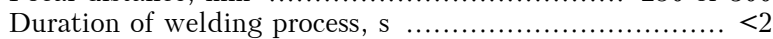

The main advantages of laser welding using tongs are the following: possibility of production of welded joints from dissimilar metals, high
Table 2. Influence of heat treatment mode on microhardness of section of L63 brass partially mixed with $12 \mathrm{Kh} 18 \mathrm{~N} 10 \mathrm{~T}$ steel

\begin{tabular}{|c|c|c|c|}
\hline \hline Mode & $T,{ }^{\circ} \mathrm{C}$ & $t, \mathrm{~h}$ & $H V 0.5, \mathrm{MPa}$ \\
\hline 1 & 400 & 1.3 & $950-1030$ \\
\hline 2 & 350 & 3.0 & $870-940$ \\
\hline 3 & 500 & 3.0 & $850-890$ \\
\hline
\end{tabular}

welding speed, short-time heating, and as a result, virtually, complete absence of HAZ, possibility of automation and robotization of the technological process. Application of program control for laser equipment and adjusted technology can provide high index of repeatability of the welding process, that is very important under conditions of serial production. Commercial implementation of laser complexes of «IRE-Polus» requires no fundamental changes in the technological process of welding, the equipment is sufficiently compact, consumed energy is comparable with the competitive technologies.

Nature of this process, for production of bimetals, lies in performance of joint of two or more homogeneous or dissimilar metal sheets, positioned over each other, by full penetration welds. The laser beam is traveled along the specific trajectory (Figure 2, $a$; weld - in the specimen center) in order to increase joint area. Series of specimens from 12Kh18N10T steel + L63 brass with incomplete penetration was prepared and

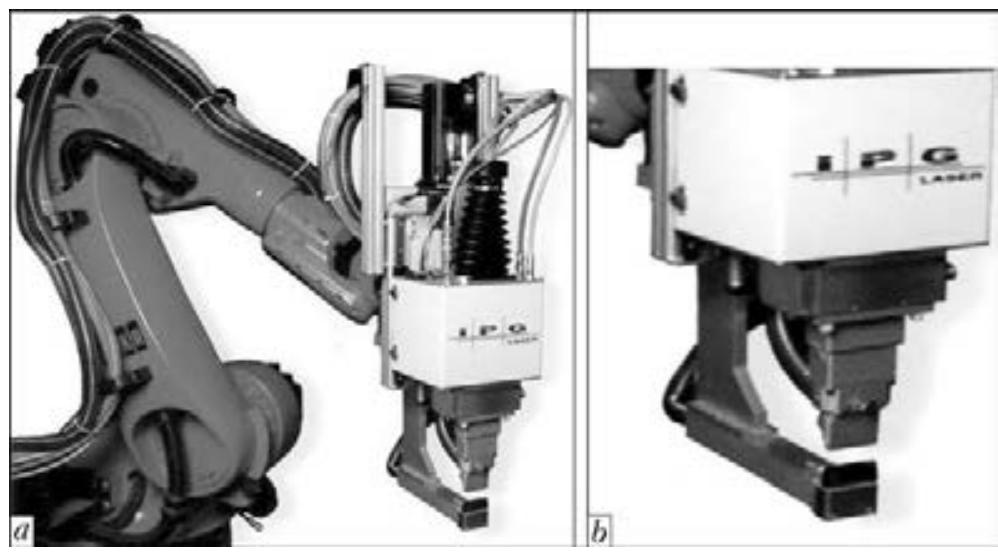

Figure 1. Appearance of machine for laser welding with LSS tongs $(a)$ and collet $(b)$

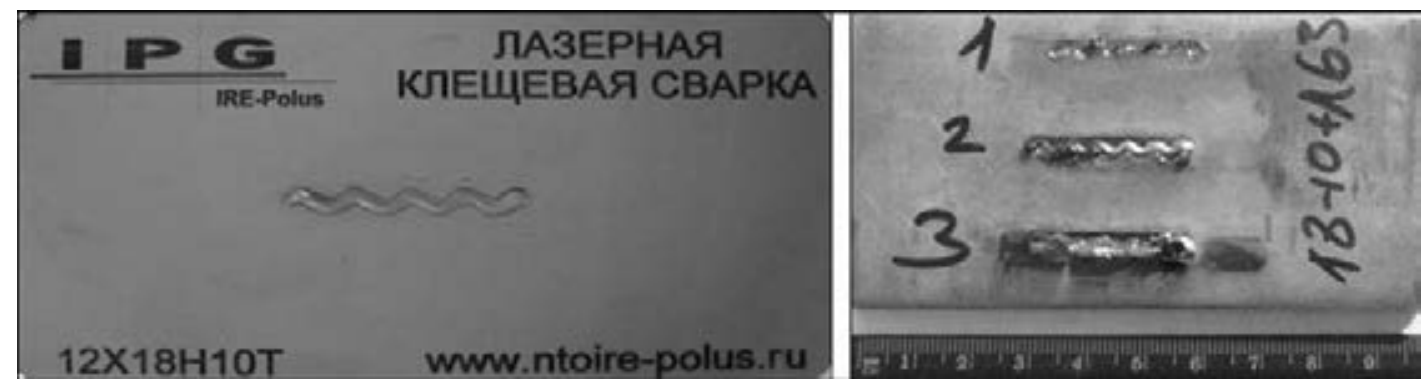

Figure 2. Laser-welded specimens: $a$ - welded joint of 12Kh18N10T $+12 \mathrm{Kh} 18 \mathrm{~N} 10 \mathrm{~T}$, one mode; $b-$ welded joint of 12Kh18N10T + L63, three modes 

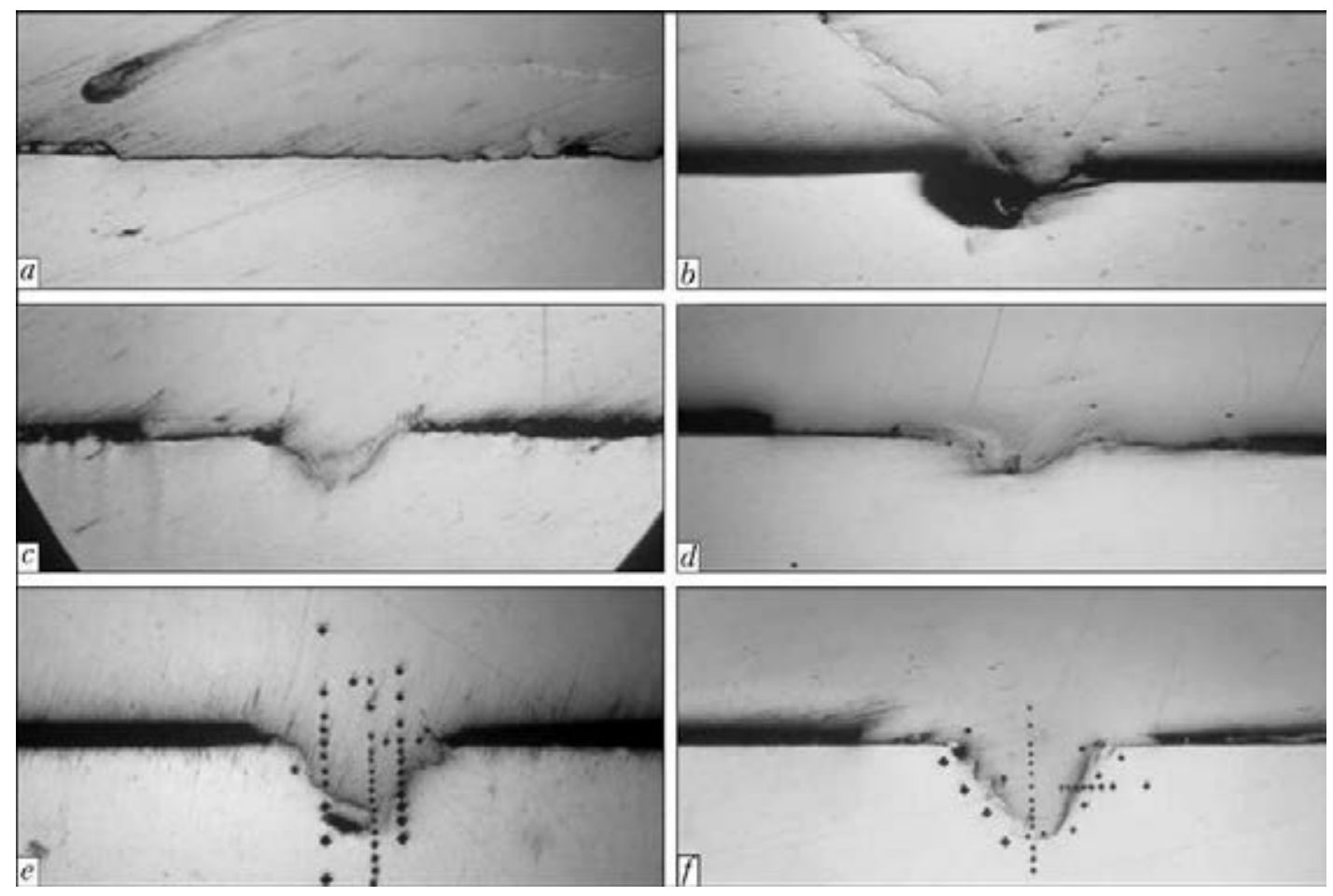

Figure 3. Transverse macrosection $(\times 100)$ of welded joint: $a$ - section 1 , depth $1 \mathrm{~mm} ; b-$ section 2 , depth $3 \mathrm{~mm} ; c-$ section 3, depth $4.5 \mathrm{~mm} ; d$ - section 4 , depth $6 \mathrm{~mm}, e$ - section 5 , depth $7.5 \mathrm{~mm} ; f$ - section 6 , depth $9.5 \mathrm{~mm}$

welded for investigation of mechanism of joint formation. Thickness of 12Kh18N10T and L63 plates made $3 \mathrm{~mm}$. The laser beam traveled along the specific trajectory on surface of steel, the specimens were welded at different modes $\left(\mathrm{Ta}^{-}\right.$ ble 1). Aging of the specimens with penetration at different modes (Table 2) was carried out after welding for determination of effect of heat treatment on mechanical properties of the joint.

Metallographic investigations were carried out using the Carl Zeiss optic microscope Axiovert 200, microhardness of the layers, fusion zones and HAZ were measured on the Remet microhardness tester HX 1000.

It was found during metallographic investigations that penetration at all modes is not constant (Figure 3). Photos of several layers of the one filled microsection were made. Specific layer of 1.5-2.0 mm thickness was removed after each investigation using grinding and polishing, photographing and investigation of the mechanical properties were repeated. The joint is inhomogeneous as can be seen from the presented photos of different on depth section of the one specimen. Metallographic investigations also showed that the sections of joint formation have an interlayer in form of solidified mechanical mixture from steel and brass. The values of microhardness have insignificant difference for these sections.

Figure 4 shows the microstructure of joints with indentations, area of large indentations in the left part of the photo (Figure 4, $a$ ) was made at $H V 1$ load. However, as it was necessary to determine sufficiently narrow transition zones,

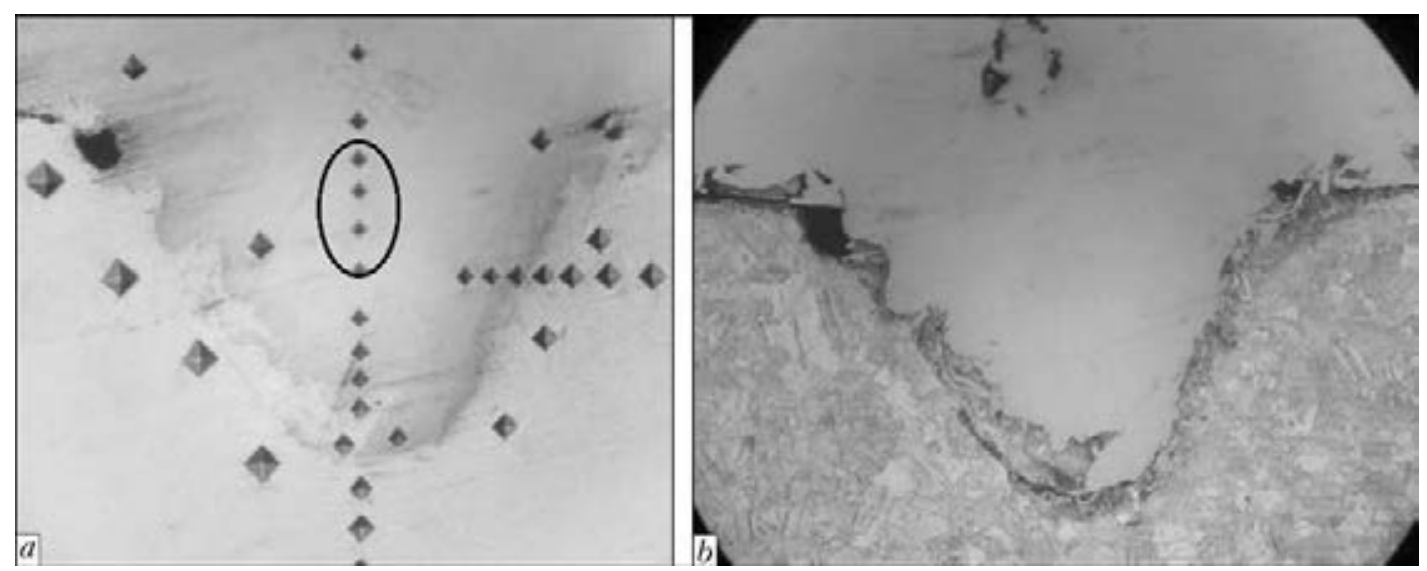

Figure 4. Macrosection $(\times 250)$ of one section of welded joint with incomplete penetration after measuring of microhardness (a) and etching $(b)(12 \mathrm{Kh} 18 \mathrm{~N} 10 \mathrm{~T}$ - in the upper part, L63 - in the lower) 


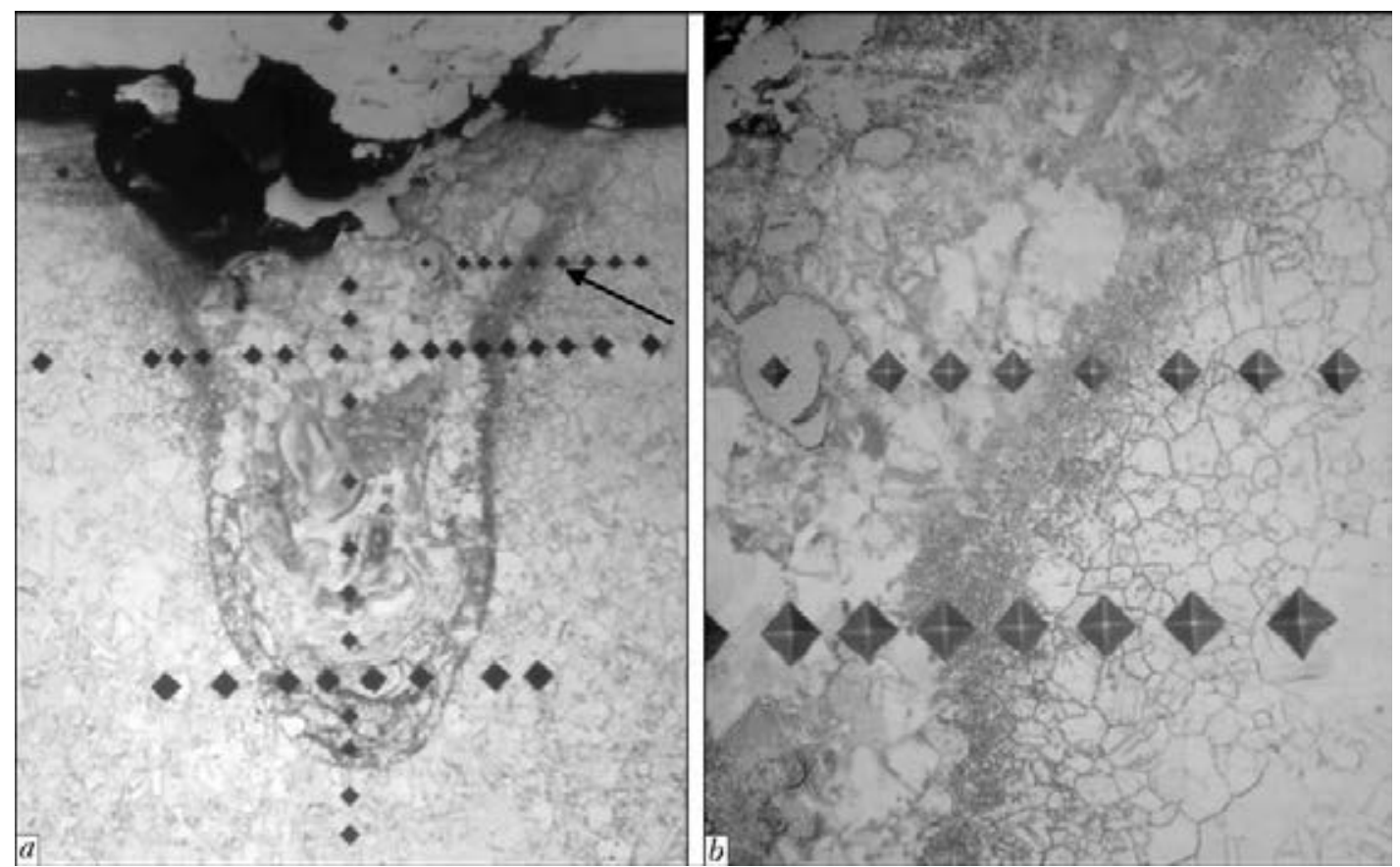

Figure 5. Macrosection of welded joint with minimum penetration: $a-$ general appearance, brass $(\times 250) ; b-$ fusion area $(\times 800)$
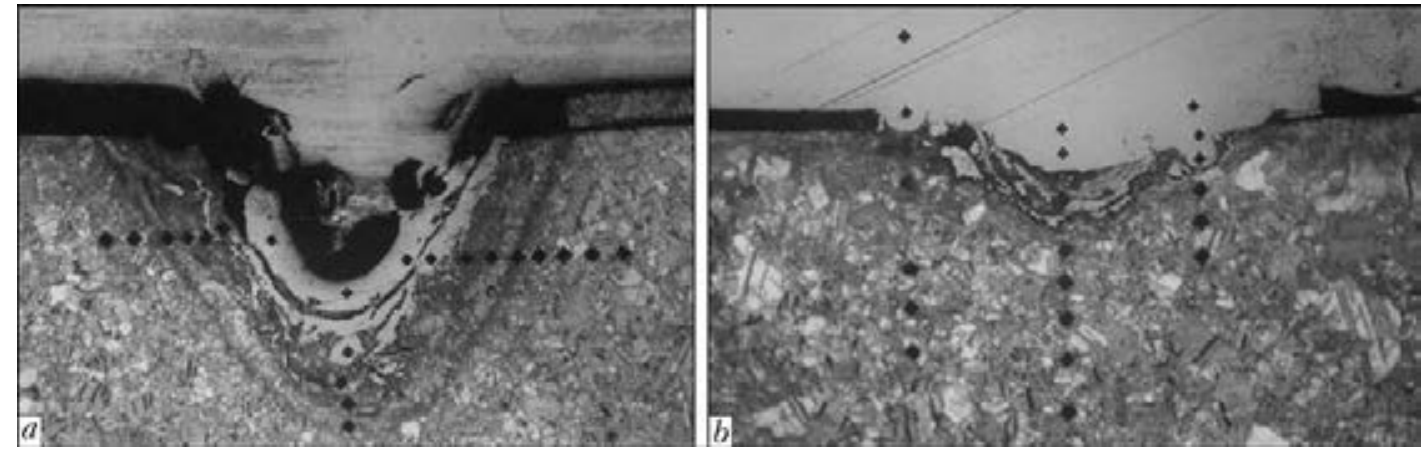

Figure 6. Macrosection $(\times 100)$ of welded joints after heat treatment at modes $1(a)$ and $2(b)$

and alloys have relatively low hardness values, the basic measurements were carried out at $H V 0.5$ load. Fusion lines, defects in form of pores, structural changes after laser beam thermal influence are clearly seen in the photos before and after etching. Microhardness of different sections of steel after laser influence is in $H V 1^{-}$ 1700-2500 MPa range, at that the maximum values are represented in the central part of the photo (Figure 4, $a$ ). Brass-steel fusion line is in HV1-1050-1750 MPa range, brass base metal has HV1-870-1050 MPa.

Figure 5, $a$, presenting a microsection of the specimen without heat treatment, clearly depicts depth of penetration by laser beam, steel to brass fusion line is virtually absent. Figure $5, b$ shows structural changes in the fusion line, laser-affected base metal and brass sections with steel inclusion. Microhardness in Figure 5, $b$ was measured at $H V 0.25$ (upper line of indentations) and $H V 0.5$ (lower line). It can be seen that using of lower loading allowed measuring exactly the val- ues for fusion line, where microhardness of brass is comparable with steel values and lies in $H V 1^{-}$ 1500-1700 MPa range.

Macrosections of specimen with small fusion section, subjected to heat treatment by modes 1 and 2 (Table 2), are represented in Figure 6, $a$ and $b$. Heat treatment of given joints was carried out for the purpose of mutual diffusion of alloy components in order to increase joint strength. It can be seen in the photos that heat treatment provoked balancing of the structure, values of microhardness of this brass section have no rapid drops in comparison with the specimens, which are not subjected to heat treatment. However, expected increase of joint strength due to mutual diffusion was not registered.

\section{Conclusions}

1. Laser welding with full penetration can be considered as a promising method of production of bimetal joints, since the process can be auto- 
mated and allows joining metals of different combinations in a wide range of thicknesses.

2. Mechanical properties of the joints after welding are inhomogeneous, therefore, heat treatment can be used for their balancing, if necessary.

The work was carried out with support of the grant of the Ministry of Education and Science of $R F$ in scope of decree No.220, application No. 14z50.31.0023.

1. Bely, A.I. (2010) Influence of main technological parameters of the plasma cladding process on properties of composite deposited metal. The Paton Welding J., 6, 25-27.

2. Ryabtsev, I.A., Kondratiev, I.A., Vasiliev, G.V. et al. (2010) Investigation of structure and service properties of deposited metal for reconditioning and strengthening of rolling mill rolls. Ibid., 7, 12-15.
3. Neklyudov, I.M., Borts, B.V., Lopata, A.T. et al. (2010) Development of zirconium- and stainless steelbased composites for manufacture of adapters to NPP structures. Ibid., 8, 45-49.

4. Shlensky, P.S., Dobrushin, L.D., Fadeenko, Yu.I. et al. (2011) Chambers for explosion welding of metals (Review). Ibid., 5, 47-51.

5. Lyushinsky, A.V. (2011) Application of nanopowders of metals in diffusion welding of dissimilar materials. Ibid., 5, 31-34.

6. Sokolov, M., Salminen, A. (2013) Laser welding of low alloyed steels: Influence of edge preparation. Ibid., 2, 48-52.

7. Quiroz, V., Gumenyuk, A., Rethmeier, M. (2012) Investigations on laser beam welding of high-manganese austenitic and austenitic-ferritic stainless steels. Ibid., 1, 10-14.

8. Khaskin, V.Yu. (2011) Laser welding of overlap joints of low-carbon steels by through-thickness welds. Svarshchik, 5, 24-26.

Received 11.12.2013 


\title{
DRY ICE - USEFUL MATERIAL IN WELDING PERFORMANCE
}

\author{
S.N. ZHIZNYAKOV \\ Belarusian National Technical University \\ 65 Nezavisimosti Ave., 220013, Minsk, Belarus. E-mail: zhiznyackov@yandex.by
}

\begin{abstract}
The problem of modification of welding methods applied in industry, including application of new welding consumables, is challenging. It is shown that as an efficient welding consumable in arc methods of welding the dry ice (solid carbon dioxide) can be applied, which is facilitated by its unique properties, namely possibility of sublimation with formation of great amount of gases and very low temperature. Dry ice staying in welding zone forms a reliable protective gas environment of specific composition, which predetermines also a favorable arrangement of forces acting on the drop of electrode metal. In welding a stable mild arcing without excessive spattering with a good weld formation is observed. The ice sharply decreases residual welding deformations in welding of thin-sheet metal. In principle, the new arc welding method using consumable electrode, i.e. welding under dry ice, was offered, which is performed applying conventional welding equipment. Welding under dry ice can be used during manufacture, erection and repair of steel structures. The experiments showed that dry ice as an additional welding consumable is applicable in manual arc welding using covered electrodes, welding using flux-cored wire, in shielding gas and also during performance of surfacing works. 4 Ref., 4 Figures.
\end{abstract}

$\boldsymbol{K} \boldsymbol{e} \boldsymbol{y} \boldsymbol{w} \boldsymbol{o} \boldsymbol{r} \boldsymbol{d} \boldsymbol{s}:$ arc welding, dry ice, complete gas protection, stable process, minimum deformations, application

Welding consumables, i.e. covered metallic electrodes, shielding gases, solid wire and flux-cored wire, fluxes, non-consumable electrodes, directly participate in the process of arc welding, performing the most important technological and metallurgical functions providing possibility of efficient fulfillment of welding works and producing quality welded structures [1]. The given list of welding consumables (it was shown by the investigations performed in the Belarusian National Technical University) can be supplemented by the dry ice (solid carbon dioxide) characterized with clearly distinct specific properties quite useful for welding process.

These properties are:

- very low temperature of ice, not exceeding $-78.5^{\circ} \mathrm{C}$. At forced interaction of ice with metal the latter cools down intensively. The layer of ice is capable to be very long time on the metal surface under the normal conditions preserving its structure and physical properties. The cold efficiency of dry ice several times exceeds that of water ice;

- capacity of dry ice to sublimation, i.e. transition from solid crystal state immediately to the gaseous one omitting the liquid phase with absorption of heat in the amount of about $590 \mathrm{~kJ} / \mathrm{kg}$ at normal pressure and temperature

(C) S.N. ZHIZNYAKOV, 2014 of $-78.5{ }^{\circ} \mathrm{C}$. Here about 0.81 of carbon gas is formed of $1 \mathrm{~g}$ of ice at its complete evaporation;

- dry ice is characterized by a very high purity. According to GOST 12162-77 the mass fraction of carbon dioxide in it amounts to $99.96-99.98 \%$, practical content of carbon dioxide in the yield product amounts to $99.998 \%$ at negligible humidity content.

Dry ice is convenient for realization. It is transported and stored in the thermal containers of different capacity from 2 to $250 \mathrm{~kg}$ and more. Depending on design peculiarities of container and ambient temperature the dry ice does not loose its characteristics within several days. The losses during storage usually amount to $2-10 \%$ of mass of ice per day. The ice is not toxic, not scarce, it is widely used in industry, agriculture, medicine, etc. The ice is usually supplied in the form of blocks and granules of different size. The density of dry ice is $1560 \mathrm{~kg} / \mathrm{m}^{3}$.

High temperature non-uniform heating with next cooling of elements being joined in arc welding causes the occurrence of residual deformations in them hindering the production of welded structures and deteriorating their quality. One of the most rational technical solutions directed to reduction of deformations is local cooling of metal in the welding zone. It narrows the sizes of areas of welded joint, heated in the welding process to the possible minimum, to the temperatures when compression forces arise exceeding the yield strength of metal being welded (for the steels, mainly, the zones heated to the temperatures of 


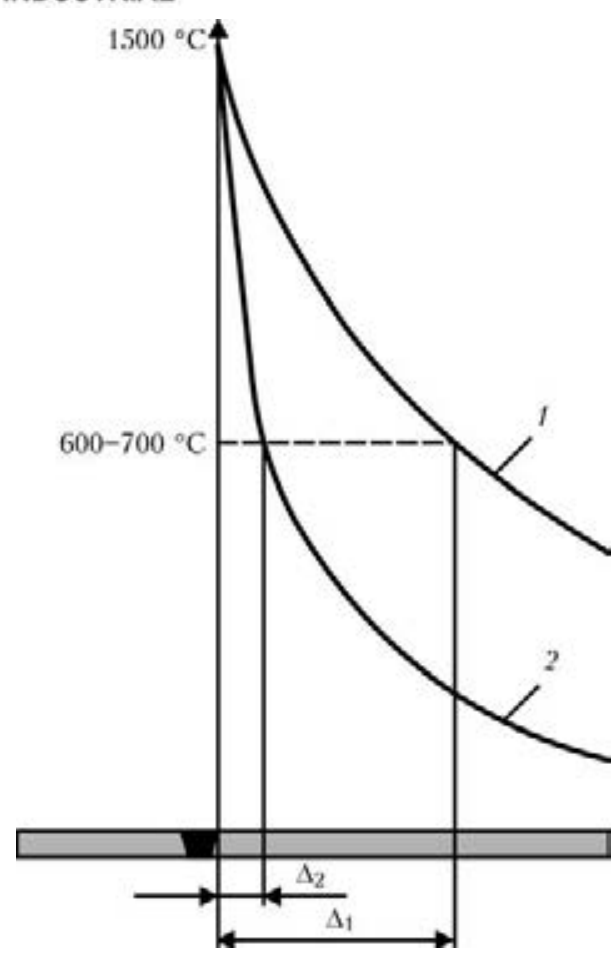

Figure 1. Scheme of distribution of maximum temperatures of heating of metal (steel) in welding in carbon gas using conventional method (1) and under layer of dry ice (2): $\Delta_{1}$ and $\Delta_{2}-$ width of areas of metal heated above $600-700{ }^{\circ} \mathrm{C}$ in welding without and with dry ice, respectively

more than $600-700{ }^{\circ} \mathrm{C}$.) It is the origination of such critical areas that predetermines initiation with the following propagation of plastic deformations and producing of welded joints and structures with residual welding deformations and stresses.

The applied methods for heat removal from the metal heated during welding (water-cooled copper backing and shoes, massive clamping devices, liquid coolers in the form of directed solid and sprayed jets) are not capable to render the noticeable local effect on critical high-temperature zones of metal, especially those being near the weld pool. It was found that this function on spot contact heat removal from the metal heated in welding can be successfully performed by dry ice.

Experimental and theoretical investigations [2] allowed authors to develop main guidelines of universal technology of argon arc welding of thin-sheet high-alloyed steel of austenite class of the type 18-8 applying solid carbon dioxide for the forced cooling of high-temperature area of elements being welded, allowing several times decreasing the residual deformations as compared to welding without cooling. In welding of metal of $1 \mathrm{~mm}$ thickness the rational area of contact cooling in high-temperature zones at the certain distance from the boundary of weld pool amounted to $60-90 \mathrm{~mm}^{2}$ at length of not less than $6 \mathrm{~mm}$. The development of welding technology was carried out using the developed methods [2] of numerical modeling of temperatures, stresses and deformations in different areas of plates being welded considering the specifics of behavior of austenite steel and peculiarities of low-temperature cooler, i.e. dry ice.

In welding of steel plates in carbon gas the unique possibility of cooling of metal using dry ice was revealed, which is heated directly ahead the arc along the frontal boundary of weld pool. It occurs in welding under the layer of dry ice. Layer of ice being at the surface of plates almost does not react with the metal before welding. However at entering the direct counteraction with the metal, heated in welding to higher temperatures up to melting, the active sublimation of ice with absorption of great amount of heat occurs. Dry ice, which did not manage to evaporate as a result of sublimation, comes into contact with weld pool, where, after reaction with liquid metal, it vanishes immediately, i.e. weld pool appears to be bordered by low-temperature solid dry ice. Interaction of metal adjacent to weld pool with dry ice reduces sizes of high-temperature areas, where active propagation of plastic deformations is possible (Figure 1).

Thus, in welding of thin-sheet metal using the technology under the layer of dry ice providing additional cooling of cooled weld metal and HAZ on the high-temperature areas using ice cooling, the welded joints and structures without any residual deformations can be produced. Application of dry ice as an intensive cooler is possible in manual covered electrode arc welding and other fusion methods. The noticeable increase of rate of cooling of the thin-sheet metal in this case affects its structure and properties (in this article this issue is not considered). It is naturally that welding using dry ice can be applied only for metal not prone to formation of brittle hardening structures, cracks and other defects during sharp cooling.

The experiments on welding under the layer of dry ice allowed revealing the important phenomenon for the further investigations, namely the amount of gases formed in the welding zone is sufficiently enough for its reliable protection from the air. Moreover, the composition of gaseous phase represents not a pure carbon gas but its mixture with carbon oxide (Figure 2). The formation of gaseous phase of this composition can be explained in the following way.

Carbon gas is formed as a result of sublimation of a part of dry ice directly adjacent to the surface 
of metal heated in welding. With increase of temperature of metal the rate of evaporation of ice grows by many times and reaches maximum at the temperatures close to the temperature of its melting. As the major mass of ice does not manage to evaporate, its bigger part «creeps down» to the neighboring high-temperature area of weld pool in the process of welding, where it comes into direct contact interaction with the molten metal being in the constant movement. In the limited space almost instant sublimation of ice with evolution of enormous amount of carbon gas occurs, resulting in sharp growth of its concentration and partial pressure in the area of contact of liquid and gaseous phases. It instantly causes high-rate and full-scale running of reaction $\mathrm{Fe}_{1}+$ $+\mathrm{CO}_{2}=\mathrm{FeO}_{1}+\mathrm{CO}$. Carbon oxide formed in a great amount, as well as remnants of carbon gas which did not entered the reaction, form together with carbon gas the sublimated dry ice, being in contact with hot surface of solid metal, a protective gaseous phase of welding zone. The carried out investigations give grounds to suppose that content of carbon oxide as a product of the considered reaction in the arc zone in welding of steel under the layer of dry ice can reach $60-70 \%$. At interaction with air the carbon oxide reacts with oxygen transforming into carbon gas.

The arc welding process in mixture of carbon with carbon oxide differs considerably (and it was confirmed during experimental investigations) from the welding process in carbon gas only. In welding in mixture the stable mild arcing without excessive spattering of molten metal is observed, coarse-rippled surface of weld is absent. The process is similar to welding in the mixture of argon with carbon gas. Stable arcing and good weld formation and its outer appearance are typical of welding under the protection of carbon oxide only [3].

Change in nature of arcing and type of electrode metal drop transfer in welding in the mixture of carbon oxide with carbon gas is connected with low concentration of carbon gas in the mixture. The presence of great amount of carbon oxide in the arc gap hinders the dissociation of carbon gas, resulting in intensive cooling of arc plasma and constriction of its active spots, and as a result the extremely unfavorable arrangement of forces affecting the drop of electrode metal, in the first turn, the force of pinch-effect, reactive force of pressure of vapors of metal and force of pressure of arc plasma flows. High concentration of carbon oxide in gaseous phase delays the oxidation processes running in the welding zone to a certain degree.

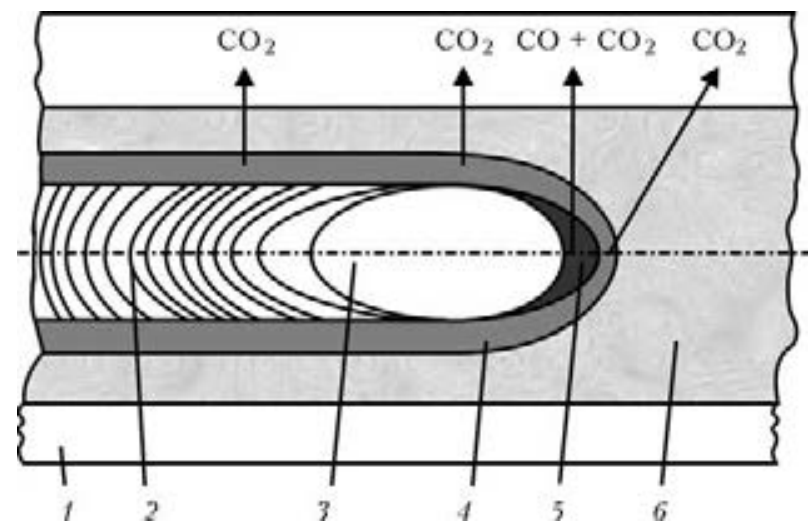

Figure 2. Scheme of formation of protective gaseous phase in arc welding under the dry ice layer: 1 - base metal; 2 - weld; 3 - weld pool; 4 - areas of contact of dry ice layer with surface of metal heated up to high temperatures in welding; 5 - zone of interaction between the metal of weld pool and dry ice; 6 - layer of dry ice

Basing on the results of investigations carried out in co-authorship with colleagues from the Belarus National Technical University, the principally new method of arc welding using consumable electrode, namely welding under dry ice [4], was developed. Mechanized and automatic consumable electrode arc welding under dry ice is carried out without outer gas and slag (flux) protection (Figure 3). The basic welding consumables are solid carbon dioxide and wire containing deoxidizers.

Deposition of beads and welding of butt and T-joints of low-carbon and low-alloyed steels of average thickness, applying solid carbon dioxide according to GOST 12162-77 and wires of grade Sv-08G2S according to GOST 2246-70, showed stable arcing with minimum spattering of molten metal, good formation and appearance of a weld, absence of pores, solid inclusions and other inadmissible defects in welded joints (Figure 4). Welds are characterized by high mechanical properties: tensile strength $\sigma_{\mathrm{t}}=580-620 \mathrm{MPa}$, elongation $\delta_{5}=23-27 \%$, impact toughness at normal temperature $K C U=135-160 \mathrm{~J} / \mathrm{cm}^{2}$. In welding

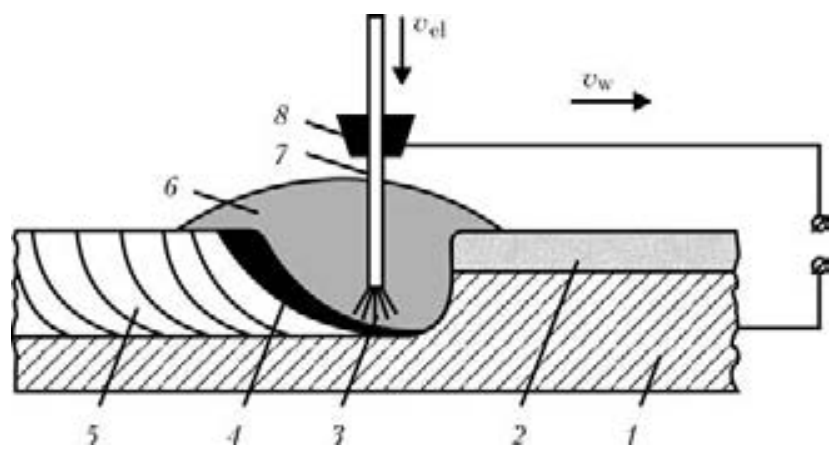

Figure 3. Scheme of arc welding under the dry ice layer: 1 - base metal; 2 - dry ice layer; 3 - arc; 4 - weld pool; 5 - weld; 6 - gas protection of welding zone; 7 electrode welding wire; 8 - current collecting tip (current conductor) 

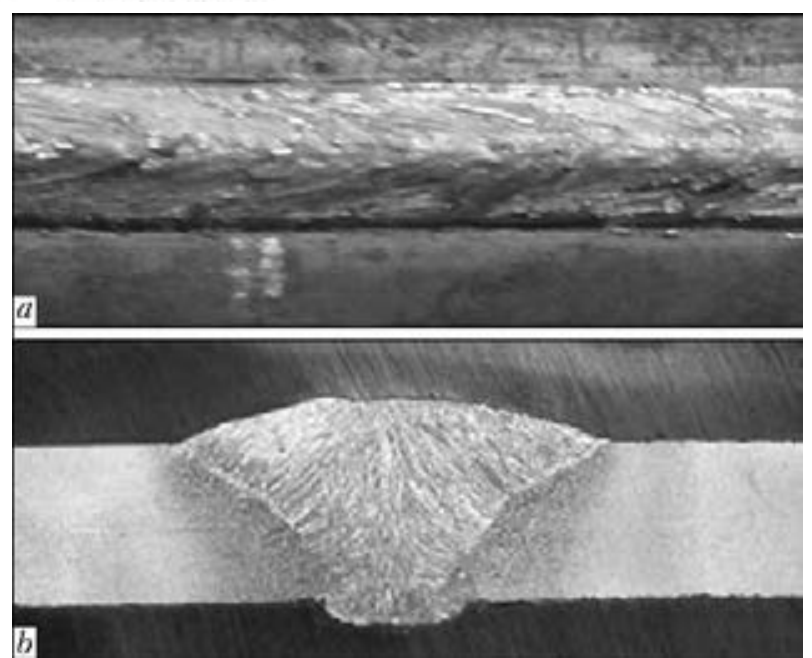

Figure 4. Appearance $(a)$ and macrosection $(b)$ of welded joint in mechanized welding of low-alloyed steel $6 \mathrm{~mm}$ thick under the dry ice

of thin-sheet steel the decrease of residual welding deformations by 5-10 times was observed.

The techniques and technology of welding under dry ice are differed form welding in carbon gas, which is predetermined by the peculiarities of formation of protective gaseous phase in arc zone and specifics of welding process performance. The noticeable effect of force of pressure of carbon gas, forming at explosive high-temperature sublimation of dry ice at the surface of liquid metal, on weld pool should be also considered. Welding of butt, fillet and spot welds can be performed using dry ice in the form of briquettes, plates and granules of different sizes produced also in crushing and refining of initial materials. Ice prepared for welding is laid out preliminary at the whole length of welded joint by the layer of a definite thickness and width or introduced «beneath the arc». In both cases the scheme of welding can be applied, at which dry ice is additionally supplied behind the arc on preset areas of cooled weld and/or HAZ metal. The similar scheme of process represents interest for one pass deformation-free welding of thin-sheet metal and multipass welding of metal of average and large thickness, when layer-by-layer cooling of weld is necessary, for example, in welding of austenite steel.
Mechanized and automatic welding under dry ice is performed using conventional equipment. Here simplified designs of welding torches and flexible hoses are applied, as far as there is no longer need in supply of shielding gas to the welding zone through the torch. The cylinders with shielding gas and gas equipment are replaced by a simple thermostat with dry ice.

\section{Conclusions}

1. Dry ice is capable to participate directly in the arc welding process, performing important technological and metallurgical functions and providing stable running of the process of producing the quality welded joints itself. It gives grounds to consider it as a full-fledged welding consumable suitable for successful application in welding production.

2. The developed principally new method of welding using consumable electroand - Ice Metal Arc Welding - not requiring the gas and slag protection and performed applying conventional welding equipment, can be used in manufacture, repair and erection of steel structures and constructions.

3. Dry ice as a welding consumable is applicable in manual covered-electrode arc welding and other fusion methods, and also during performance of surfacing works and cutting of metals.

1. Zhiznyakov, S.N. (2013) Proper selection and preparation of welding consumables as a base of efficient welding production works. Svarshchik v Belorussii, 1, 32-38.

2. Panteleenko, F.I., Zhiznyakov, S.N., Heidari Monfared, A. (2013) Minimization of deformations in argon arc welding of sheet austenitic steel by local cooling of high-temperature field. In: Advanced materials and technologies. Ed. by V.V. Klubovich. Vitebsk: UO VGTU, 172-187.

3. Novozhilov, N.M. (1979) Principles of metallurgy of gas-shielded arc welding. Moscow: Mashinostroenie.

4. Zhiznyakov, S.N., Panteleenko, F.I., Viktorovsky, D.I. et al. (2013) Arc and ice. New method of consumable electrode arc welding. In: Powder metallurgy: surface engineering, new powder composite materials. Welding: Proc. of 8th Int. Symp. (Minsk, 10-12 April, 2013), Pt 2. Minsk: Bel. Navuka, 347-349.

Received 21.12.2013 